ช 





\section{INFANTILE PARALYSIS}

IN MASSACHUSETTS IN 1909.

I. The Occurrence of Infantile Paralysis in Massachusetts in $\mathbf{1 9 0 9 .}$

Reported for the Massachusetts State Board of Health by Robert W. Lovett, M.D.

II. Infantile Paralysis as Observed in Health District No. 15 during 1909. By Lyman A. Jones, M.D.

IiI. Methods of Treatment in Infantile Paralysis.

By E. H. Bradford, M.D., Robert W. Lovett, M.D., E. G. Brackett, M.D., Augustus Thorndike, M.D., Robert Soutter, M.D., Robert B. Osgood, M.D.

IV. The Diagnosis of Infantile Paralysis in the Prodromal and Early Acute Stage, as Found in the Experimental Study of Acute Poliomyelitis in Monkeys. With Report of Findings in Four Human Cases.

By William P. Lucas, M.D.

\section{Reprinted from the}

Monthly Bulletin of the Massachusetts State Board of Health for" June, 1910.

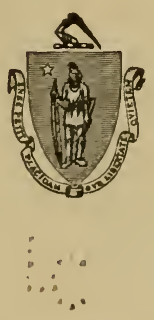

BOSTON :

WRIGHT \& POTTER PRINTING CO., STATE PRINTERS, 18 POST OFFICE SQUARE. 
<smiles>C1C[Te][Te][Te]1</smiles>

APPROVED BY

The State Board of Publication.

\author{
D. OF D. \\ NOV 18.410
}




\section{THE OCCURENCE OF}

\section{INFANTILE PaRalysis IN MassachusetTs IN 1909.}

Reported for the Massachusetts State Board of Health by Robert W. Lovett, M.D. BOSTON.

The medical profession of to-day is confronted with the task of constructing a new literature on the subject of infantile paralysis. What was written five years ago is to-day largely out of date, and the standard text-books cannot naturally present the latest point of view so rapid has been the recent progress of our knowledge in regard to this disease. The chief contributors to this rapid advance have been, first and foremost, Flexner and Lewis in demonstrating the etiology, Wickman, of Sweden, in giving us a new symptomatology and defining types not before recognized, and Harbitz and Scheele, of Norway, in formulating the pathology.

The present paper will consist, first, of a condensed report of the recent progress of our knowledge with regard to the disease, and, secondly, of the data obtained with regard to the disease in this State in 1909 by the State Board of Health.

\section{REPORT OF PROGRESS.}

The most important step in our knowledge of the disease consists in the establishment during the past year of its infectious character by several observers. With the ability to produce the disease in monkeys by inoculation, there has been given the opportunity to study its etiology, symptoms and pathology, which opportunity did not exist before.

1 Portions of this report were read in abstract before a joint session of the $A$ merican Orthopedic. and Pediatric Societies in Washington on May 4, 1910, and hefore the Massachusetts Medical Society in Boston, June 8, 1910. Reprinted from the "Boston Medical and Surgical Journal," July 14, 1910. 


\section{ExperimentaL Production.}

Infantile paralysis has been recently shown to be an infectious disease, caused by a living organism so small that it can pass through the finest bacterial filter. It is invisible to the microscope and the ultramicroscope. ${ }^{17}$ This places the disease in a class with those caused by a filterable virus, similar diseases of this class being yellow fever, foot and mouth disease, pleuro-pheumonia of cattle, etc. It can be caused in monkeys by inoculation with an emulsion of certain tissues from a human being dying of the disease, and from affected monkeys.41, 17, 10, 30, 50

The virus is contained in the brain and spinal cord, the mucous membrane of the nasopharynx, infected lymphatic glands, in the salivary glands, ${ }^{10}$ and, in the acute stage, in the blood and cerebro-spinal fluid. ${ }^{17}$

The disease may be caused by inoculation by the following routes: intracerebral, subdural, intraneural and perineural, intraperitoneal, subcutaneous, by the circulation, and by implantation in the anterior chamber of the eye.10, ${ }^{17},{ }^{41}$

By the digestive route it has been caused by introducing an emulsion into the stomach by means of a catheter and by introduction of the virus into intestines paralyzed by opium.41

By the respiratory route the disease has been caused by rubbing the nasal mucous membrane after scarification 17 with a virulent suspension, by the same procedure without scarification, by inhalation of a virulent emulsion, and by implantation of infected tissue in the trachea.41

The fact that the disease may be caused by virus entering both respiratory and digestive tracts must be remembered when we come to inquire how the virus enters the human body.

Inoculations into horses, calves, goats, pigs, sheep, rats, cats, mice,30 rabbits, ${ }^{39}$ chickens, ${ }^{42}$ guinea pigs 30 and dogs have proved negative except for the results of Krause and Meinicke, ${ }^{24}$ who caused paralysis in rabbits by inoculation with virulent material, but their results are not generally accepted by other observers as they are in contradiction to practically all other experimental work and not sufficiently supported by pathological evidence.

The virulence of an emulsion is not impaired by drying for seven days, by freezing nor by suspension in glycerine, ${ }^{10},{ }^{17}, 30$ but is injured by a temperature of $45^{\circ}$ to $50^{\circ}$ C.17 The virus is not always affected by dilution, a solution of one to a thousand working as quickly and effectually as the full strength. ${ }^{41}$

The stage of incubation in monkeys is from six to upwards of thirty days, and the long incubation period in monkeys suggests the possibility that in the human being some of the late fall and early winter 
cases may have acquired their infection when the disease was prevalent in August and September. The ordinary incubation period in human beings is not known. It is generally stated as from one to fourteen days.

\section{IMmUnity.}

One attack of the disease apparently confers immunity to future attacks.17, ${ }^{10},{ }^{31},{ }^{41}$ This is the accepted clinical history in human beings; and has been found to be the case in monkeys inoculated experimentally.

Active immunization in monkeys has been secured by the repeated injection of small doses of virus, after which a full dose has had no effect. ${ }^{1 i}$

Passive serum protection has been obtained by mixing with an active dose of the virus an equal amount of the blood serum of a recovered monkey, which neutralizes the effect of the virus, and in the same way the blood serum of children who have recovered, when mixed with the virus in proper proportions, neutralizes its effect.17 Attempts to secure a neutralizing serum from horses who have received repeated injections of virus have not been successful. Even if we had at hand a therapeutic serum for this disease, it must be evident that such a serum to be of use must be used early in the disease, and at present our diagnostic knowledge is not sufficient to enable us to use it before the destruction cccurs in the cord. The diagnosis is now rarely made before the paralysis occurs, and a better knowledge of the early symptoms and diagnostic signs of the disease is one of our most urgent needs, and indicates the line in which our investigation for the present year should progress.

\section{Diagnosis.}

In the matter of clinical diagnosis, the last year has added a little to our knowledge, chiefly in the way of a better knowledge of early symptoms. The eight types of the disease as described by Wickman are not, however, sufficiently known in the English language, and a translation of his book would be of great value (Wickman: Beiträge zur Kenntniss der Heine Medinschen Krankheit, Berlin, 190\%), although a short abstract has been made of it. ${ }^{18}$

Miüler,33 investigating, at the request of the authorities, an epidemic in Westphalia in 1909, considered three symptoms of great importance in the early stages. These were (1) tendency to profuse sweating, (2) hyperesthesia and sensitiveness to morements, and (3) leucopenia. Respiratory and digestive symptoms were common in the earlier stages, and the incubation period was at least five days.

Krause 23 was commissioned by the government, in 1909, to investigate an epidemic, consisting of 436 cases, occurring in Germany in the 
meighborhood of Hagen. He found digestive symptoms present in 90 per cent. of all cases at the onset, and occasionally respiratory symptoms. He calls especial attention to the importance of sweating and tenderness as early symptoms.

The later laboratory findings suggest that certain characteristics of the blood and cerebro-spinal fluid in the stage preceding paraylsis may enable us to make an earlier and surer diagnosis, but these findings have not yet appeared in print.

\section{INCREASING Frequenct OF OCCURRENCE.}

It is generally believed that infantile paralysis is becoming more common and more widespread of late years, but one must bear in mind that there is a possibility that this is because the disease is better known and more frequently recognized. As this is a matter of importance, it seems proper to examine the evidence on this point.

The recognition of outbreaks of infantile paralysis is of comparatively recent date. Bergenholz, a Swede, writing in 1881, is generally credited with having been the first to recognize and describe such an outbreak with sufficient accuracy to make it acceptable. Since that time outbreaks have been reported with increasing frequency. From the time of the first generally accepted outbreak until the close of 1909 is, roughly, thirty years. If this interval be subdivided into periods of five years, beginning with 1880-84 inclusive and ending with 1905-09 inclusive, and if we set down in each period the number of outbreaks reported, we have the following table:-

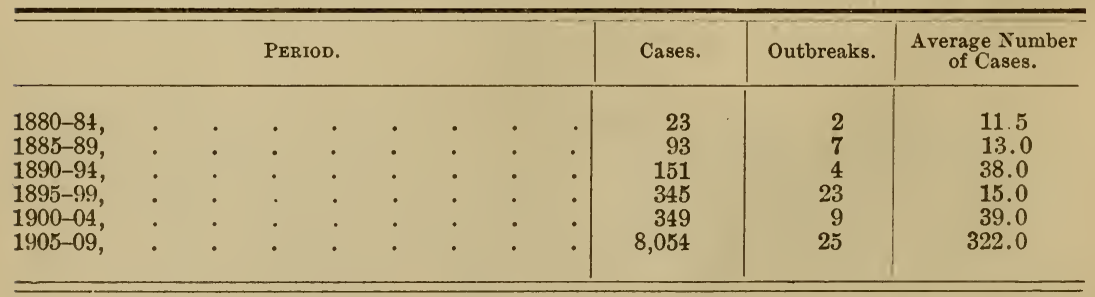

\section{Distribution of OUtbreaks.}

The recent outbreaks have been widely distributed. From Norway and Sweden have been reported large and carefully studied epidemics, especially in the last ten years. Zappert,46 in 1908 and 1909, collected 266 cases in Vienna and lower Austria, and Ghon noted many cases in upper Austria (Styria and Carinthia). In Germany, in 1909, the disease was very prevalent. The Westphalia epidemic of 436 cases ${ }^{23}$ has been spoken of above. In Rhenish Prussia there were said to have been about 100 cases, and around Marburg about 50. There were cases 
in the province of Hanover and about 50 cases in Silesia. Numerous small epidemics were reported. It is estimated that there must have been over 1,000 cases in Germany in 1909.47 In Holland, 24 cases were reported from Leyden, and others between August and October in other parts of the country. ${ }^{47}$

England seems to have been comparatively immune, and only a small epidemic of 8 cases was reported from Spain. Although no large epidemic occurred in France, there was a consensus of opinion among the medical men quoted by Netter that an unusually large number of cases of infantile paralysis had been seen in 1909.47, 49

The United States suffered severely. Minnesota 48 had several hundred cases; Nebraska, ${ }^{36} 619$; Kansas, about 80; and Massachusetts, nearly 1,000 .

The report51 of the New York epidemic of 1907 has just become available for study. The fact that this epidemic of 2,500 cases was the largest ever reported, the painstaking character of the work done and the scientific standing of the committee in charge of the investigation make the report of the greatest importance and value. It is impossible in thi: place to abstract so condensed and exhaustive a work.

A most interesting and important epidemic of 140 cases has been reported as occurring in 1909 in the Province of Santa Clara, in Cuba.53 Previous epidemics have been reported from the temperate zones of the north and south hemispheres, chiefly in the northern parts of the former. The Cuban epidemic, as the first reported from the tropics, possesses peculiar interest as to season, distribution, etc. Apparently the disease did not exist in Cuba prior to 190\%. In $190 \%$ and 1908 one or two suspicious or authenticated cases appeared in the neighborhood of Havana, the disease becoming epidemic in the Province of Santa Clara in 1909. A survey of the field makes it seem very probable that the disease was imported from New York as a result of the $190 \%$ epidemic there, and that certain unknown determining conditions made the Province of Santa Clara susceptible to a severe outbreak. As in the temperate zones, the disease occurred during the summer, reaching its maximum in July and August. The chief incidence was between the ages of one and three; males were predominantly affected; and the black race was evidently much less affected than the white, in 72 cases the proportion being: whites, 60 ; mixed race, 4 ; negroes, 8 . The mortality rate was 7.89 per cent.

The time has gone by when the routine reports of epidemics is of any especial value, nor is the exact tabulation of numbers of epidemics of any particular use except as throwing light on the general distribution of the disease, and possibly in this way defining some of its characteristics. 
The disease is manifestly prevalent, and it is widespread and increasing. Useful work in the future will consist in the exact and careful house-to-house study of epidemics, both large and small.

Of the 8,054 cases reported in the last five years (number, of course, only approximately correct), the United States contributed 5,514 cases, cr about fire-serenths of the total number of cases. The bulk of these cases has, moreorer, been reported from the northern States, the outbreaks in the southern States being insignificant. In the same way in Europe, Norway and Sweden contributed about 1,500 cases and Germany practically the rest, except for an outbreak in Australia, which occurred in March, which is their early fall.

As the literature has been very carefully gone over, and as, in the present state of interest in the subject, it seems fair to assume that large outbreaks in any civilized country have been reported, it would seem that the following conclusions were justified:-

1. That outbreaks of infantile paralysis have rery greatly increased in sereral parts of the world in the last five years in a measure not to be explained in any way by the increased interest in the disease.

2. That it is more prevalent in cold than in warm countries.

3. That from the northern part of the United States hare been reported more cases than from any part of the world.

The study of these 70 outbreaks, reaching over a period of thirty years, has led, of course, to the knowledge of certain facts with regard to the disease, but they have not given us the essential facts as to how the disease enters the body nor how to prevent or check its spread.

\section{Relation to INfluenza.}

A recent book 52 deals with the theory that the disease is merely a form of influenza, a contention already discussed prior to 1905 and antagonized by Wickman. The book in question deals with a study of 303 cases occurring in Sweden, each case being considered by itself. The point of view of the author is shown in the following quotation: "I must, therefore, regard this (the intermittent type of influenza) as a very certain proof for my view, acquired on other grounds, that acute infantile paralysis is a nerrous form of influenza." Recent progress in the epidemiology of infantile paralysis makes this view seem improbable.

\section{TRANSMISSIBILITY.}

In the writings of the last year there is no dissent from the opinion that the disease is communicable. Direct transmission is apparently frequent, transmission by means of a healthy carrier is more than prob- 
able, and infection occasionally appears to remain in a house where the disease had previously occurred.

On the other hand, the disease is evidently not very "contagious" in the ordinary acceptance of the term. In the epidemic in the Deerfield ralley, in Massachusetts, in 1908, so carefully studied by Emerson,2 there were 67 cases. There were 166 other children in the families of those affected, and 86 other children known to be in intimate contact with the 6\%. Of the 252, 4 later developed the disease.

Hill, ${ }^{48}$ of the State Board of Health of Minnesota, has contributed a careful study of the transmissibility of the disease, written in a spirit of scientific skepticism. Of 161 cases reported as anterior poliomyelitis, he accepted only 85 as surely valid, and analyzed 81 of these, occurring in 69 families. Sixty-nine of these cases were primary and 12 occurrea secondarily in the same families. The secondary cases thus were $1 \%$ per cent. of the primary. Contrasting this with the records of other infectious diseases in the same State, the percentage of secondary cases to primary was as follows:-

Per Cent.

Scarlet fever, . . . . . . . . . . . . . . . 40

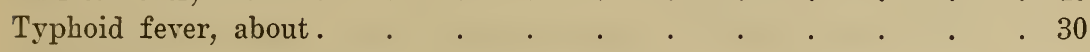

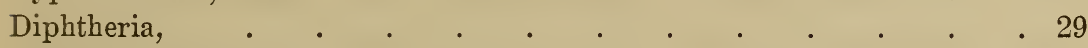

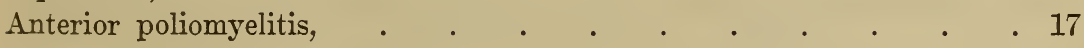

Of persons known to have been exposed to diphtheria, scarlet fever and anterior poliomyelitis, the percentage contracting the disease was as follows:-

Scarlet fever,

Diphtheria,

Anterior poliomyelitis,

The disease is thus apparently less readily transmissible than the diseases mentioned in persons exposed, but such figures cannot be considered representative until the abortive cases are included.

The study of the epidemiology of a disease falls into two parts, the study in the labolatory and the study in the field. The most notable contribution as yet to our knowledge of this disease is from the laboratory, where Flexner and Lewis have established its infectious nature. This fact has narrowed the field of our inquiry and enables us to pursue a more definite and promising scheme, but one should remember that work in the field, comparatively fruitless as it has so far been, holds its place. Te knew for many years the organism of malaria and the pathological changes occurring in the disease, but we could not control malaria 
until we found that it entered the body through the agency of the mosquito. So it is quite possible to us to know much of the bacteriology and pathology of a disease from the laboratory without being able to control or suppress it, and such knowledge must be supplemented by field work; that is, a study of external conditions to round out our investigation and to make it as effective as we should wish.

\section{INFANTILE PARALYSIS IN MASSACHUSETTS IN 1909.}

In the year 1909, Massachusetts suffered as much from the disease as any country in Europe; as many cases were reported here as in the two other most severely affected States in the Union - Nebraska and Minnesota - taken together.

In Massachusetts, in 190\%, we had begun the investigation of the disease by sending out inquiry blanks to be filled in by the general practitioner. That resulted in a loose collection of 234 cases, the results of which were published. 1 In 1908, half of our 136 cases occurring in the State were located in Franklin County, and these 67 cases were thoroughly studied by Emerson, who lived in the district a month for the purpose. These studies were published.2

In 1909 it was decided to take up the matter more seriously. A special agent, Mr. Sheppard, a fourth-year student at the Harvard Medical School, was detailed as a special investigator, and in February, 1910, another special investigator was added to the staff in the person of Dr. Hennelly, a recent graduate of the Harvard Medical School and of the Boston City Hospital. It was thought desirable to have expert advice in conducting the inquiry, and three gentlemen were requested to act as an advisory committee to the Board. These were Dr. Theobald Srnith, professor of comparative pathology; Dr. M. J. Rosenau, professor of preventive medicine and hygiene, and Dr. J. H. Wright, pathologist to the Massachusetts General Hospital and assistant professor of pathology, all of the Harvard Medical School. The secretary of the Board, Dr. Mark W. Richardson, has given freely of his time and effort in conducting the details of the inquiry. This advisory committee has met the members of the Board who are concerned in the inquiry at frequent conferences, studied the reports submitted and advised as to the most promising lines of investigation.

The two investigators have conducted a house-to-house investigation and have filled out their own blanks; they have been instructed to work in all cases through the family physician; they have obtained from the family a careful history of the attack and they have examined the affected children. It has not been possible under these conditions to make rapid progress, and at this time only 150 cases have been thus carefully studied. 


\section{1}

It seemed to us better to confine the investigation to certain localities, making it exhaustive in certain affected districts in the neighborhood of Boston, rather than to take up a scattered investigation throughout the State. Up to this time the expense of the inquiry had been borne by the Board out of its regular appropriation, but in January, 1910, the Board asked the Legislature for a special appropriation of $\$ 5,000$ to enable the Board to make a proper and adequate inquiry into this disease as it occurred in the State in 1910. This sum of money was voted without question or opposition. It is our purpose to have on hand a sufficient number of investigators during the coming summer to be able to look into the surroundings of every case within forty-eight hours of the time when the case is reported.

In presenting for the Board some of the results obtained in 1909, it is only proper to say that in the present state of our knowledge no one can say which data are relevant and important and which are not. It is possible that certain facts which now seem of no importance may be of assistance to some future investigator. So far as practicable, our data are presented in graphic form. There are three classes of cases dealt with in this report: $(a)$ the total number reported $(923)$; $(b)$ the number in which blanks were filled out $(628) ;(c)$ the number thoroughly studied (150). All three classes are utilized in different tables, some being available for one purpose and some for another.

\section{Distribution in the State.}

A consideration of the distribution of the disease in the State of Massachusetts for the past three years shows that in all three years the disease occurred in scattered foci in all parts of the State, but was more frequent in the river valleys than away from rivers; that a case rarely occurred in a town without one or more cases in contiguous towns, and thiat localities severely affected one year were lightly affected the next; e.g., the outbreak in the upper Connecticut valley in 1908 was followed by very few cases in 1909 in that region. In the next year but one, however, localities markedly affected may again show many cases; e.g., in $190 \%$ the extreme western end of the State showed many cases, in 1908 almost none, and in 1909 again many cases. The metropolitan district shows, of course, a large number of cases, and it will be noted that in general there were more cases of the disease in the towns north of Boston than in towns south of it. 


\section{Distribution in Boston.}

Analyzing the relative prevalence of the disease in the different parts of Boston, the distribution of the cases shows nothing. The incidence was greatest in Dorchester, which is on the shore and not altogether thickly settled; next, in Charlestown, on the shore and densely populated; next, in the city proper, densely settled; and so on, districts on the shore and inland alternating, and density of population having apparently no influence.

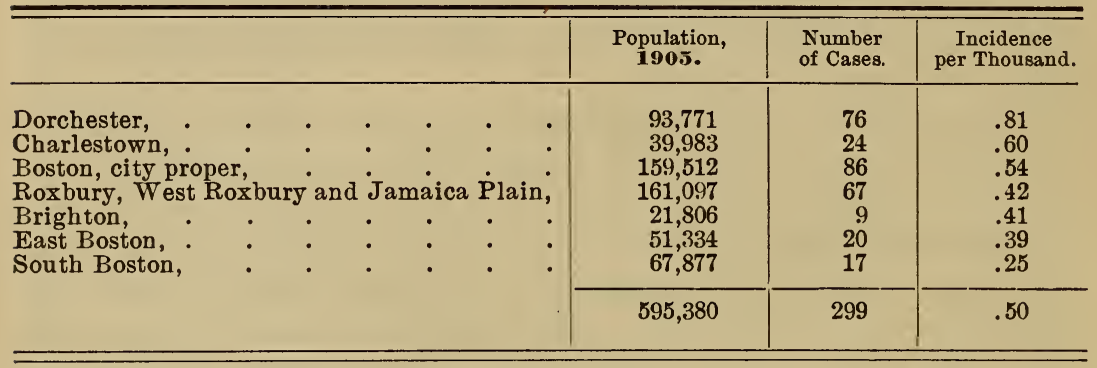

Relative Distribution in Cities and Towns.

There are 354 cities and towns in Massachusetts, in 136 of which there occurred cases of infantile paralysis in 1909. These 136 cities and towns were listed according to the prevalence of the disease in each per 1,000 of the inhabitants. The incidence ran from 526 per 100,000 inhabitants to 15 in 100,000 . Taking the first 25 , where the incidence per 1,000 was highest, the average population was 3,295 , and only 4 towns were over $\%, 000$. Taking the last 25 on the list, where the incidence per 1,000 was least, the average population was 34,860 , and no city or town was under 7,000 in population. Therefore, in 1909 the disease was relatively much more prevalent in small towns than in the cities and larger towns. 




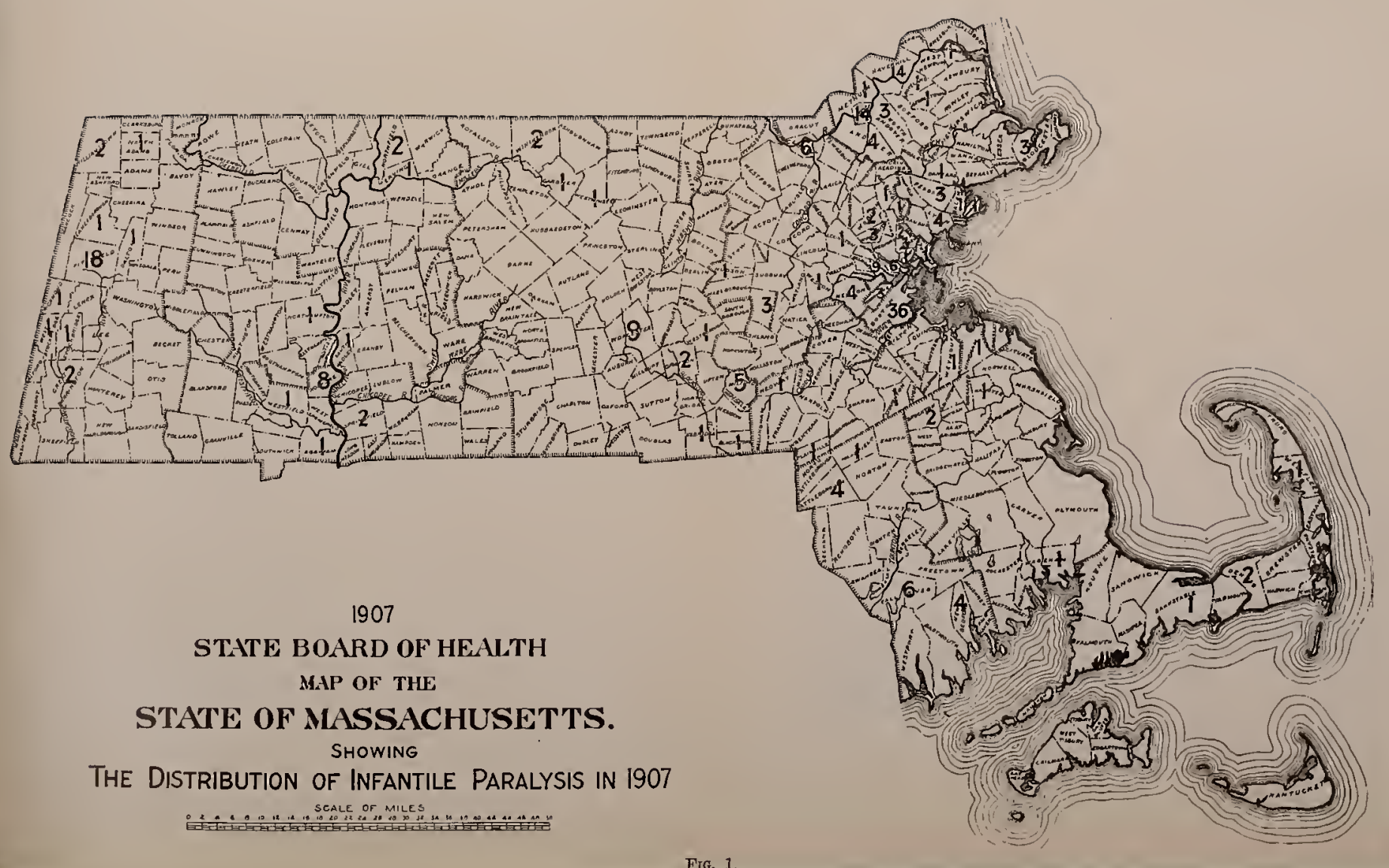







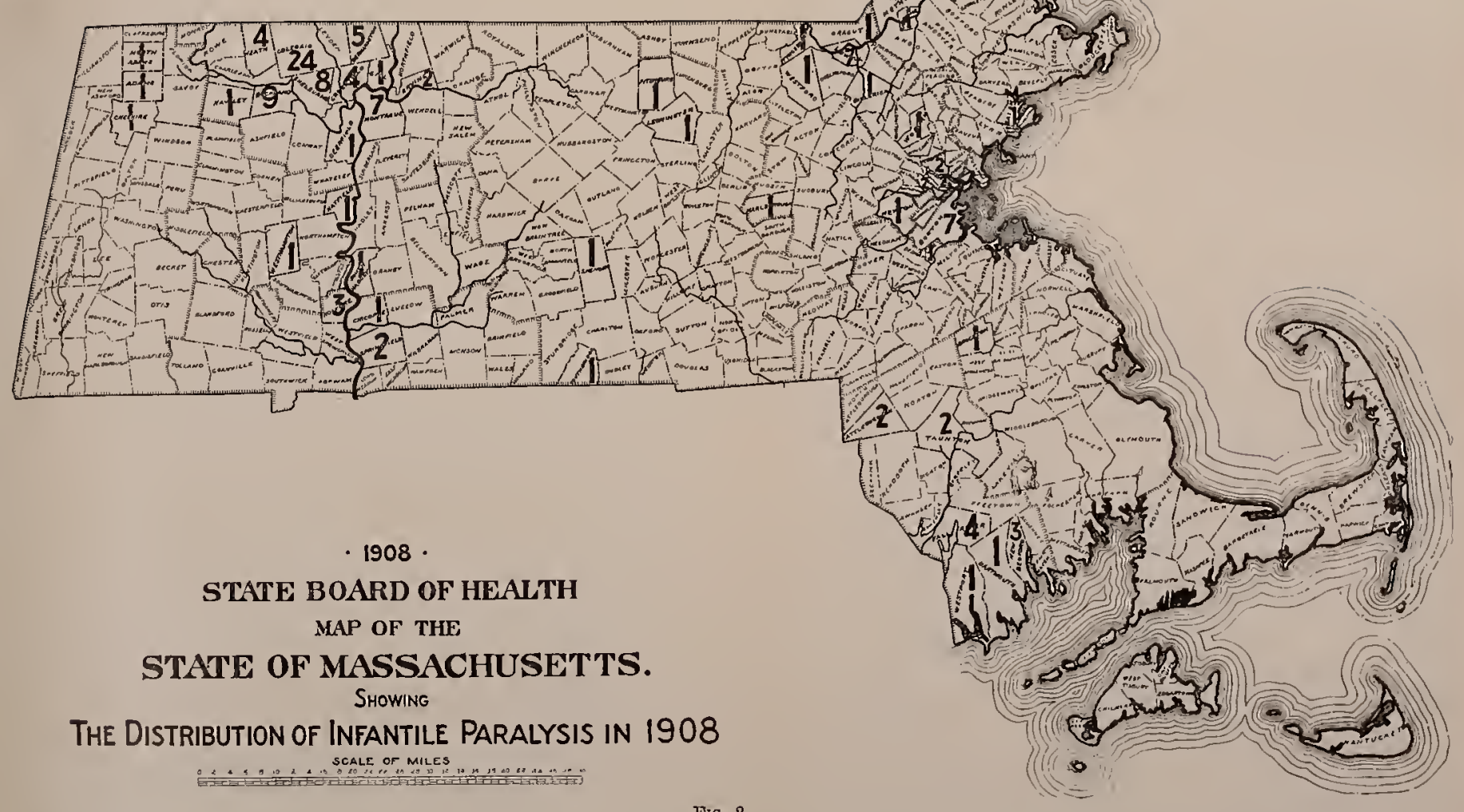

FIG. 2. 




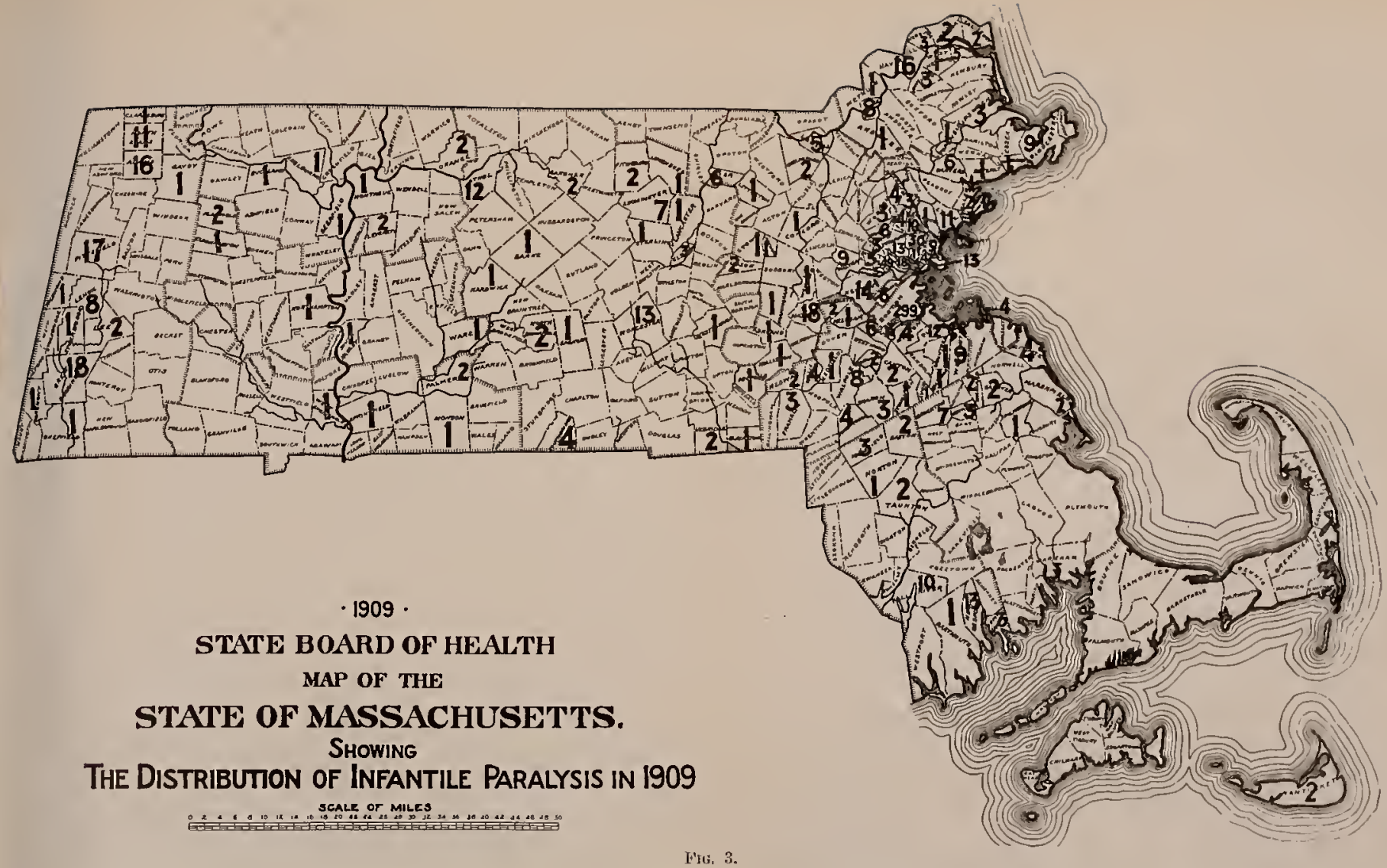



List of 25 Cities and Touns where the Disease was most prevalent.

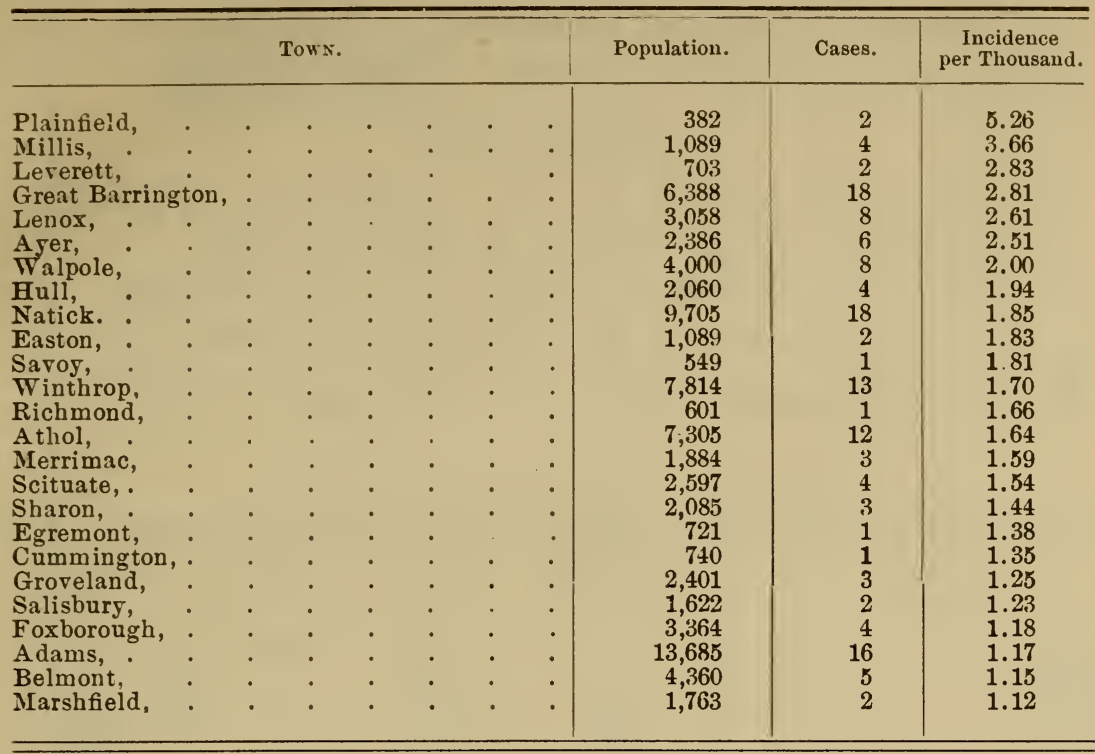

List of 25 Cities and Towns where the Disease was least prevalent.

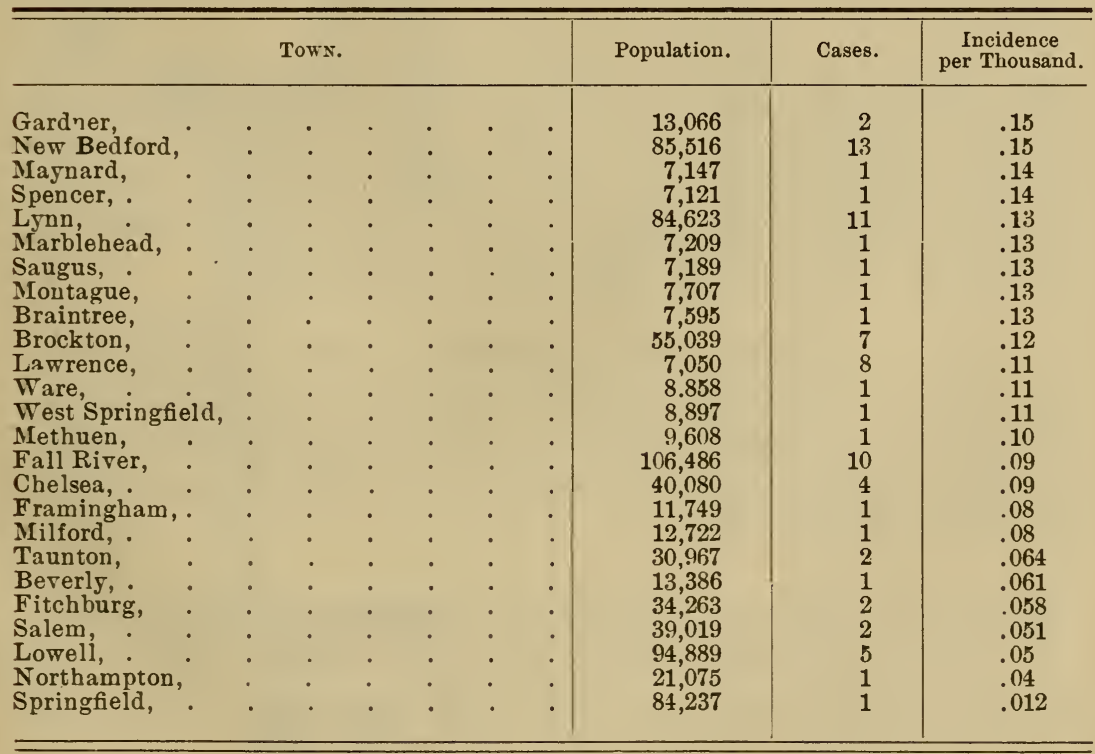




\section{General Conditions.}

Aside from the immediate environment of the patients, there are certain general considerations of possible interest.

\section{Rainfall by Years.}

The last six years have been very dry. In 1907 there was practically a normal rainfall, and 234 cases in the State. In 1908, a very dry year with 7 inches deficiency of rainfall, there were few cases -136 . in 1909, with more rain (3 inches deficiency), there were 923 cases. In Massachusetts the prevalence of the disease by the year has not, therefore, been coincident with deficiency of rainfall.

Deficiency Rainfall, 1904-1909, inclusive.

\begin{tabular}{|c|c|c|c|c|c|c|c|c|c|}
\hline & & EA & & & & Cases in State. & Actual. & Normal. & Deficiency \\
\hline \multirow[t]{2}{*}{$\begin{array}{l}1904, . \\
1905, \cdot \\
1906, \text {. } \\
1907, \text {. } \\
1908, \text {. } \\
1909, \text {. }\end{array}$} & \multirow[t]{2}{*}{$\dot{\text {. }}$} & \multirow[t]{2}{*}{ : } & \multirow[t]{2}{*}{ 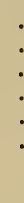 } & \multirow[t]{2}{*}{ : } & \multirow[t]{2}{*}{$\dot{.}}$. & \multirow[t]{2}{*}{$\begin{array}{c}- \\
\overline{-} \\
234 \\
136 \\
923\end{array}$} & \multirow[t]{2}{*}{$\begin{array}{l}43.81 \\
37.60 \\
43.21 \\
44.49 \\
37.61 \\
42.10\end{array}$} & \multirow[t]{2}{*}{$\begin{array}{c}45.16 \\
- \\
- \\
- \\
- \\
-\end{array}$} & $\begin{array}{l}-1.35 \\
-7.56 \\
-1.95 \\
-0.67 \\
-7.55 \\
-3.06\end{array}$ \\
\hline & & & & & & & & & -22.14 \\
\hline
\end{tabular}

Rainfall by Months in 1909.

The chart of the rainfall in 1909 in the State, arranged by months, does not correspond with the prevalence of the disease in the State, arranged also by months, the driest month preceding the month of greatest frequency of the disease in the same way that the driest rear preceded the year when the disease was most prevalent.

\section{Temperature by Months in 1909.}

The curve of the average monthly temperature in Massachusetts in 1909 does not correspond with the curve of the frequency of the disease, the highest average temperature falling away before the highest incidence of the disease occurs.

Nuarber of Families affected and Possible Abortive Cases.

To make the following analyses clearer, the following table is important as showing that the 150 cases carefully studied occurred in 142 families, and also showing the probable existence of a fairly large number of abortive cases associated with them. 
$n-6-$

L
$\underline{2}$
1

u

[ग

-4-

he

nt

se

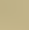

${ }_{-1}^{1}-2-\frac{1}{6}$

${ }_{-1}^{1}-2-\frac{1}{2}$

4

2

4

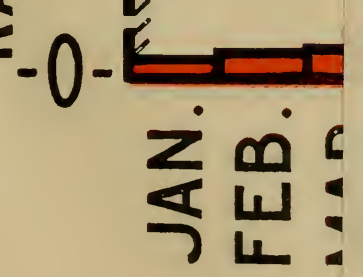





\section{INCIDENCE OF CASES( $\square)$ AND RAINFALL(嚾)BY MONTHS}
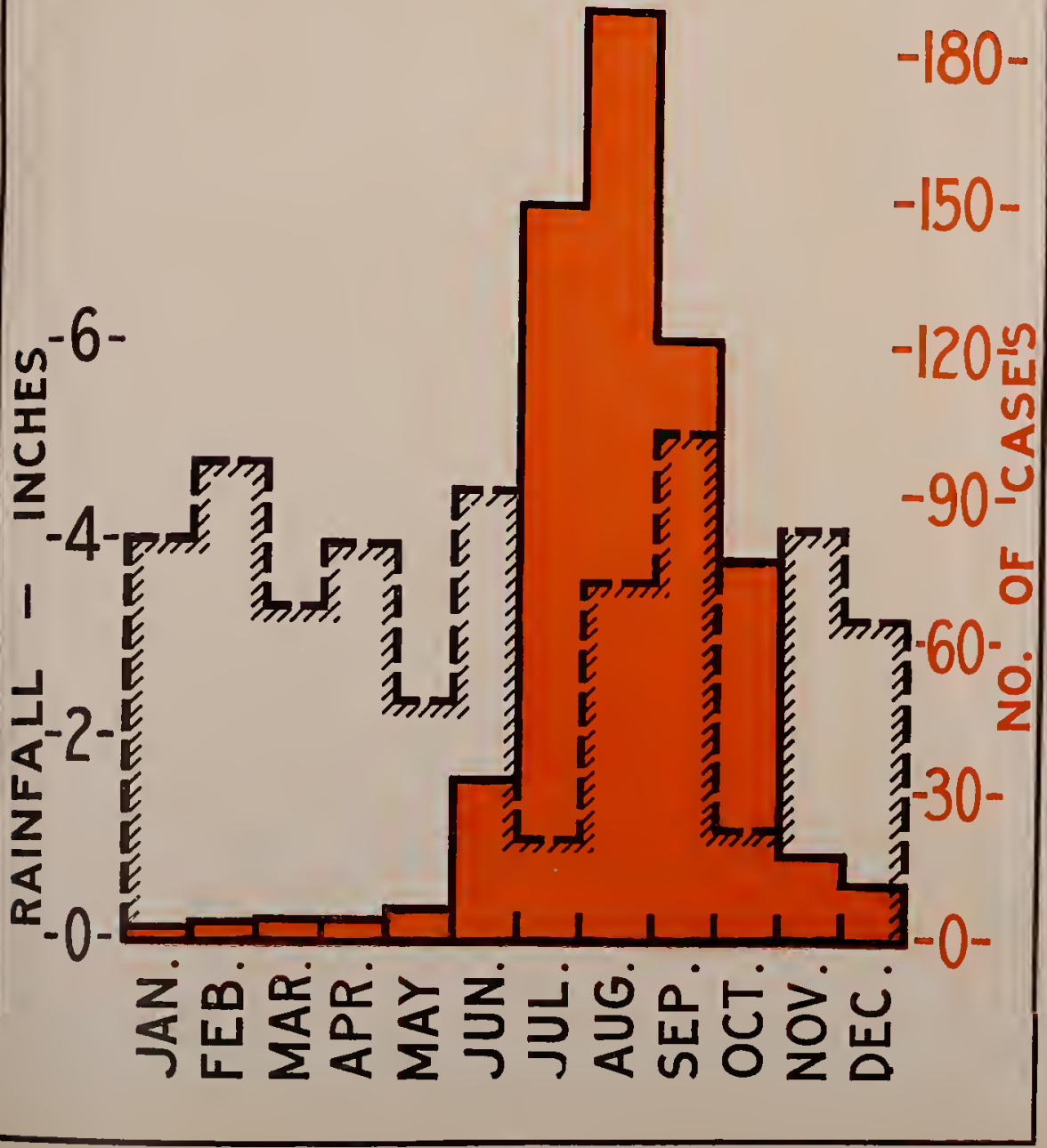
ce]

a

ye:

in

In

the

190

190 ?

1901

190:

190 \&

190 ?

do

arl

grt

pre

19

the

des

pos

far

ber 
INCIDEN

ilies.

i was

MEAN

fam-

and

e 12

$s$ ill-

BY MI

ssible

-80 -

$\alpha$

I

L

$n^{-60}$

II
II
0
0
0

I the

ount

hese

bulk

Cases.

7

4

4

$-0-\frac{1}{z \infty}$ 



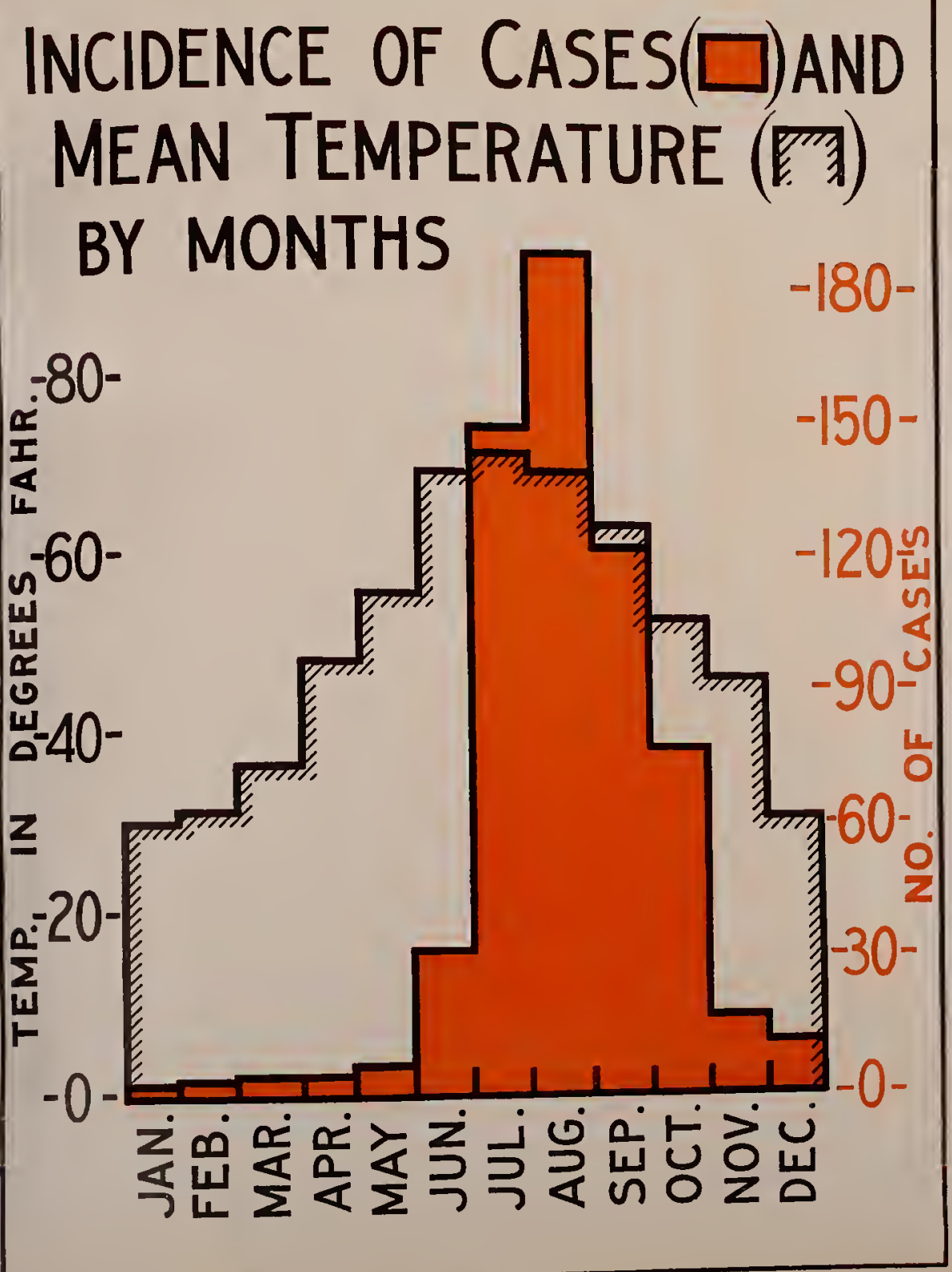

FIG. 5. 
cE]

a

ye:

in

In

thi

190 .

190:

$190 \mathrm{r}$

190 '.

190 :

190 !

do

ar]

grt

prt

19

the

des

po]

far

ber 
The 150 cases of paralysis carefully studied occurred in 142 families. The total number of children under fifteen in these 142 families was 4\%9. The total number of children sick from any cause in these families contemporaneously with the occurrence of paralysis was $18 \%$, and 12 adults. Of the $18 \%$ sick children, 149 were paralyzed; of the 12 adults, 1 was paralyzed. This leaves 49 cases of contemporaneous illness, not followed by paralysis, which are to be reckoned as possible abortire cases of the disease.

\section{Analysis of Cases thoroughly studied.}

[ 150 cases of paralysis in 142 families.]

Total number of children,

Number of children sick,

Number of adults sick,.

Number of children paralyzed,

Number of adults paralyzed,

Possible abortive cases, .

\section{Surrodndings of Patients.}

The following tables ${ }^{\circ}$ relate to the environment of the patients in the 150 cases carefully studied, and are largely self-explanatory.

The nearness of the house to the railroad was investigated on account of the data of certain Swedish observers, showing its frequency in these localities. Even in a district where railroads were frequent, the bulk of the cases were well remored from the tracks.

\section{Nearness of House to Railroad.}

$\mathrm{On}$

Within 20 yards,

Within 40 yards,

Within 100 yards,

Within 200 yards,

Within 300 yards,

Within 500 yards,

Over 500 yards,

Cases.

7

4

4

17

22

13

37 
Nearness to Water (Stream, Pond or Beach).

Within 50 yards,

Within 100 yards,

Within 200 yards,

Within 300 yards,

Within 400 yards,

Within 500 yards,

Within 600 yards,

Within 700 yards,

Within 800 yards,

Orer 800 yards,

Houses.

Cases,

Analyzing the age of infected houses, it is evident from the following table that most of the 150 cases occurred in old houses. Yet the majority of houses in a city are old. But in Dorchester, where many cases were investigated, building is active and many of the houses are new. It seemed as if the arerage age of infected houses was probably highor than that of the houses of those districts taken as a whole.

$$
\text { Age of House. }
$$

1 year old, .

Houses.

$1 \frac{1}{2}$ years old,

3 years old,

4 years old,

5 years old,

10 years old,

15 years old,

20 years old,

30 years old,

$30+$ years old,

Sanitary Conditions.

Excellent, .

Good,

Fair,

Bad, .

Not stated, 
Location of House.

Cases.

High, . . . . . . . . . . . . . 43

Medium, . . . . . . . . . . . . . 65

Low,

Dry, . . . . . . . . . . . . . . 105

Damp, . . . . . . . . . . . . . 45

150

Character of House.

Cases.

Detached house, . . . . . . . . . . . 64

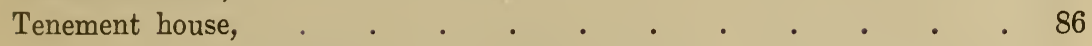

Floor of House inhabited by Family.

The whole house, . . . . . . . . . . . 55

The first floor ( 3 of which also occupied basement), . . . . 43

The second floor, . $\quad . \quad . \quad . \quad . \quad . \quad . \quad . \quad . \quad . \quad .36$

The third floor, . $\quad . \quad$. $\quad . \quad$. $\quad . \quad$. 20

Character of Sewage Disposal.

Sewer, metropolitan,

Sewer, city, . .

Cesspool,

Vault,

Privy,

Character of Water Supply.

Metropolitan, ·

Town,

City, .

Well,

The amount of dust as described by the families may be taken at its face value, the majority of cases reporting from a moderate amount upward. 


\section{Relation to Dust.}

No dust,

Very little dust,

Moderate amount of dust, Much dust,

Excessive amount of dust,

Cases.

Prevalence of Vermin, Insects and Rodents.

Inasmuch as the disease in many respects suggests that it is insectborne, the following table was compiled from the account of the family aided by the observation of the investigators. It may be added that the investigators were fully aware of the importance of obtaining accurate answers to this question.

Among 142 families, 134 had vermin, etc., as follows:-

Flies were present in . . . . . . . . . . 113

Mosquitoes were present in . . . . . . . . . 75

Mice (house) were present in . . . . . . . . . 63

Rats were present in $\quad . \quad$. $\quad . \quad . \quad . \quad . \quad . \quad . \quad 54$

Ants, red and black, were present in . . . . . . . . 35

Roaches were present in . . . . . . . . . . . 35

Bedbugs were present in . . . . . . . . . . . . $\quad$. 31

Spiders were present in . . . . . . . . . . . 28

Mice (field) were present in . . . . . . . . . . 20

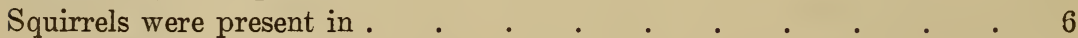

Biting flies were present in . . . . . . . . . 3

Grubs and caterpillars were present in . . . . . . 3

Fleas were present in . . . . . . . . . . . . 2

Brown-tail moths were present in . . . . . . . . . 1

Moles were present in

\section{Paralisis in Domestic Animals.}

The occurrence of paralysis among domestic animals and forvls has been found to coincide with outbreaks of the disease in the human beings in some instances reported. Inquiries were, therefore, addressed to every veterinary surgeon and every animal inspector in Massachusetts as to the occurrence of such paralysis in animals in 1909. The reported cases were then carefully laid off on a map of the State and the relative distribution of the animal cases compared with that of the human cases. No correspondence was found to exist, so that, so far as these data can be depended on, no obvious connection on the whole existed between the two classes of cases in Massachusetts in 1909. 
The health of the domestic animals in the 142 families is shown in the table. In 34 out of 87 families having domestic animals, sickness, paralysis or death occurred in these animals about the time of the paralyo sis in human beings.

The relation of this disease to paralysis in domestic animals is, however, a matter requiring much more extensive investigation and is at present wholly unknown.

Data as to Domestic Animals.

No animal of any kind in . . . . . . . . . . . 55

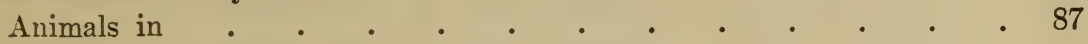

(a) 22 homes had 28 dogs without sickness.

53 homes had 73 eats without sickness.

11 homes had 760 hens without sickness.

9 homes had 17 birds without sickness.

7 homes had 11 horses without sickness.

1 home had 20 cows without sickness.

1 home had 3 pigs without sickness.

1 home had 1 lamb without sickness.

(b) 3 homes had 3 dogs with sickness.

10 homes had 10 cats with sickness.

4 homes had 6 hens with sickness.

1 home had 1 bird with sickness.

(c) 2 homes had 2 eats with paralysis.

3 homes had 4 hens with paralysis.

1 home had 1 dog with paralysis.

(d) 4 homes had deaths in 5 cats.

4 homes had deaths in 4 hens.

1 home had deaths in 2 rats.

1 home had death in 1 dog.

18 homes had illness in 20 animals.

6 homes had paralysis in 7 animals.

10 homes had deaths in 12 animals.

Total, 34 homes had illness, paralysis or deaths in 39 animals. ${ }^{1}$

1 The following letter, which reached the Board through the State Board of Health of Minnesota, is of possible interest in this connection :-

"In my reterinary practice during the past five or six years I have found a disease appearing among one and two year old colts that shows a line of symptoms corresponding very closely to anterior poliomyelitis of children. I have had from 5 to 10 cases a year during this time, the cases always occurring during the summer months, and the majority of them during the month of August. The affected colts are usually found in the pasture, unable to stand. The owner sometimes will notice an unsteady gait for twenty-four hours before entire loss of motion occurs. At first these colts have a rise of temperature ranging from $103^{\circ}$ to $104^{\circ} \mathrm{F}$; p pulse and respiration accel- 


\section{Relation to Rabies.}

The relation of the disease to rabies was investigated, and in 3 of the towns carefully studied epidemics had occurred in the past, but no outbreak of rabies in 1909 had any relation to these 150 cases of paralysis, and no one of the 150 paralyzed children had in the past received the Pasteur treatment.

\section{COMIMUNICABILITY.}

With regard to evidences of communicability in our series of cases, it seems proper that in so important a matter our conclusions should only be presented after a very careful study of all the facts.

We have had instances of direct contagion from child to child, with an incubation period of one to fourteen days. We have had a number of instances of what appeared to be indirect contagion by a healthy carrier, and finally we have had 11 instances in the 150 cases where the disease followed intimate contact with persons with old infantile paralysis, often of many years' standing. The latter cases seemed to be unworthy of mention in a serious report, but after consultation with our advisory board it seemed worth while to allude to the matter for what it is worth; e.g., a child of two and one-half was not, so far as known, in direct or indirect contact with any acute case, but was, previous to his attack, daily fondled and cared for by a girl of fourteen, paralyzed twelve years previously. On Aug. 14, 1909, he developed the disease. The Board would not wish to be understood as advocating the view that chronic cases were sources of infection, but the frequency of such histories make it proper to mention the matter as one worthy of following up, although the general history of other diseases caused by a filterable virus would make it seem unlikely.

Instances of what would appear to have been contagion occurred in 35 out of 150 cases. They may be analyzed as follows:-

erated; animal sweats profusely; appetite remains fairly good, but there is some trouble noticed in swallowing, especially water; slight derangement of the bowels, tending toward constipation; more or less tympanitis present; retention of urine, - for a few hours at least; head drawn back so the end of the nose tends to assume a position somewhat on a line with the neck. The death loss is less than 10 per cent. but in those that do not recorer the market value is depreciated to a very great extent because of the faulty gait the animal assumes after an attack of this disease, due to atrophy and contraction of certain muscles, or certain groups of muscles. It seems that the flexor muscles of the limbs especially are more often affected than the extensor, and in almost all the cases some of these deformities are likely to remain permanent. The flexors of the limbs are liable to contract and cause rolar flexion of the fetlock. The elevators of the head are also likely to become affected, so as to cause the head to have a poky appearance; that is, it is carried out from the body.

"After one of these attacks the colt will remain down from one to three weeks, and will then continue to improve for a period of one year, but seldom, if erer, makes a complete recovery.

DR. C. S. SHORE. 


\section{Instances of Contagiousness.}

Certain direct contact with acute case, . . . . . . . . 14

Certain direct contact with abortive case, . . . . . . . . 1

Certain direct contact with chronic case, . . . . . . . 14

Certain direct contact with both acute and chronic cases, . . . 2

Certain indirect contact with acute case by third person, . . . . 4

The contact was so intimate between the cases, and so constant, that there is no certain means of determining the day of the illness on which the sick child gave the disease to the other; or, in other words, the period of incubation in the recipient.

Families with more than One Case.

$13 \pm$ families with

$\tau$ families with

1 family with

142

Cases among the Acquaintances of Patient.

(a) In 22 instances there occurred 1 other acute case, either shortly before or after.

(b) In 2 instances there were 2 acute cases each among acquaintances.

(c) In 2 instances, 4 acute cases each.

(d) And in 1 instance there were 6 acute cases.

(e) In 13 instances there was 1 chronic case each among the acquaintances of patient.

It is not demonstrated that contact necessarily took place between these individuals.

As bearing on the question of contagion, the places to which visits were made within a month before the attack was investigated.

Places visited by Patient before Attack.

(a) No history of risits known, 42 ; (b) Revere Beach, 38; (c) City Point, 18; (d) Sarin Hill Beach (Dorchester), 15; (e) Boston, 12 ; (f) Nantasket, 11; $(g)$ Winthrop Beach, 8; $(h)$ Dorchester Beach, 6; (i) Gloucester, 5; $(j)$ Dewey Beach (Charlestown), 5; (all these places were known to be infected areas); (k) 3 other towns were visited by 4 cases each; of these 3 towns, 2 were known to be infected areas; (l) 8 
other towns were risited by 3 cases each; of these 8 towns, 7 were known to be infected areas; $(\mathrm{m}) 10$ other towns were risited by 2 cases each; of these 10 towns, 7 were known to be infected areas; $(n) 40$ other towns were visited by 1 case each; of these 40 towns, 25 were known to be infected areas.

\section{- Institutions for Children.}

It was suggested by the advisory committee that it might be worth while to look into the prevalence of the disease in asylums, etc., where healthy children lived and were removed from the ordinary conditions of street life, many of which institutions were in the midst of infected districts. Forty-five such institutions were investigated, where 3,600 young children lived. Only 1 child of the 3,600 developed the disease, and this was under such remarkable conditions that the case may be mentioned.

E. R. (age two years and four months) entered the St. Mary's Infant Asylum in Dorchester on Aug. 28, 1908. In February, 1909, the child had measles and was taken to the South Department of the Boston City Hospital. No other sickness since becoming an inmate of the asylum.

On Sept. 30, 1909, the child had a typical attack of infantile paralysis; the diagnosis was made by the attending physician and confirmed at the Children's Hospital. Partial paralysis of one leg still persists.

This child is one of a class of walking children in the institution, numbering in all 40. At the time of his illness, 2 or possibly 3 other children suffered from slight vomiting and diarrhœa. Nothing else remarkable.

This child lived as regular institution children do, playing with his 40 companions on one flcor and one porch.

The child never left the institution after he entered save to go to the City Hospital at the time of the attack of measles, several months before. No one had visited the child or sent food, toys, etc., for several months before onset.

During the month of September only 6 new ehildren were admitted to that part of the asylum. None of these had illness of any sort.

The child, at the time of onset, showed no marks or bites or wounds. His diet was that usually given in an asylum for children, viz., mashed potatoes, meat juices, soups, bread and milk, oatmeal, and, very rarely, fruit. The children sleep 16 in a room, and all eat in the same dining hall.

The child was not isolated during his illness and no other cases occurred.

Conditions, General and Special, precedixg the Attack.

The general and individual conditions preceding the attack are shown in certain matters in the following tables:- 


\section{Swimming or Wading.}

The frequency with which swimming or wading was mentioned as an antecedent in previous years attracted our attention and was embodied in a question on our blank. Nearly half of the cases had been swimming or wading in water contaminated by sewage shortly before the onset of the disease.

Out of 150 cases, 62 were swimming or wading just before onset.

Water was contaminated by sewage in

- 54 instances.

Water was contaminated more or less in . . . . 8 instances.

62

No history of swimming or wading in

88 instances.

Exposure to Heat, Cold or Dampness preceding the Attack.

To heat,

To cold,

To dampness,

Not exposed,

Accident, Fall or Overexertion preceding Attack.

Cases.

107 cases had no such history.

34 cases had history of fall.

9 eases had history of overexertion. 
Diseases prevalent in Town at Time of Occurrence of Infantile Paralysis.

Not known,

Families.

La grippe,

Measles,

Whooping cough,

103

Digestive troubles,

Rheumatism,

Mumps,

Scarlet fever,

Malaria,

Tonsilitis, .

Coryza,

Chickenpox,

Typhoid,

Diphtheria,

\section{Diet.}

General (45 had limited or modified diets), . . . . . . 105

(a) Raw cow's milk, . . . . . . . . . . . 120

(b) Condensed milk, . . . . . . . . . . . 14

(c) Breast milk and other food, . . . . . . . . . 14

(d) Breast milk alone, . . . . . . . . . . . .

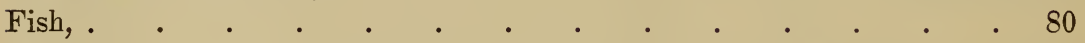

Fruit, . . . . . . . . . . . . . . . 100

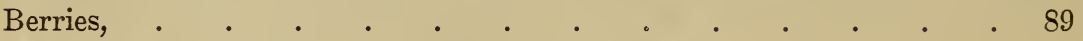

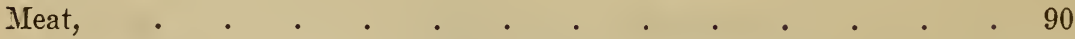

Canned goods: (a) fruits; $(b)$ vegetables; $(c)$ or fish, . . . . . 82

Cereals, . . . . . . . . . . . . . . . 15

Bread and butter, . $. \quad . \quad . \quad . \quad . \quad . \quad . \quad . \quad . \quad .23$

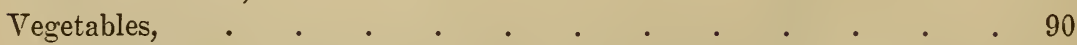

Stews and soups, $. \quad . \quad . \quad . \quad . \quad . \quad . \quad . \quad . \quad . \quad .11$

Eggs, . . . . . . . . . . . . . . 14

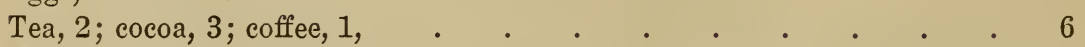

Malted milk, . . . . . . . . . . . . . 2

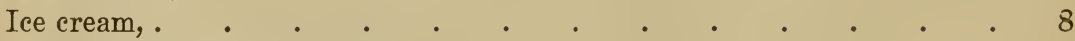

Predigested and beef juices, . . . . . . . . . . 4

Candy, . . . . . . . . . . . . . . . . 2

Bananas, . . . . . . . . . . . . . 6

Articles of diet are said to have been taken by the affected children, as shown in the accompanying table. As many of the cases partook 
of sereral kinds of food, the total is much in excess of the total number of cases.

It is important to note that no child living on breast milk alone in the 150 cases carefully studied was affected by the disease.

\section{Data as to School Attendance.}

School was not attended by . . . . . . . . . . . 115

School was attended by

Of the 35 cases attending school:-

Cases.

Edward Everett, Dorchester, was attended by . . . . . . 3

Winthrop Primary (including center) was attended by . . . . . 4

Concord Street, Boston, was attended by . . . . . . . 2

Sarin Hill School was attended by . . . . . . . . 2

Each at a different school, . . . . . . . . . . . 22

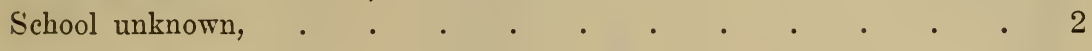

Possibly favoring Conditions preceding or attending Infection.

Insect bites or stings, 35 ; wounds, 13 ; sore throat, 42 ; diarrhœa, 35 ; otitis media, 2 ; coryza, 4 ; measles, 1 ; pin worm, 1 ; bronchitis, 1 .

Ninety-three had one or more of the above possible sources of infection; $5 \%$ had no such history. 'Total, 150 cases.

\section{Incidence of the Disease.}

Sex. - Three hundred and sixty-three males and 263 females were affected.

Age. - By the figures it is seen that the incidence is greatest between the ages of two and three. After ten years of age the chart deals only with ten-year periods and the average number of cases per year only is represented.

In the chart of age periods it is shown that only 7 per cent. of the cases occur in the first year of life, but 71 per cent. of cases occur in the first five years and $8 \%$ per cent. of cases in the first ten years.

\footnotetext{
1 School attendance, was not, howerer, necessarily continuous up to the time of the attack.
} 
By Ages.

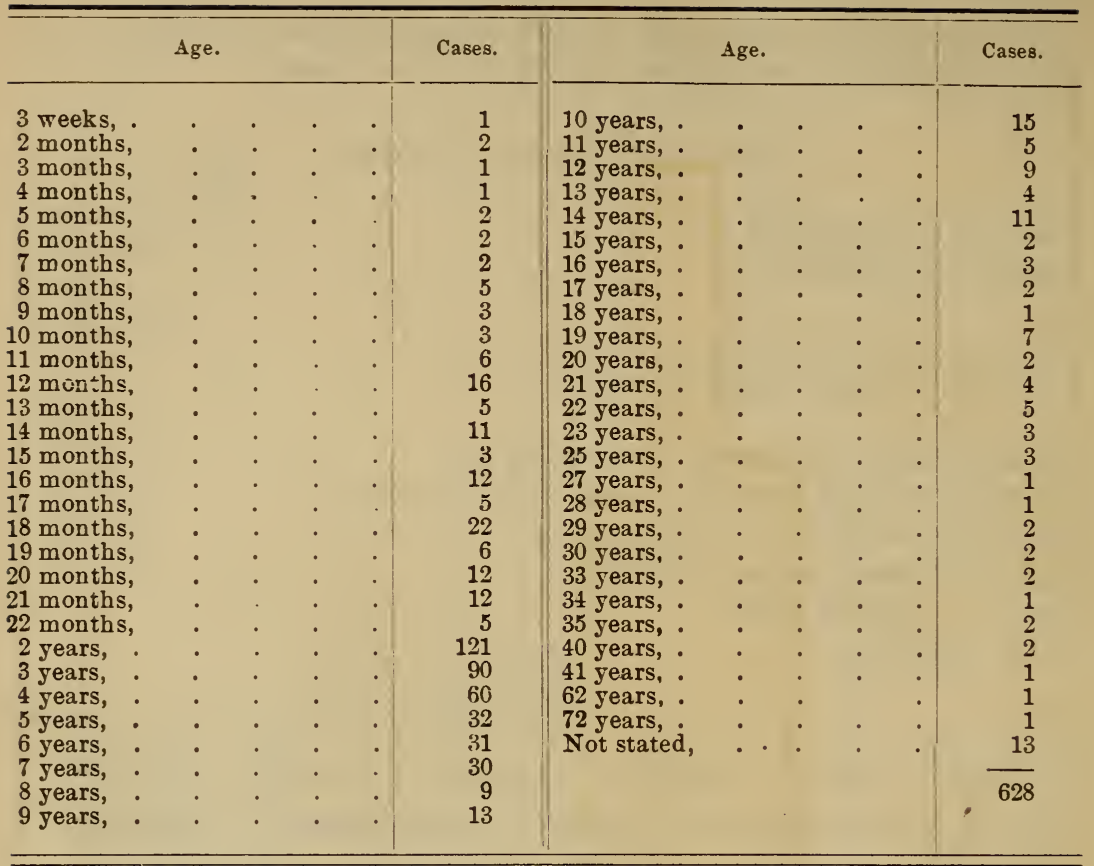

By Age Periods.

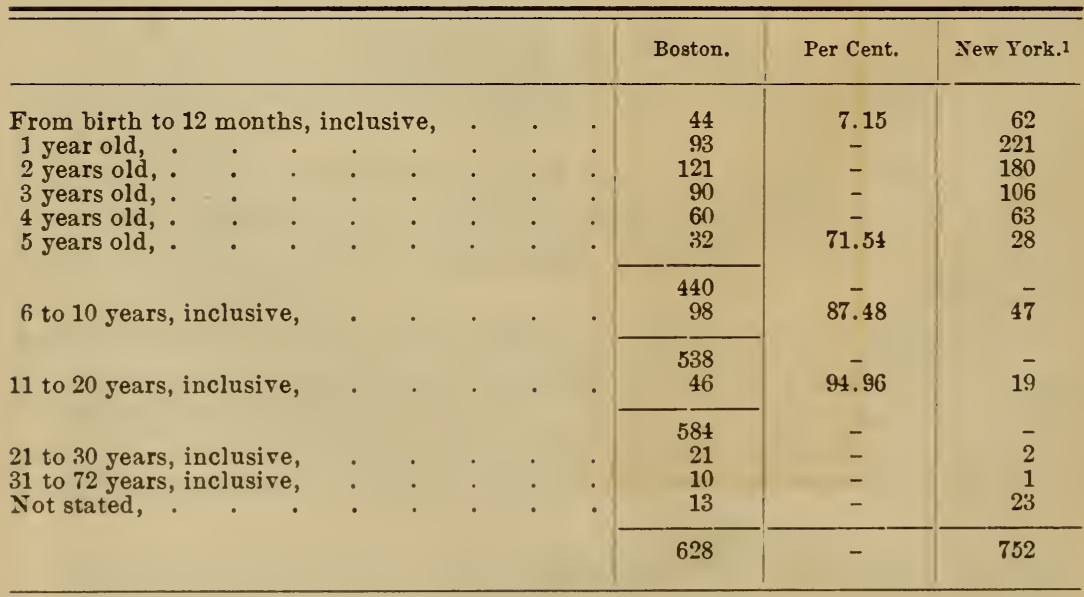

1 For purposes of comparison the New York figures are included. 


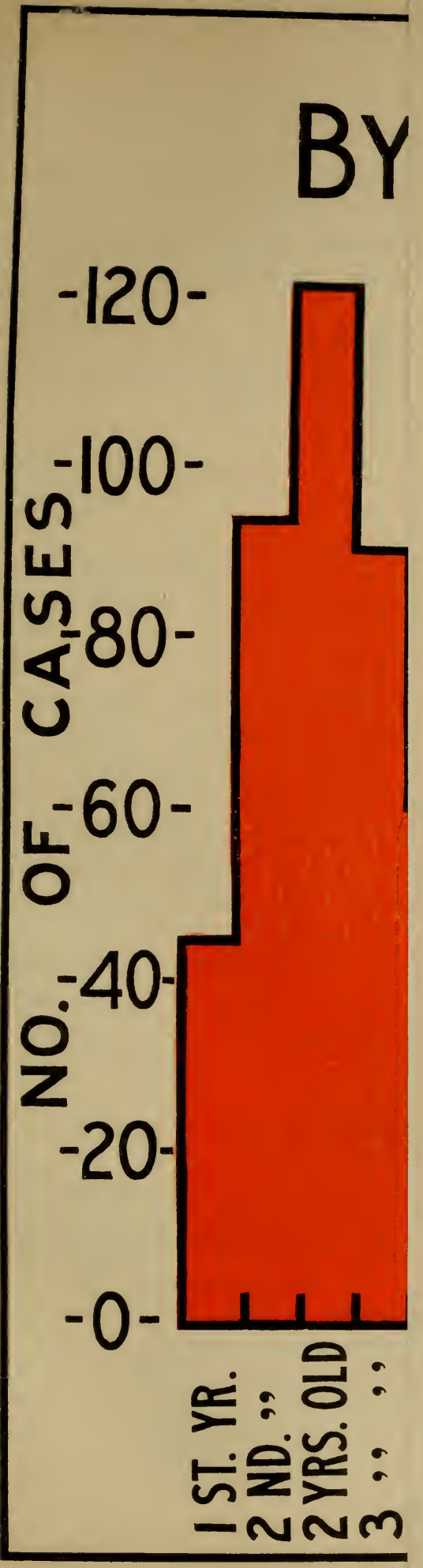





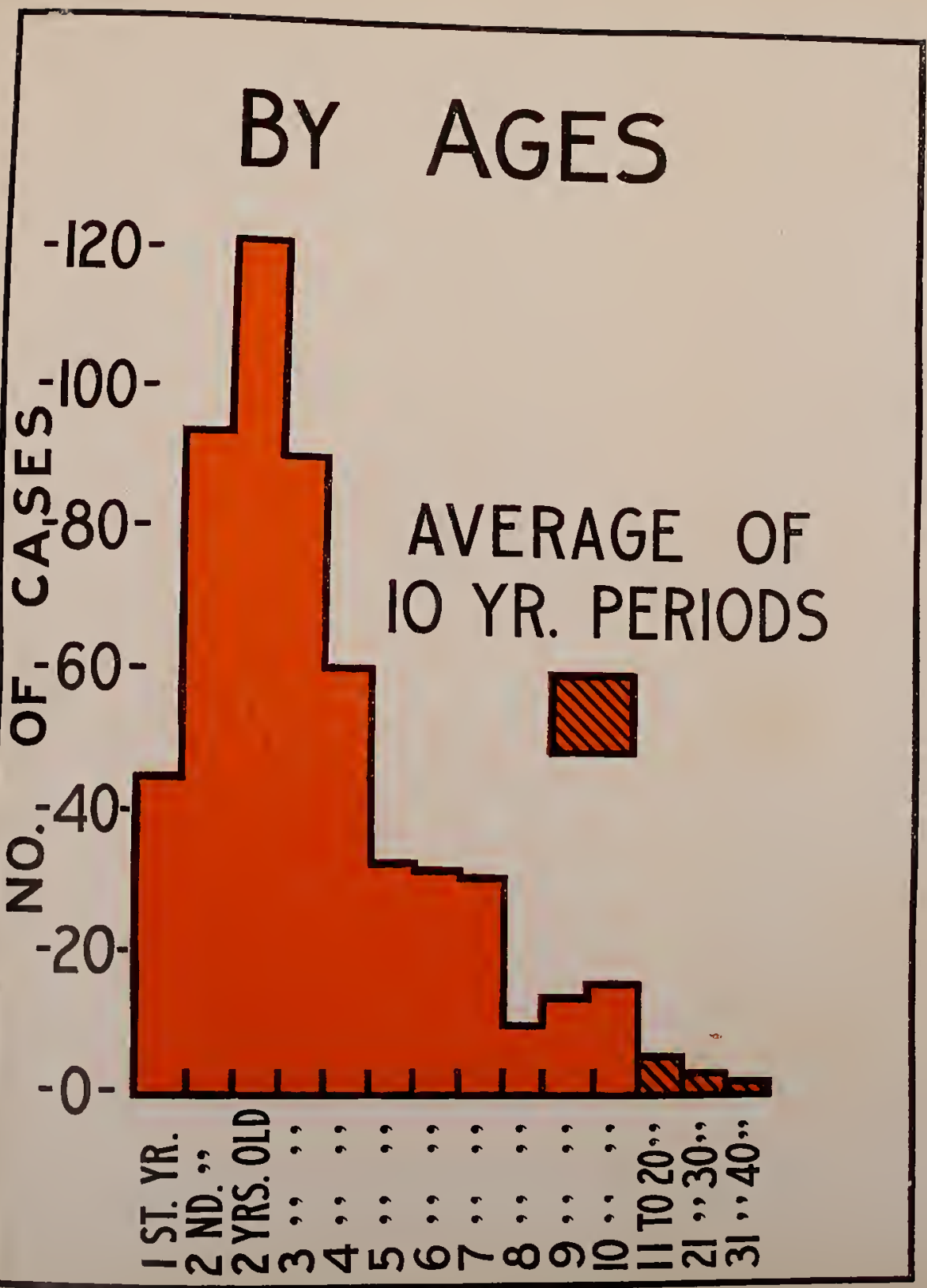




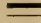

\begin{aligned} $3 \mathrm{I} \\ 2 \mathrm{I} \\ 3 \mathrm{I} \\ 4 \mathrm{I} \\ 5 \mathrm{I} \\ 6 \mathrm{I} \\ 7 \mathrm{I} \\ 8 \mathrm{I} \\ 9 \mathrm{I} \\ 10 \mathrm{I} \\ 11 \mathrm{I} \\ 12 \mathrm{I} \\ 13 \mathrm{I} \\ 14 \mathrm{I} \\ 15 \mathrm{I} \\ 16 \mathrm{I} \\ 17 \mathrm{I} \\ 18 \mathrm{I} \\ 19 \mathrm{I} \\ 20 \mathrm{I} \\ 21 \mathrm{I} \\ 22 \mathrm{I} \\ 2 \mathrm{I} \\ 3 \mathrm{~J} \\ 4 \mathrm{I} \\ 5 \mathrm{~J} \\ 6 \mathrm{I} \\ 7 \mathrm{y} \\ 8 \mathrm{~J} \\ 9 \mathrm{I} \\$\hline$=\end{aligned}$

$=$

Frc

2 !

3 !

5 !

$6 t$

111

21

31 t

No

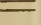




\section{Mortality.}

The average total death-rate in 628 cases was 8 per cent. The mortality was greatest over ten years of age, reaching 20 per cent. in that period. Under one year the mortality was also high -16 per cent.; between the ages of one and ten being lowest -4 per cent.

Mortality by Age.

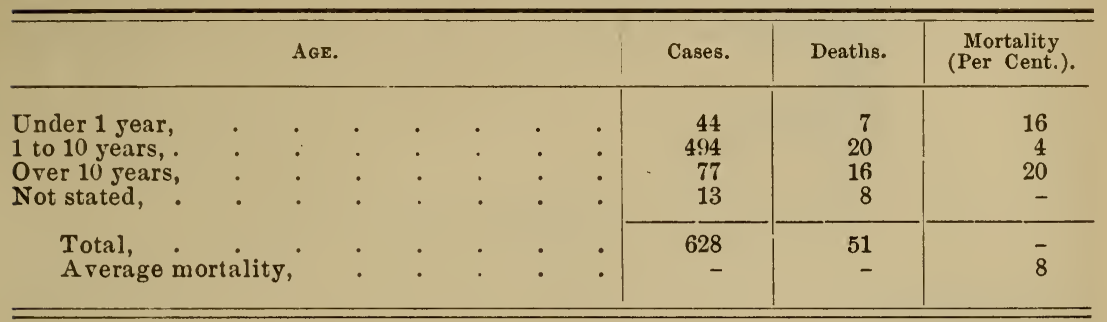

Early Symptoms.

Cases, 150. Cases not stated, 3.

Symptoms reported in $14 \%$ cases: fever, 132 ; pain, 110 ; tenderness, 108 ; vomiting, 67 ; constipation, 72 ; retraction of head, 60 ; diarrhœa, 38 ; headache, 33 ; delirium, 15; anorexia, 15; irritability, 24 ; stupor and restlessness, 14; malaria, 9 ; nausea, 18; convulsions, 4 ; twitchings, 3 ; cough, 8 ; dyspnea, 4 ; sore throat, 8 ; numbness, 3 ; chills, 2 ; weakness, 1 ; coma, 2 ; abdominal distention, 7 ; pain in abdomen, 1 ; jaundice, 1 ; vertigo, 2 ; double vision, 2 ; difficulty or inability to swallow, 4; difficulty in articulation, 2; gastro-intestinal upset, 2; diaphragmatic breathing, 1 ; coryza, 1.

Six cases had skin eruptions; 1 , measles and mumps; 1, whooping cough ; 1 , malaria.

Details of Digestive Disturbances connected with Attack.

(a) Not stated,

(b) Having no digestive disturbance, . . . . . . . . 15

(c) With digestive disturbance, tabulated as follows:-

(1) Preceding attack:-

Indigestion or stomach " upset," . . . . . 4

Nausea and vomiting, . . . . . . . . 37

Constipation, . $\quad . \quad$. $\quad . \quad$. $\quad . \quad$. $\quad . \quad$. 31

Colic, . . . . . . . . . . . .

Diarrhœa, . . . . . . . . . . 12

Mucus in stools, $\quad . \quad$. $\quad . \quad$. $\quad . \quad$. 2 
(2) Accompanying attack:-

Cases.

Indigestion (indefinite), . . . . . . . 3

Nausea and romiting, . . . . . . . . 51

Constipation, . . . . . . . . . 55

Colic,

Diarrhœa, .

Mucus in stools,

(3) Following attack:-

Nausea and vomiting, . . . . . . . 4

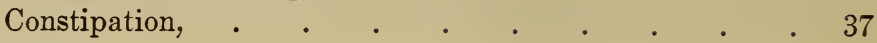

Colic, . . . . . . . . . . . . 2

Diarrhœa, . . . . . . . . . . . 10

Mucus in stools, . . . . . . . . . 2

Disturbances of Intestines during Attack.

No disturbance in

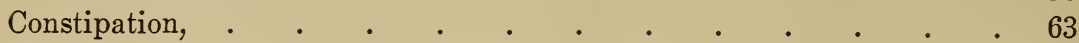

Diarrhœa, .

Involuntary defecation, .

Constipation, later diarrhœa,

Diarrhœa, later constipation, 
The pain or tenderness lasted:-

No pain,

One day or less,

Tro days,

Three days,

Four days.

Five days.

Six days, .

A few days, . . . . . . . . . . . . . 13

One week, . . . . . . . . . . . . . . . . 477

One to two reeks, . . . . . . . . . . . . . 75

Two to three weeks, . . . . . . . . . . . . . 36

Three to four weeks, . . . . . . . . . . . . . . 26

One to two months, . . . . . . . . . . . 28

Two to three months, . . . . . . . . . . . . 5

Sereral months, . . . . . . . . . . . . . 3

Until death, . . . . . . . . . . . . . . . 11

Present when report was made, . . . . . . . . . 107

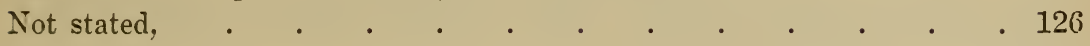

628

Appearance of Paralysis in Days after Onset of Fever.

Same day, .

Cases.

One day,

Two dars, .

Three dars,

Four days,

Five dars,

Six dars, .

Seren days,

Eight days,

Eleven days,

Twelve days,

Fourteen days, .

Sixteen dars,

Not known, fatal,

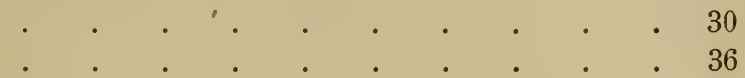

$$
\begin{aligned}
& 27 \\
& 23 . \\
& 14
\end{aligned}
$$

Distribution of Paralysis.

The distribution of the paralysis is shown in the table. It is interesting to note that when one arm and leg are paralyzed a hemiplegic distribution is more common than a crossed paralysis, and the frequency of facial paralysis is worthy of note. 


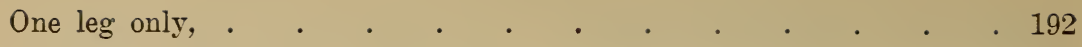

Both legs only, . . . . . . . . . . . . . . . . . 151

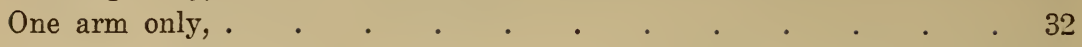

Both arms only, . . . . . . . . . . . . . . 11

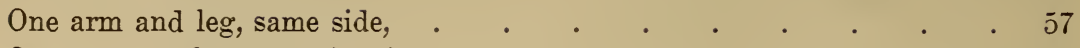

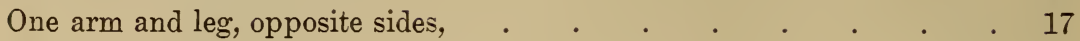

Both legs and one arm, . . . . . . . . . . . . . . 35

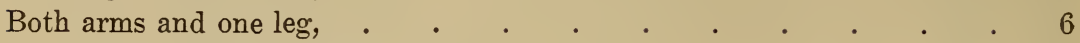

Both arms and both legs, . . . . . . . . . . . . 82

Not stated, . . . . . . . . . . . . . . . 12

Back, . . . . . . . . . . . . . . . . 83

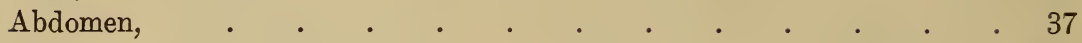

Face, . . . . . . . . . . . . . . . 8

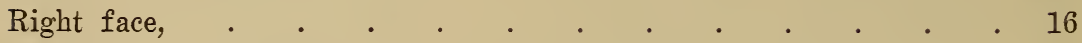

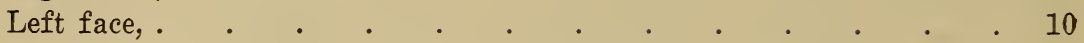

Progrosis.

Recovery Rate in 628 Cases.

In answer to the question, "Has paralysis entirely disappeared?" the replies were as follows:-

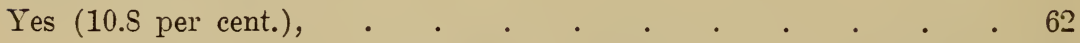
No, . . . . . . . . . . . . . 404

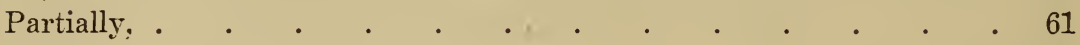

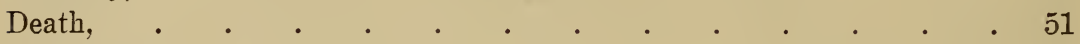

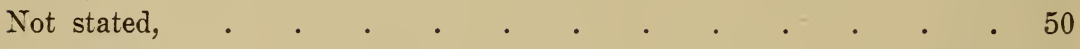

628

This table is intended to emphasize the fact that what appears to be recovery in the eyes of the family physician occurs more frequently than is generally supposed, 10 per cent. of such cases being reported. This led to a closer investigation of the recoveries in the 150 cases carefully investigated, and it was reported by the investigators that 25 of these (16.7 per cent.) had wholly recovered. This report was not accepted and the investigators were sent again to these children, and each child was stripped naked and the separate morements of ankle, knee, hip, spine, abdomen and arms were separately tested. From this careful examination it is sure that 25 children out of 150 have recovered since the disease in 1909. The following tables deal only with these 25 cases. 


\section{Age of 25 Recovered Cases.}

So far as one may generalize from these few cases, it would seem that the arerage age of the children was higher than in the cases in general.

\begin{tabular}{|c|c|c|c|c|c|c|c|c|c|c|c|c|}
\hline & & Age & & & & Cases. & & Age & & & & Cases. \\
\hline \multirow{2}{*}{$\begin{array}{l}1 \text { year, } \\
2 \text { years, } \\
3 \text { years, } \\
4 \text { years, } \\
5 \text { years, } \\
6 \text { years, } \\
7 \text { years, }\end{array}$} & : & : & $\dot{\text { : }}$ & $\dot{.}$ & $\dot{5}$ & \multirow{2}{*}{$\begin{array}{l}3 \\
1 \\
5 \\
5 \\
2 \\
4 \\
1\end{array}$} & \multirow[t]{2}{*}{$\begin{array}{r}9 \text { years, } \\
10 \text { years, } \\
14 \text { years, } \\
21 \text { years, }\end{array}$} & \multirow[t]{2}{*}{$:$} & \multirow[t]{2}{*}{$\dot{\text {. }}$} & \multirow[t]{2}{*}{ : } & \multirow[t]{2}{*}{$:$} & $\begin{array}{l}1 \\
1 \\
1 \\
1\end{array}$ \\
\hline & : & • & : & 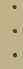 & : & & & & & & & 25 \\
\hline
\end{tabular}

\section{Onset.}

The character of the onset was mild in 6 , moderate in 17 and severe ir 2.

\section{Evidence of Paralysis.}

The presence of paralysis in the beginning is vouched for by the attending physician in 23 cases and by the family in 2 , and the distribution of paralysis was on the whole fairly extensive, as shown by the table.

\section{Extent of Paralysis in 25 Recovered Cases.}

One thigh and leg, Both thighs and legs, Both thighs, One leg, One arm, . One leg, arm and back, One leg and back, One thigh, leg, arm and forearm, One arm, forearm and cervical region, Cerrical region, Indefinite staggering gait, .

The extent of the paralysis, therefore, did not differ essentially from that of the whole group presented above. 
Duration of Paralysis in 25 Recovered Cases.

\begin{tabular}{|c|c|c|c|c|c|c|c|c|c|c|c|}
\hline \multicolumn{6}{|c|}{ Time. } & Cases. & \multicolumn{4}{|c|}{ Time. } & Cases. \\
\hline \multirow{2}{*}{$\begin{array}{l}3 \text { days, } \\
1 \text { week, } \\
2 \text { weeks, } \\
3 \text { weeks, } \\
4 \text { weeks, }\end{array}$} & $\dot{.}$ & $\dot{.}$ & $\dot{.}$ & $\dot{.}$ & $\dot{.}$ & \multirow{2}{*}{$\begin{array}{l}2 \\
3 \\
3 \\
2 \\
3\end{array}$} & \multirow[t]{2}{*}{$\begin{array}{r}8 \text { weeks, } \\
12 \text { weeks, }\end{array}$} & \multirow[t]{2}{*}{$\dot{.}$} & \multirow[t]{2}{*}{$\dot{.}$} & \multirow[t]{2}{*}{. $\quad}$. & $\begin{array}{l}8 \\
4\end{array}$ \\
\hline & $\dot{.}$ & $\dot{.}$ & $\dot{.}$ & $\dot{.}$ & $\dot{.}$ & & & & & & 25 \\
\hline
\end{tabular}

\section{Tenderness in Recovered Children.}

It was thought that such cases being slighter might show less tenderness in the acute stage, but the tenderness was about as frequent as in the severer cases.

Pain or tenderness in the acute attack existed in 19 out of 25 recorered cases.

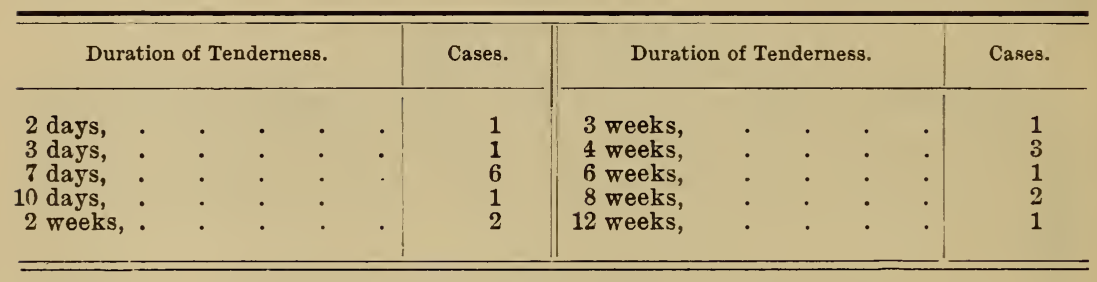

The statement may, therefore, be made that in the whole group of 628 cases, 10.8 per cent. were reported as wholly recovered; that in the smaller group of 150 cases, 16.7 per cent. are known to have recovered; and that a study of character of onset, distribution and tenderness in these cases gires no means of distinguishing them from other cases at the time of the attack.

\section{Prevention.}

In the matter of prevention of the disease in Massachusetts, in Norember, 1909, it was made one of the notifiable diseases, like scarlet ferer, etc. In a recent circular addressed to physicians it has been adrised by the Board that such cases should be quarantined, and that urine, stools and sputum should be disinfected, and we have called attention to the existence of abortive cases as probable sources of contagion. ${ }^{1}$

\footnotetext{
1 In a recent communication, Flexner and Lewis report that a 1 per cent. solution of peroxide of hydrogen in perhydrol has been found to distroy the virus. In riew of their belief that the entrance of the virus is probably by the respiratory tract, the use of a nasal douche of this character would seem adrisable.
} 


\section{CONCLUSIONS.}

These data are presented as a report of progress in an inrestigation "hich will be continued, and no conclusions are drawn from them.

That the effort of the State Board meets with general approval is -hown by the fact that the following resolution was adopted in Washirigton, on May 5, 1910, by the American Orthopedic Association and the American Pediatric Society:-

It having been shown by recent epidemics, and investigations connected with the same, that epidemic infantile spinal paralysis is an infectious, communicable disease which has a mortality of from 5 per cent. to 20 per cent., and that 75 per cent. or more of the patients surviving are permanently crippled, State Boards of Health and other health authorities are urged to adopt the same or similar measures as already adopted and enforced in Massachusetts for ascertaining the modes of origin and manner of distribution of the disease, with a view to controlling and limiting the spread of so serious an affection.

That the course of the disease may be in 1910 in Massachusetts cannot be predicted. It would be expected from the history of the disease that a year of comparative immunity in the State as a whole would follow the great prevalence of the disease in 1909, and it is, therefore, disappointing to find 22 cases reported in the first five months of 1910 , as against 15 cases for the same five months in 1909. Whether this means merely an increased attention on the part of the profession, or a really increased prevalence of the disease, time alone will show.

The object of the inquiry in 1910 will be twofold.

First, the formulation and classification of early symptoms and types $c_{\perp}$ the disease, with especial reference to early diagnosis; and, second, a study of the conditions under which contagion seems to occur, with a continued search as to the mode of entry of the virus into the body.

The medical profession must remember that the Board of Health acts only as the agent of the profession in assembling the data provided by them, and depends on them for the same willing co-operation that it has met and is profoundly grateful for in the past.

The report for 1910 will be what the profession makes it, and the Board is anxious not only for the prompt and full report of typical cases, but also for notification of suspicious and atypical cases, which are possibly of the abortive type and a most important link in the chain of eridence. 


\section{BIBLIOGRAPHY.}

[The more important articles are indicated by asterisks.]

1. *Trans. Mass. Med. Soc., 1908.

2. *Bull. State Board Health, Mass., July, 1909.

3. *E. Lissianski: Emmendingen, 1908, Dölter. 35 pp.

4. *Starr: Jour. Am. Med. Asso., July 11, 1908.

5. Treves: Brain, Vol. XXXII., Part 127, 1908, p. 285.

6. Berg: Med. Rec., Jan. 4, 1908.

7. A. S. Hamilton: Jour. Minn. Med. Asso. (etc.), Minneapolis, 1909, XXIX., pp. 423-428.

8. R. Neurath: Beibl. z. d. Mitt. d. Gesellsch. für inn. Med. u. Kinderh. in Wien, 1909, VIII., pp. 46-51.

9. K. Potpeschnigg: Wien. klin. Wochenshr., 1909, XXII., p. 1334.

10. *Landsteiner and Levaditi: Compt. rend. Soc. de Biol., Dec. 3, 1909; Dec. 24, 1909.

11. J. K. Friedjung: Wien. med. Wochenschr., 1909, LIX., pp. 2311-2314.

12. Gasters: Heine-Medin'schen Krankheit. Ztschr. für Med. Beamte, Berl., 1909, XXII., pp. 613-616.

13. *H. D. Stephens: Australas, Med. Cong. Trans., Victoria, 1909, III., pp. $42-47$.

14. Reichman: Deutsche med. Wochenschr., Leipz. u. Berl., 1909, XXXV., 1. 1500 .

15. H. Heiman: Arch. Pediat., New York, 1909, XXVI., pp. 506-516.

16. G. H. Fellman: Milwaukee Med. Jour., 1909, XVII., pp. 171-175.

17. *Flexner and Lewis: Jour. Am. Med. Asso., Nov. 13, 1909, p. 1639; Dec. 4, 1909, p. 1913; Dec. 18, 1909, p. 2095; Jan. 1, 1910, p. 45; Feb. 12, 1910, p. 535; April 2, 1910, p. 1140 ; May 28, 1910, p. 1780. Jour. Exp. Med., Mar. 14, 1910.

18. Sneve and Ramsey: St. Paul Med. Jour., Sept., 1909. (Translation of extracts from Wickman, Harbitz and Scheel: Geirsvold.)

19. M. Berliner: Wien. klin. Wochenschr., Vienna, May 27, 1909, No. 21, pp. $737-770$.

20. J. Manning: Wisconsin Med. Jour., Milwaukee, 1908-09, VII., pp. 611618.

21. W. A. Jones: Jour. Am. Med. Asso., Nov. 13, 1909.

22. G. Vieten: Ztschr. für aerztliche Fortbildung, Oct. 15, 1909, p. 633.

23. *P. Krause: Deutsche med. Wochenschr., No. 42, Oct. 21, 1909.

24. *P. Krause and E. Meinicke: Idem, p. 1825.

25. L. Strauss: Jour. Nerv. and Ment. Dis., Lancaster, Pa., 1909, XXXVI., pp. 288-291.

26. H. T. Machell: Dominion Med. Month., Toronto, 1909, XXXII., pp. 211-213.

27. T. E. Green : Intercolon. Med. Jour., Australas., Melbourne, 1909, XIV., pp. 197-202. 
29. L. E. La Fetra: Areh. Pediat., New York, 1909, XXVI., pp. 328-340. Also: Trans. Am. Pediat. Soc., New York, 1908, XX., pp. 158-170.

29. B. S. Rutherford: Kentucky Med. Jour., Bowling Green, 1908-9, VIII., p. 133.

30. "Römer: Münch. med. Wochenschr., Dec. 7, 1909; Dec. 14, 1909; Feb. $1,1910$.

31. *Römer and Joseph: Ibid., Feb. 15, 1910; March 15, 1910.

32. Hohmann: Ibid., Dec. 7, 1909.

33. "Muller: Ibid., Nov. 30, 1909.

34. Hochhaus: Ibid., Nov. 16, 1909.

35. O. Foerster: Berl. klin. Wochenschr., No. 49, Dec. 6, 1909.

36. *George P. Shidler: Jour. Am. Med. Asso., Jan. 22, 1910.

37. "Strauss and Huntoon: N. Y. Med. Jour., Jan. S, 1910.

3s. Bremer: Lancet, Feb. 12, 1910.

39. F. Eichelberg: Deutsch med. Wochenschr., No. 3, Jan. 20, 1910.

40. Sir W. R. Gowers: Brit. Med. Jour., Feb. 5, 1910.

41. ${ }^{*}$ C. Leiner and R. V. Wiesner: Wien. klin. Wochenschr., Vienna, Jan. 20, 1910, XXIII., No. 3, pp. S3-11S; IX., 329, 1910.

12. Beneke: Münch. med. Wochenschr., Jan. 25, 1910.

43. L. L. Cazenavette: New Orleans Med. and Surg. Jour., Feb., 1910.

44. R. Kraus: Wien. klin. Wochenschr., Feb. 17, 1910.

45. Symes: Lancet, Feb. 12, 1910.

46. Zappert: Wien. med. Wochenschr., 1909, LIX., 26S3-2690.

47. Netter: Bull. et mém. de la Soc. Méd. des Hôp. de Paris, 12, 19 and 26, Nov., 1910.

48. H. W. Gill: Northwest, Lancet, Minneap., Mar. 15, 1910.

49. Job and Froment: Rev. de Méd., Mar. 10, 1910.

50. Knopfelmacher: Wien. med. Klin., 1909, 44, 1671.

51. Epidemic Poliomyelitis, Report, etc., on the New York Epidemic of 1907. Nervous and Mental Disease, Monograph Series, No. 6, New York, 1910.

52. Akute Kinderlähmung und Influenza. Brorström. Leipz., 1910.

53. Lebredo and A. Recio: Sanidad y Beneficencia Boletin Oficial de la Secretaria, Habana, March, 1910.

5t. K. Furntratt: Oesterr. San.-Wes., Wien, 1909, XXI., 79-97.

5.5. Krause: Münch. med. Wochenschr., 1910, LVII., 47.

56. J. Locker: Oesterr. San.-Wes., Wien, 1909, XXI., Beil., 71-7S.

57. A. Netter: Bull. et mém. Soc. méd. d. hôp. de Par., 1909, 3 s., XXVIII., 515-52S, 553-567, 629-631, 746-761.

5S. WT. R. Ramsey: Jour. Minn. M. Asso. (etc.), Minneap., 1910, n. s., IXX., 9-15.

59. A. Recio: Rev. med. cubana, Habana, 1909, XV., 66-70.

60. C. K. Russel: Montreal Med. Jour., 1909, XXXVIII, S45-851.

61. O. M. Schloss : Arch. Pediat., New York, 1909, XXVI., 926. Am. Jour. Obst., New York, 1910, LXI., 166.

62. J. Schonka: Oesterr. San.-Wes., Wien, 1909, XXI., 498-501.

63. Bourgoin: Union méd. de Canada, Montréal, 1909, XXXVIII., 683-688. 
64. J. Hoffmann: Deutsche Ztschr. für Nerrenh., Leipz., 1909-10, XXXVIII., 146-166.

65. L. Huismans: Deutsche Aerzte-Ztg., Berl., 1909, 506-50S.

66. D. J. MeCarthy: Rep. Henry Phipps Inst., Phila., 1909, T., 437-142.

67. R. Wilke: Deutsche tierärztl. Wochenschr., Hannor., 1909, XVII., 69i701.

6S. Wollenweber: Ztschr. für Med.-Beamte, Berl., 1909, XXII., 7£う-793.

69. Reckzeh: Med. Klin. Berl., 1909, V., 1704.

70. F. E. Batten: Clin. Jour., Lond., Feb. 23, 1910.

71. H. Bonhoff: Deut. med. Wochenschr., March 24 and 31, and April 7, 1910.

72. J. Grober: Wien. med. Klin., Nor. 21, 1909.

73. E. Job and J. Froment: Rerue de Médecine, Paris, March, XXX., No. ก, 1910 .

74. P. Krause and E. Meinicke: Deut. med. Wochenschr., April 7, 1910.

75. E. J. Melrille: Termont Med. Month., Burlington, March, 1910.

76. Römer and Joseph: Münch. med. Tochenschr., Feb. 1, 1910.

i7. R. Kraus: Med. Klin., Berlin, March 20, 1910.

TS. E. Meinicke: Deut. med. Tochenschr., April 14, 1910.

79. J. W. MeCreery, Whittemore: Iowa Med. Jour., April, 1910.

\section{INFANTILE PARALYSIS AS OBSERVED IN HEALTH DIS- TRICT NO. 15 DURING 1909.}

Lractix A. Joxes, M.D., State Inspector of Health.

During 1909 there rere 82 cases of anterior poliomyelitis in District To. 15 (Berkshire County), 2 cases on the eastern border of the district, in Plainfield, and 2 orer the line in Nerr York State, in Austerlitz, making a total of 86 cases included in this report.

\section{APPEARANCE OF CASES.}

January and February were the only months in the year when there were no cases. Sixty-eight cases, orer i9 per cent., occurred during August, September and October.

\section{LOCATION OF CASES.}

With the exception of 2 cases in Plainfield, 1 in Saroy, 1 in Richmond and 2 in Austerlitz, 6 in all, the remaining 80 cases were in the central part of the county, running north and south, following for the most part very closely the course of the streams, along which lie also the principal means of communication, including highways, electric railways and steam cars. 
Cases by Towns.

\begin{tabular}{|c|c|c|c|c|c|c|c|c|c|}
\hline \multicolumn{8}{|c|}{ City or Town. } & $\begin{array}{r}\text { Population. } \\
12,548\end{array}$ & $\begin{array}{c}\text { Number of Cases. } \\
19\end{array}$ \\
\hline $\begin{array}{l}\text { Adams, } \\
\text { Clarksburg, } \\
\text { Egremont, } \\
\text { Great Barrington, } \\
\text { Lee, . } \\
\text { Lenox, } \\
\text { North Adams, : } \\
\text { Pittsfield, } \\
\text { Richmond, : } \\
\text { Savoy, } \\
\text { Shefteld, } \\
\text { Stockbridge, : } \\
\text { Plainfeld, } \\
\text { A usterlitz, N. } \text { Y., }\end{array}$ & $\dot{0}:$ & $\begin{array}{l}: \\
\vdots \\
: \\
\vdots \\
\vdots\end{array}$ & $\begin{array}{l}\dot{:} \\
: \\
: \\
: \\
:\end{array}$ & $\dot{:}: \dot{ }$ & : & $\begin{array}{l}\dot{0} \\
\dot{0} \\
\dot{0}\end{array}$ & : & $\begin{array}{r}12,548 \\
1,200 \\
721 \\
6,152 \\
4,000 \\
3,058 \\
23,000 \\
30,000 \\
600 \\
549 \\
1,728 \\
2,022 \\
382 \\
-\end{array}$ & $\begin{array}{r}19 \\
1 \\
1 \\
19 \\
2 \\
7 \\
11 \\
17 \\
1 \\
1 \\
1 \\
2 \\
2 \\
2\end{array}$ \\
\hline
\end{tabular}

\section{Appearance of Cases Chronologically.}

A table giving the occurrence of cases in chronological order shows that cases appeared impartially through the central portion of the county all through the season, except that in Great Barrington there were 19 cases, all of which appeared between September 3 and October 7, inclusive.

The number of cases in the family, and the day of illness upon which the paralysis appeared, are given below.

Number of Cases in a Family.

\begin{tabular}{|c|c|c|c|c|c|c|c|c|c|c|}
\hline & & & & & & & & & Families. & Cases. \\
\hline \multirow[t]{2}{*}{$\begin{array}{l}\text { One case, . } \\
\text { Two eases, }\end{array}$} & \multirow[t]{2}{*}{ : } & \multirow[t]{2}{*}{. } & \multirow[t]{2}{*}{ : } & \multirow[t]{2}{*}{$\dot{.}$} & \multirow[t]{2}{*}{. } & \multirow[t]{2}{*}{$\dot{.}$} & \multirow[t]{2}{*}{ : } & \multirow{2}{*}{$: \quad:$} & $\begin{array}{r}72 \\
7\end{array}$ & $\begin{array}{l}72 \\
14\end{array}$ \\
\hline & & & & & & & & & 79 & 86 \\
\hline
\end{tabular}

Appearance of Paralysis.

\begin{tabular}{|c|c|c|c|c|c|c|c|c|c|}
\hline \multicolumn{4}{|c|}{ Day of Disease. } & & Number of Cases. & \multicolumn{3}{|c|}{ Day of Disease. } & Number of Cases. \\
\hline \multirow{2}{*}{$\begin{array}{l}\text { First, } \\
\text { Second, } \\
\text { Third, } \\
\text { Fourth, } \\
\text { Fifth, } \\
\text { Sixth, } \\
\text { Seventh, }\end{array}$} & \multirow{2}{*}{ : } & \multirow{2}{*}{\multicolumn{2}{|c|}{ : }} & \multirow{2}{*}{ : } & \multirow{2}{*}{$\begin{array}{r}8 \\
16 \\
14 \\
17 \\
5 \\
4 \\
3\end{array}$} & \multirow[t]{2}{*}{$\begin{array}{l}\text { Eighth, } \\
\text { Ninth, } \\
\text { Fourteenth, } \\
\text { Not stated, }\end{array}$} & \multirow[t]{2}{*}{$\dot{:}$} & \multirow[t]{2}{*}{$\therefore \quad:$} & $\begin{array}{r}4 \\
2 \\
2 \\
11\end{array}$ \\
\hline & & & & & & & & & 86 \\
\hline
\end{tabular}


Possibility of the Disease being spread by Phisicians.

The 86 cases were seen or attended by 40 physicians, the number of cases to each physician being as follows:-

22 physicians attended 1 case each.

8 physicians attended 2 eases each.

5 physicians attended 3 cases each.

2 physicians attended 5 cases each.

1 physician attended 6 eases.

1 physician attended 7 cases.

1 physician attended 10 eases.

In no instance was any evidence discovered to suggest that the disease had been brought into a home or transferred elsewhere by the physician in attendance. Nor were there any cases in physicians' families.

There were 6 fatal cases. There were 4 abortive cases (59, 62, 69 and 79 ), while 2 other possible abortive cases, not included in the summary, are mentioned in connection with cases 1 and 18 .

Aside from the instances where a second case in a family developed at an interval of from three to fifteen days after the initial case, and where the primary case may possibly be regarded as the source of infection; and aside from two instances to be mentioned, there is very little evidence pointing toward the active contagiousness of the disease in Berkshire County in 1909.

While in many places facts have accumulated indicating that in some localities, at some times, the disease is readily communicated from one person to another, and that it may perchance be carried by a third person, this series of cases, as well as the series in Western Massachusetts in 1908, studied by Emerson, leads to the conclusion that the contagiousness of the disease varies greatly in different groups of cases, even though the various groups in a given locality occur at the same period and are situated comparatively near each other.

For example, the cases in the North Adams group afford no known points of contact with each other. The same is largely true for the cases in the Pittsfield group.

The two instances particularly suggestive of contagion are given in detail in the summaries for Adams and Great Barrington (q.v.).

In the former, two children, giving a positive history of close personal contact (kissing) with a child already ill with the disease, promptly developed the disease themselves, and one died.

In Great Barrington, out of 19 cases within a period of thirty-four days 13 were associated with one school, 5 pupils themselves contracting 
the disease, the remaining cases having brothers, sisters or other relatives, with whom they came in close contact, in attendance at the school. The 5 cases in pupils of the school were confined to the second, third and fourth grades, where the contact might readily be the more intimate on account of the younger age of the children in attendance.

These two instances are of especial interest because of the possibility of the infection entering the system through the nasopharyngeal spaces.

That the virulence of the infection varies greatly is further evidenced by the fact that in most instances but 1 case occurred in a family, that no cases occurred among the friends or relatives of a given case, and that, too, notwithstanding the most intimate contact, such as occupying the same room, sleeping in the same bed, assisting in caring for or entertaining the patient by brothers and sisters or neighboring children, and the entire absence of any attempt at isolation or quarantine.

If, as has been maintained by some, every case is to be traced to direct or vague indirect contact with some preceding case, it becomes exceedingly difficult to account for the immunity of the much larger number who are in close to intimate contact with the patient.

A map of the cases emphasizes what has been pointed out previously, that with a half dozen exceptions the cases are located in the valley, close to the streams, the travelled highways and the steam and electric railway lines.

Under the circumstances it seems reasonable to isolate the patient ill with acute anterior poliomyelitis until the acute stage is past, and to urge physicians and families to be suspicious of acute attacks of disturbances of digestion, accompanied by fever and pain, particularly if at the time there are other cases of the disease known in the community.

\section{Summary, North Adams and Vicinity.}

In North Adams in March occurred a sporadic case, the first of the year. The remaining cases, 11 in all, occurred in May (1 case), September 15 to 29 ( 4 cases), and October 4 to 20 ( 5 cases).

One case taken ill March 2, involving eventually the whole body, was fatal twelve days later from paralysis of respiration.

In each instance there was but 1 case in the family, unless the brother of the Clarksburg case (case 1), taken ill two days later with fever, romiting and general achiness, be regarded as an abortive case.

It is doubtful if the sister of case \%, ill for two days at the same time with fever, is to be considered as an abortive case. 


\section{Location.}

Two cases were within one-half to one-quarter mile of the North Branch of the Hoosick River, while 10 were close to or comparatively near the Hoosick River or its North or South Branches.

With the exception of case 7, September 29, cases 10 and 11, October 20 , which were comparatively near each other, the cases were widely scattered.

So far as school attendance was concerned, but 4 of the children attended school (cases 1, 6, 8 and 10), and no 2 cases occurred in children attending the same school; and in but one instance (case 6, taken ill September 26, and case 9, taken ill October 14) were other children in the same family attending the same school, though even here they were in different grades.

Ten of the cases were attended by as many different physicians. One physician had 2 cases (case 1 , October 4 , case 8 , October 11), but he did not attend the second family until called to see the child already ill.

There were no cases in physicians' families, though in four of them . there are children.

With the possible exception of the abortive case in the family of case 1 , above mentioned, none of the cases appear to have been associated with each other in any known manner.

In this connection, however, 5 cases (case 2A, May; case 3, August 13; case 4 , September 15; case 5, September 25; case 11, October 20) are located on streets through which electric cars run. These same streets are also used somewhat by touring automobiles.

None of the cases are near railroad stations, and but 3 (cases 2A, 3 and 5) are at all near the railroad tracks.

\section{Case 1.}

C. R., six years, Clarksburg. Dr. F. D. Stafford, North Adams. Apparently an isolated case. Was not away from home except in North Adams several times during the week beginning September 6 (Old Home Week). After complaining of being tired for one week, taken ill October 4 with nerrousness, fever $\left(103^{\circ}\right)$, retraction of the head and pain in the legs. On October 6, paralysis in both legs, more marked in the left. October 20, paralysis still present in the left leg.

Five other children in the family; they attend school in Clarksburg.

\section{Abortive Case.}

The brother Charles, eight years, was taken ill on October 6, after eating choke cherries, as his brother had done, with fever, vomiting, nervousness and general achiness. No paralysis. 


\section{Case 2.}

T. G., one year, 329 River Street. Dr. W. F. McGrath, North Adams. An isolated case. Taken ill March 2 with fever and dullness. On following day the fever continued, vomiting and convulsions occurred, though the patient appeared better. The convulsions were repeated later, and according to the physician there was paralysis of the whole body, especially of the muscles of the chest and neck. Fatal on March 14, from paralysis of respiration.

One other child in the family; none in school.

\section{Case $2 A$.}

B. R., 23 West Main Street, North Adams. Dr. C. W. Wright, North Adams, first saw case; later, Dr. J. H. A. Matte. Without preliminary symptoms, except a slight cold for two or three days, patient suddenly felt that the left side of the face was stiff and queer, and on the following day there was complete paralysis of the left side of the face. This was probably in May. Though the condition is improved, the paralysis is still well marked (Feb. 19, 1910).

\section{Case 3.}

C. C., ten months, 183 State Street. Dr. J. H. A. Matte, North Adams. $\mathrm{Had}$ been having whooping cough during the preceding five weeks. Taken ill August 13, at which time the whole of the right arm was found paralyzed. September 21, paralysis still present from the shoulder to the elbow.

One other child in the family; none in school.

\section{Case 4.}

L. R., three years, 95 Beaver Street. Dr. N. M. Crofts, North Adams. With no symptoms preceding except a three-days cold, taken ill on September 15 with fever. On September 18, paralysis appeared of the right side of the face. Still present December 16 .

Two other children in the family; none in school.

A sixteen-year-old girl, patient's cousin on mother's side, had paralysis at fourteen months of age, and is still unable to walk. She often visits this family.

\section{Case 5.}

E. M:, three years, 1527 West Main Street, Blackinton. Dr. J. B. Hull, Williamstown. Early in August fell down stairs. No apparent injury. A week later had a prolapse of the rectum, which required replacing by a physician. During the last half of August was in Winchendon, Mass. At the end of August, on her return from Winchendon, had an attack of bowel disturbance, accompanied with fever, vomiting and diarrhœa. About September 25 became feverish $\left(102^{\circ}\right)$, irritable, restless, with pain in the back and legs, followed by vomiting and diarrhœa. About October 1 paralysis appeared in both legs. Still present, especially in the left leg (October 14). 
One other child in the family, attending Blackinton School, grade 2.

Query: Did this case really begin at the end of August, and were the later symptoms in September a recurrence?

\section{Case 6.}

R. T., one year, 27 Harris Street. Dr. M. M. Brown, North Adams. During the early part of July had bowel trouble for three or four weeks. Taken ill with fever on September 26, and on following day the right arm was paralyzed.

Six other children in family; 1 attending Veazie School, grade 2, and 1 attending Johnson School, grade 5.

\section{Case 7.}

G. P., nineteen months, 60 Cliff Street. Dr. W. A. Brosseau, North Adams. Previously well. Fever on September 29. Very little pain. Constipated. On October 2, paralysis in right leg.

Five other children in the family, 2 of whom attend the Notre Dame School, grades 2 and 5 .

At the time this child was taken ill a sister had a ferer for two days. No other symptoms. It seems unlikely that this was an abortive case.

Case 8.

J. M., seven years, $57 \mathrm{Kemp}$ Avenue. Dr. F. D. Stafford, North Adams. Taken ill October 11, with fever, headache, vomiting and pain back of eyes and in back of neck. Paralysis in right side of the face on October 13.

No other children in the family. The patient attends Houghton School, grade 3.

\section{Case 9.}

G. M., two years, 45 Williams Street. Dr. O. J. Brown, North Adams. For two weeks preceding, fingers and eyes seemed sore. On October 14, fever, vomited, did not seem to see well, and had been very quiet for two days before. On October 18 there was retention of the urine, and paralysis of both arms and both legs. Could not hold the head up.

Three other children in household; 1 attends the Johnson School, grade 7, and one attends the Drury School. Four cousins, living on Loftus Street, were frequent visitors during the illness, and they attend the Veazie School, kindergarten and grade 1.

\section{Case 10.}

J. M., six years, 14 Montgomery Street. Dr. J. F. C. Forster, North Adams. Sent home from school on October 19 on account of a headache. Nosebleed that evening for nearly two hours. On following day there was slight paralysis of the left side of the face, gradually becoming more pronounced during the succeeding two days.

Four other children in family. Patient returned to school at St. Joseph's, grade 1 , on October 22 or 23. 


\section{Case 11.}

R. T., two and one half years, 132 Union Street. Dr. A. A. Harper, North Adams. No fever. Illness began October 20 with vomiting, pain in both legs and in the right arm. Paralysis on same date in both legs and in right arm.

Two other children in the family; none in school.

\section{Sumarar, Adams and Vicinity.}

In Adams and vicinity there were 22 cases (Adams 19, Savoy 1, Plainfield 2).

Saroy and Plainfield cases are included in this group because Adams is the natural trading center and source of supplies.

The first cases in Adams were 3 which occurred at the end of the month on the 2\%th and the 29th of July. On August 3 occurred the case in Saroy, while in Adams there were cases on the 8th, 20th and 30th of the month. In Adams there were cases September 8, 18 (2) and 26.

Late in the month, September 22 and 29, occurred the Plainfield cases, both in the same family.

In October, on the $2 \mathrm{~d}, 3 \mathrm{~d}$ and 21st, occurred further cases in Adams. Between November 2 and 5 (about) there were 3 cases, and the last were on December 4 and 7 , both in the same family.

Paralysis, more or less severe, was present in every case but 1 (case 28).

One case, taken ill on July 29, with paralysis of both legs and throat on August 1, was fatal on August 3, from paralysis of respiration (case 13).

In three instances there were 2 cases in the same family. In all the remaining instances but a single member of the household was afflicted.

An infant of nineteen months on High Street, was taken ill on August 20, with paralysis of the right leg on August 26 (case 18).

On August 31 a two-year-old baby living upstairs in the same house was taken with fever, diarrhœa and loss of appetite. It recorered within a few days without further symptoms. There had been some communication back and forth between the two families, and possibly this should be regarded as an abortive case.

All of the Adams cases were practically in the valley near the north and south center of the town, and near or comparatively near the South Branch of the Hoosick River. Those farther away were in every instance near some small brook feeding into the branch of the river just mentioned.

With reference to the town itself two or possibly three groups of cases may be distinguished. 
One group is at the south part of the town, where the first cases occurred. Between July 27 and September 18 there were 8 cases, with 2 more somewhat at one side early in December, both in the same family.

At the north end of the town, near Renfrew, was another group of 4 cases, 3 in two adjoining tenements, between September 18 and November $\check{5}$.

The 5 remaining cases, more or less scattered, were in the central portion of the town, on August 7, 30, October 2, 21, and November 2, respectively.

In Adams, again, school attendance, with one possible exception, seems to have had no part in the spread of the disease.

Two boys who attended the first grade of the Liberty Street School were taken ill on October 21 (case 23) and November 2 (case 24), respectively. The former child was out of school during the week of October 25, except for a half day on October 26. He was in attendance from November 1 to 4, inclusive, and has not been in school since. The second boy left on November 2, so that there was possible contact on October 26 and again on November 1 .

Aside from these two none of the patients attended school. Nor were there any instances where other children in the same family with the patient attended the same school, except that on September 13 other children from four families where the disease existed earlier in the summer began attendance at the Commercial Street School. No new cases developed here, however.

The 22 cases were attended by 7 different physicians. In no instance had an interval of less than a month intervened between the time the physician last called at the house and the time he was called to attend the patient already ill with paralysis.

There were no cases in the families of physicians, though in four or five of the families there are children.

Possible evidences of contagion are shown in the following instances:-

The first case appeared in the south part of the town, in a boy three years of age, on July 27 (case 12). He played much with his cousin, a three-year-old-girl, who lived on an adjoining street, and kissed her on the day he became ill. She also visited him daily, and probably kissed him until she herself became ill, two days later, on July 29 (case 13). This case was fatal on August 3.

This child played frequently with a little girl of two and a half years, living two doors away, who was taken ill on August 8 (case 16). In this case there is a history of the child having kissed the preceding (case 13) after she was taken ill. 'The mother of the third case also visited the house of the second case after the patient's decease, and viewed the remains, on August 4 or 5 . 
These 3 cases are of special interest in view of the recent announcement of Dr. Flexner showing that the secretions of the nasal passages contain the infecting material. ${ }^{1}$

The remaining cases in the immediate neighborhood afforded no history which would indicate the source of the disease.

Of the group of 4 cases at the north end of the town, 3 appear to have been somewhat in contact.

A boy of five years (case 17A), living in a six-tenement block, was taken ill on or about September 18. A brother, seventeen years old, became ill on October 3 (case 17B).

An infant of twenty-one months (case 25A), living in the adjoining tenement, was taken ill November 5 or shortly after. This patient's mother visited in the adjoining tenement during the illness of the older brother, and the younger children played more or less with the younger brother (case 1\%A).

There is no evidence of the association of these cases with others in the town.

The possible contact of 2 cases in the scattered group in the center of the town has already been indicated in the paragraph on schools (cases 23 and 24).

There is nothing to indicate the source of the disease in cases 26 and 27 , a brother of four years and a sister of twenty-one months, taken ill on December 4 and $\%$, respectively, except that if the incubation period in the majority of cases is from two to four days, as suggested by Wickman, it would seem reasonable to conclude that the sister received her infection from the brother.

With reference to the cases 29 and 30, daughter and father, in Plainfield, the following is of interest: -

The daughter, three years, became ill in the evening of September 22, after her return from Adams, where she had been during the day, on a trading trip with her mother. There was no known contact with other cases. This was the first time she or her mother had been away from home for two or three months.

At this same time, September 22, her father was ailing, but he did not really give up till September 29. Earlier in the month he had driven some horses to Springfield, spending four days in the round trip. So far as known he did not come in contact with other cases.

This man's father, who lived with him, died from heart disease on August 16. The minister from the adjoining town, who conducted the funeral two or three days later, had a child ill at the time with infantile paralysis. If this can be considered the source of infection, the incubation period was much prolonged. 
Two cases (case 13, July 29, and case 16, August 8) are on streets through which electric cars pass, while 5 are located on side streets very near electric car lines.

Automobile traffic through the town follows almost entirely the line of the electric cars.

\section{Case 12.}

Boy, D., three years, 15 Elm Street, Adams. Dr. P. S. Potter, North Adams, Dr. H. B. Holmes, Adams. Taken ill July 27, with fever, intense headache, vomiting, constipation. Tried to walk, but fell. Tenderness along the spine. July 29, paralysis in both legs.

There is one other child, of six years of age. No school at this season, though the child began in the fall at the Commercial Street School, grade 1.

This patient is a cousin of the following case, A. D. (case 13). The two children played together constantly. The case 13 child saw this patient the night he was taken ill and kissed him. She also saw him each day till taken ill herself, on July 29, and probably kissed him. Father works at the Jacquard Mill.

\section{Case 13.}

A. D., three years, 123 Commercial Street, Adams. Dr. H. B. Holmes, Adams. About the end of June fell 9 feet; no apparent injury. About July 22, considerably frightened by an automobile. Taken ill July 29, with high fever, vomiting and considerable prostration. August 1, some retraction of the head, some paresis of both legs and paralysis of muscles of mouth. Fatal on August 3, from paralysis of respiration; for thirty hours previous to death was unable to speak.

This patient is a cousin of the above (case 12), with whom she played on the day he became ill, and kissed him that night, after he was ill. Also saw him daily till taken ill herself. Also played with case 16 . There is one other younger child. Father works in the Jacquard Mill.

\section{Case 14.}

B. D., four years, 8 Pearl Street, Adams. Dr. A. K. Boom, Adams. Taken ill about July 29, with fever, vomiting and some pain (child did not want to be touched). There followed about August 1 partial paralysis of both legs; the child could not stand up, and there was some difficulty in voiding urine.

One other child, a boy of seven, in the family. Four Yankee children in the other side of the house. They do not play together much because of the difference in nationality. No school at this time. The boy now goes to the Commercial Street School, grade 1. Father works at the Berkshire Mills.

There is no information obtainable of contact with other cases. Cases 12, 13 and 16 are all near, but the mothers of all agree that this child was not acquainted with them. They all live rery near each other, however. 


\section{Case 15.}

S. G., fifteen months, 3 Godek Street, Adams. Dr. A. K. Boom, Adams. History previous to the appearance of the paralysis, about August 7, unobtainable. The family are ignorant Poles, and even with an interpreter can furnish no satisfactory information. On August 7 both legs were paralyzed.

Taking into account the time of occurrence, the age of the patient, the nationality of the family and the location of the home, contact with other cases seems improbable.

\section{Case 16.}

D. G., two and one-half years, 127 Commercial Street, Adams. Dr. A. K. Boom, Adams. Taken ill August 8 , with fever, slight stiffness of the spine and the head drawn back. On the third day vomiting. On the following day there was pain at McBurney's point, and appendicitis was suspected. On the third or fourth day, as developed later, retention of the urine occurred, only the excess from the distended bladder escaping. On the fifth day patient was removed to a hospital and operated on for a supposed intussusception of the bowel. Nothing was found except an excessively distended bladder. On August 18 appeared paralysis of both legs and the right arm, thus establishing the diagnosis.

One other child in family, attending Commercial Street School, since opened in September. Father is a fern dealer.

This child played much with case 13, and on the day he was taken ill, July 29, saw him and kissed him. Mrs. G. visited the D. family on August 4 or 5, just before the funeral, to carry some flowers, and was in the room to see the body.

\section{Case 17.}

F. O., four years, 1 Plunkett's Lane, Adams. Dr. J. H. Choquette, Adams. Taken ill on September 18 with fever, and that same night the leg (left) was paralyzed. On September 19 romited several times. This was a mild case.

One other child in the family, younger. No school. Father works in the Jacquard Mill. The visit of the family to Plainfield in August was not near any known case on the mountain.

\section{Case $17 \mathrm{~A}$.}

R. S., five years, 74 Friend Street, Adams. Dr. A. Desrocher, Adams. During July and August had whooping cough. The sister next younger also had the same disease, and died from it on August 16. Taken ill about September 18, with headache, fever, vomiting and convulsions. Retraction of the head was present, and for three days he was delirious. About September 21 both legs were paralyzed. Improvement began after two weeks.

There are 5 other children; none in school. A brother works in the eloth room at the No. 4 Berkshire Mill. The father of case 25A (early in Norember) also worked here. 
An older brother (see following case, 17B) was taken ill with this disease on October 3 .

A child in the adjoining tenement was taken ill early in November (see case $25 \mathrm{~A})$.

Case $17 B$.

C. S., seventeen years, 74 Friend Street, Adams. Dr. A. Desrocher, Adams. Without previous illness, taken ill on October 3 with fever, headache, dizziness and pain in the back. Retraction of the head present. On October 10, paralysis of left leg and the right arm. For about one week not able to get about.

At present is at work as spare hand in the main mill of the Renfrew Manufacturing Company. The left leg is smaller and also weaker than the right at present (Feb. 15, 1910).

This boy is brother of the foregoing (case 17A), and it would seem probable that this was a case of contact infection from the brother. During the illness of this patient the mother of a child next door (case 25A) came to call, and the children of both families were together more or less.

\section{Case 18.}

W. S. G., nineteen months, 10 High Street, Adams. Dr. J. A. Quest, Adams. Taken ill on August 20, with fever. On 21st seemed better; on 23d cried all day; on 24th perspired and slept much of the time. The inclination to sleep continued nearly one week. On August 26th the right leg was paralyzed.

An only child. Father works in Jacquard Mill, where father of case 12, taken ill July 27, works. Before and during the illness, children living upstairs, two, four and nine years of age, played with this baby, and soon after, possibly about August 31, the two-year-old boy was taken ill (see following case).

\section{Possible Abortive Case.}

E. G., two years, 10 High Street, Adams. Dr. J. A. Quest, Adams, who made one visit as society physician, and made no record of it. Hence the uncertainty of the date of the illness. About August 31 taken ill with fever, diarrhœa, loss of appetite. This was on a Friday or a Saturday. When sent for the physician was out of town, and did not come till the following Tuesday. Only one visit. There was some question as to circumcision, which was done some time in September. There was no paralysis, and no further symptoms. In October the child again had fever, vomiting and was dull. Seen by physician three times.

This woman keeps about 15 chickens. An indefinite time before case 18 was taken ill 2 of the chickens died, one about two weeks after the other. The deaths were sudden, and the chickens were previously well so far as known. 
Case 19.

I. C., four years, 3 Gilliad Street, Adams. Dr. A. K. Boom, Adams. August 30 taken ill with fever and vomiting. On September 1, paralysis both legs and right arm. Constipated.

One other child, ten years, at French parochial school, grade 3. Father works at L. L. Brown Paper Company, lower mill. Mother works at spinning, Berkshire Mill No. 3. The children in this family had no contact with a small child upstairs, though they now stay there while the parents are at work.

\section{Case 20.}

R. P., two years, 16 Temple Street, Adams. Dr. J. H. Choquette, Adams. Illness began with fever, slight retraction of head and pain in neck on September S, followed by headache and paralysis of right arm on September 10.

There are 2 other children, older; 1 in school at Commercial Street, grade 2, though school did not begin till September 13. The father works as a trimmer in the upper mill of the L. L. Brown Paper Company.

\section{Case 21.}

P. P., three years, 143 Bellevue Arenue, Adams. Dr. A. K. Boom, Adams. On September 26 taken ill with fever, tenderness in the legs and some pain in the neck. Constipation. On September 28, paralysis in both legs. Retention of urine for twenty-four to thirty-six hours.

One other child, older, attending the Maple Grove School, grade 2. Father works for Renfrew Manufacturing Company as a painter. No known contact with other cases.

\section{Case 22.}

J. F. N., four years, 48 Maple Street, Adams. Dr. J. H. Choquette, Adams. In April had what attending physician said was eczema, but what Dr. Boom, who was called in, said was scarlet fever. Child peeled. There was subsequent weakness in walking. Just two weeks before J. was taken ill, the father was sick with grippe, and consulted the same physician at the latter's office. The physician was not in the house for at least a month before this illness began. Illness began October 22, with fever and headache. Vomited once on following day, at which time appeared paralysis of the right arm. There was also some pain in the neck and tenderness in the right arm. There was also a mild tonsilitis at this time. Constipated.

There are 2 younger children; none in school. Father employed as clerk in drug store. There are 2 French children in the family downstairs.

\section{Case 23.}

R. D., five years, 53 Spring Street, Adams. Dr. A. Desrocher, Adams. Illness began October 21, with fever, some pain and tenderness in the legs. On October 24 woke crying, and said he could not move. Brought downstairs and dressed, but was inclined to lie in a chair for this and the follow- 
ing days. On October 25 woke erying again, and said his "legs were gone." Later he got about by placing his hands on a chair and hopping. This continued for ten or twelve days, and disappeared gradually by the end of a month.

There are 2 younger children. This boy attended school at Liberty Street, grade 1 , from which room there was another case (24) on November 2.

The school record of attendance shows as follows: this boy was first out on October 25, whole day; was in in the afternoon of the 26th of October, and then out rest of the week. The following week was in from November 1 to 4, inclusive, then permanently out. From which the inference is that the dates as to the onset of the illness are not entirely accurate, though the facts stated are correct.

Early in August he was on a farm in Savoy, near the Harris farm (see case 28), whence he returned at the end of August. During the stay in the country he visited the Harris farm and saw the patient there after she had been taken ill. The interval before his own illness is too long to make this likely as the source of his infection. This boy frequently played at his father's livery stable, where he may have come in contact with the grandfather of case 20 (taken ill September 8), though the interval here seems long to trace the infection thence. The grandfather and case 20 were in frequent contact.

\section{Case 24.}

J. C., six years, 17 Randall Street, Adams. Dr. A. J. Bond, Adams. Taken ill November 2, with fever, possibly some headache. Paralysis of both legs on November 4.

Attended Liberty Street School, grade 1, where he was in possible contact with case 23 on November 1, and during the preceding week. No other cases occurred in this school.

There are 5 other children, 2 of whom attend the same school, grades 4 and 9. They lost no time from school during the whole of the brother's illness. Father is a master plumber.

\section{Case 25.}

F. B., twenty-seven months, 18 Pine Street, Adams. Dr. A. K. Boom, Adams. November 4, taken ill with fever and slight tenderness in left leg. On November 5, paralysis in lower part of left leg.

One younger child. Father, mule spinner, Berkshire Mill No. 4. No known contact with other cases. An English family, here only a few months, not acquainted much as yet.

\section{Case 25A.}

H. W., twenty-one months, 76 Friend Street, Adams. Dr. H. B. Holmes, Adams. During late summer and early fall had stomach trouble. Taken ill after November 5, with fever and vomiting. Constipated. No special pain. Two weeks later, about November 19, had paralysis of both legs. Still (Feb. 15, 1910) unable to walk. 
Six other children in family, 2 in Renfrew School, grades 4 and 5 . Possible contact with case $17 \mathrm{~B}$, next door, through the children who played together. Father works in cloth room, Mill No. 4, Berkshire Mills.

\section{Case 26.}

A. T., four years, 13 Enterprise Street, Adams. Dr. J. H. Choquette, Adams. December 4 , fever $\left(104^{\circ}\right)$, delirious and pain in the neck and right hip and leg. Tomiting. Constipation. December 5, paralysis of right leg.

Brother of case 27.

\section{Case 27.}

C. T., twenty-one months, 13 Enterprise Street. Dr. J. H. Choquette, Adams. Taken ill December 7 , with fever $\left(102^{\circ}\right)$, slight retraction of head, some pain in the back and legs.

December 10, paralysis of both legs and the right arm.

Sister of case 26.

Ten other children, older, in the family at home. Some attend the parochial school and some work, but there is no known contact, either direct or indirect, between these cases and others. This is probably a contact infection from the first case in the family.

\section{Case 28.}

E. H., five years, Brier, Savoy. Dr. W. W. Pascoe, Savoy. Taken ill August 1, and on August 3 had fever, vomiting, slight sore throat, pain and tenderness in the leg. No marked paralysis, but rather weakness in legs.

A brother, fourteen years, had a similar attack at five years of age. Now has marked atrophy of left leg. No known contact with other cases previously (see case 23).

\section{Case 29.}

M. J., three years, Plainfield. Dr. W. W. Pascoe, Savoy. Entirely well, living remote from neighbors, was taken ill on September 22, with fever, delirium and pain in the back. Also had nosebleed, vomiting and diarrhœea. On day of onset had made a trip to Adams with her mother, but so far as known came in no contact with any Adams case. On September 26, paralysis of both legs and some difficulty in voiding urine.

The following case is the child's father.

\section{Case 30.}

H. J., thirty-three years, Plainfield. Dr. W. W. Pascoe, Savoy. This patient, father of the preceding, was ailing at the time his daughter was taken ill, or even a day or two before, but he did not give up till September 29, when he had fever, nosebleed, pain in the neck and delirium. There was retention of urine, paralysis of both legs and both arms, and partial paralysis of right side of the face. There was also disturbance of the 
respiratory muscles. At the present time he is in a Springfield hospital, and is only now (December 24) beginning to move his toes.

Some time previous to the illness he drove several horses over the road to Springfield, being absent three or four days. So far as known he came in contact with no other cases. On August 16, the patient's father, who lived with him, died of heart disease. The funeral, a day or two later, was conducted by a minister from Cummington, whose child was ill at the time with infantile paralysis. Here is a possibility of infection through a third party, though the interval between exposure and onset is considerable.

Beside the daughter above mentioned, there are 2 other children in the family, one younger, one older.

\section{Sommary, Pittsfield and Vicinity.}

In point of time the Pittsfield cases were much more closely grouped together than in the other communities, with the exception of Great Barrington.

Between July 14, previous to which date there was 1 case (case 31, June 22), and September 9, 14 cases occurred, 10 of which were in August. In October there were 3 cases (case 46 on October 8 , case 47 on the 2\%th, and case 48 in Richmond on the 28th).

Paralysis, in every case involving the legs, was present.

There was but 1 case in a household. There were no suggestive abortive cases.

It is worth noting that here again the large majority of the cases are located near or comparatively near the Housatonic River.

While in one locality 6 cases occurred moderately near each other, on June 22, July 19, August 7, 14, 15 and 20 (cases 31, 34, 36, 37, 38 and 40 , respectively), the fact that all of the patients were but three years old or less makes the likelihood of contact between them exceedingly slight. The history of these cases also discloses no evidence of contact.

Another group of cases, in the southern and western part of the city, on July 14, 17, August 15, 21 and 22 (cases 32, 33, 35, 39, 41 and 42, respectively), show equally slight probability of contact, except that case 35 , in an Italian family, and case 39 , in a Jewish family, opposite each other on the same street, may have been in indirect contact through other children in the family.

Otherwise there are no known points of contact between the different cases.

In all but three instances there are other children in the family of the patient.

That the schools had no part in occasioning the spread of the disease in Pittsfield appears from the fact that but 3 of the cases occurred after the opening of the schools, on September $\%$. 
In but a single instance did a patient attend school (case 45, September 9).

Nor in any instance save one were children from the households of patients attending the same schools. In this instance (case 45, just mentioned, and case 46 , October 8 ) the children were in different rooms, while the interval of nearly a month since any possible indirect contact speaks strongly against infection from this source.

The 18 cases were attended by 10 physicians. One physician attended 5 cases at an out-patient department. Another physician attended 3 cases, and 2 others 2 each.

There were no cases in physicians' families, though in three of the families there are children.

In no instance is there record of the physician having recently visited the family of the patient previously to being called to attend the patient himself.

Five of the cases (case 32 July 14, case 33 July 17, case 41 August 21, case 45 October 9 , case 47 October $2 \%$ ) are either on the line of the electric cars, or very near on side streets leading from the car line. None of the cases, with the exception of those just mentioned and one or two others, are on streets frequented by automobile tourists.

Five or 6 of the cases are near the railroad, 1 of them near the station.

\section{Case 31.}

T. P., two and one-half years, 86 Danforth Street, Pittsfield. Dr. F. S. Coolidge, Pittsfield. Taken ill about June 22. Fever very slight, if any. There first appeared a weakness of the right leg, which gradually increased, till at the end of a fortnight there was complete paralysis of the right leg. This persisted for two weeks, and then gradually disappeared, full recovery being noted early in August.

One younger child. No school. No acquaintance with other cases. Father employed at Elmhurst Farm.

This was the first Pittsfield case.

\section{Case 32.}

L. L. S., twenty-two months, 59 Harris Street, Pittsfield. Dr. J. D. Howe, Pittsfield. Some time in June visited in Adams, on Elm Street, in the same neighborhood where later were cases in Adams. While there played in hot sun. June 12 had a burn of the right leg. Recovery. Taken ill with general gastro-intestinal symptoms on July 14. Fever was observed on July 19. Pain and tenderness were general over the whole body. There was suppression of urine on July 24, and two days later, on July 26, there was paralysis of both legs.

Second case in Pittsfield, in a totally different part of the city from the preceding.

Other children in the family. No school at this time. 
Case 33.

J. E. B., seventeen months, 219 New Test Street, Pittsfield. Dr. Mercer, Pittsfield. Was ailing somewhat for one or two days previous to the onset of the fever, on July 17 or 18 . The doctor was called, and for a day the patient seemed better. Then the fever returned. There was retraction of the head, considerable pain and tenderness in the back. Also some general twitehing on the first day. On July 21 there was paralysis of both legs. No bowel disturbance, no vomiting.

Three other children in the family. No school at this season.

\section{Case 34 .}

E. G., two and one-half years, 130 Madison Avenue, Pittsfield. Dr. J. A. Langlois, later Dr. G. E. Reynolds, Pittsfield. Taken ill between July 19 and 26, feeling dull and weak in the legs. At the same time paralysis of left leg appeared.

Seven other children in family; oldest is 19 years, employed at Eaton, Crane \& Pike's; others work in Musgrove Knitting Company and Stanley shops. There are 5 children in the opposite side of the house, with whom these children were in more or less contact. No school at this season. No apparent contact with other cases.

\section{Case 35.}

K. T., two years, 34 Jordan Avenue, Pittsfield. Dr. W. A. Millett, Pittsfield. Taken ill in August, with fever, stiffness of the neck and some pain in neck and legs, which continued for a week. Three days after the onset paralysis of both legs occurred, of such degree that the patient could not walk for four weeks. For two days he was unable to void.

Two other children in the family. No school. Case 39, taken ill August 15, lives on the opposite side of the street. There are children in this family as well, and notwithstanding the difference in nationality (Jews and Italians), it is conceivable that the other members of the families were in contact.

\section{Case 36 .}

R. H., three years, 94 Turner Avenue, Pittsfield. Dr. G. E. Reynolds, Pittsfield. Taken ill August 7, with fever, pain in back and neck. Constipated. On August 10, paralysis of left leg, the right leg also becoming paralyzed afterwards.

One younger child in family. No school. No contact known with other cases. They are acquainted with the family of case 31 (taken ill June 22). No history of visits. 
Case 37.

R. F. S., two years, 108 Linden Street, Pittsfield. Dr. Mercer, Pittsfield. Taken ill on August 14, with fever, some pain in back and neck. On August 15, paralysis of both legs. Constipated. Retraction of head for five days.

One other child in family. The patient had been to moving pictures with his mother several times. No school. Case 34 (taken ill July 19) is near by, but there is no history of contact between them.

\section{Case 38.}

D. K., twenty-two months, 52 North John Street, Pittsfield. Dr. F. S. Coolidge, Pittsfield. Taken ill about August 15, with fever, pain in neck and vomiting. On the following day there was paralysis of both legs, the left leg worse. Constipation.

Three other children in family, 2 older, 1 younger. No school. The parents are acquainted with the families of cases 39,40 and 43 , taken ill August 15, 20 and 25, respectively, two of them Jews. But with one family (case 39) there is no social or other relations, and with the others there was no contact until they were brought together after the occurrence of the disease. Father deals in junk.

\section{Case 39.}

D. H., eleven months, 37 Jordan Avenue, Pittsfield. Drs. England, Langlois, Coolidge, Pittsfield. Taken ill about August 15, with fever, drowsiness and soreness in the back. Three days later there was paralysis in both legs, the left leg worse.

Seven other children in the family. No school. Father is a junk collector. They know of no other cases except the Italian child on the opposite side of the street (case 35).

\section{Case 40.}

B. K., twenty months, 273 Dewey Avenue, Pittsfield. Dr. F. S. Coolidge, Pittsfield. The parents were informed that a few days before the onset of the illness the baby had been thrown from the baby carriage. The baby showed no evidence of it. Without preliminary symptoms the child's leg (left) was found to be paralyzed about August 15.

No known contact with other cases till some time later. There are other children in the family.

\section{Case 41.}

E. F., two years, 18 East Mill Street, Pittsfield. Dr. G. P. Hunt, Pittsfield. For two weeks, while company was in the house, the child had been out in the sun a good deal, and when she became feverish, on August 28, mother thought it mignt be due to exposure and fatigue. On September 2 appeared paralysis of the lower part of the left leg and the left arm.

An only child. No known contact with other cases. This house is situated close to a millpond, and on the opposite side of the pond, a short distance away, is case 32 , taken ill in June. 
Case 42.

A. R., three years, 194 Wendell Avenue, Pittsfield. Dr. J. B. Thomes, Pittsfield. On August 22, languid with fever $\left(103^{\circ}\right)$. On August 25, possible slight paralysis of right leg, but well-marked paralysis of left leg. Involuntary urination on the night of August 25.

One younger child in family. No school. No contact. An unusually well-appointed home, of the best class.

\section{Case 43.}

I. Y., two and one-half years, 130 Lincoln Street, Pittsfield. Dr. J. A. Langlois, Pittsfield. On August 22, a slight fall, nothing to it. Fever on August 25, accompanied with retraction of the head, stiffness of neck and pain in left hip and leg, continuing till September 1, when paralysis appeared in the right leg. For a week following the appearance of the paralysis could not retain the contents of the bowel or bladder.

Five other children in the family. No school at this time. The family moved here one week before the illness began, coming here from a concrete house on South Onota Street, near the Housatonic River, not far from Jordan Avenue (cases 35 and 39).

\section{Case 44.}

D. M., nineteen months, 6 Atlantic Avenue, Pittsfield. Dr. F. S. Coolidge, Pittsfield. August 29 had romiting and ferer, also pain in left leg. On September 1, paralysis of left leg.

No known contact with other cases. Family not acquainted with other Italian case (case 35), which is in another part of the city entirely. Two older children. No school at this time; Linden Street since. Many Italian laborers board here.

\section{Case 45.}

E. C., nine years, 13 Mellrille Street, Pittsfield. Dr. G. E. Reynolds, Pittsfield. From July 29 to August 25 was with his mother in Bennington, Vt., staying in a pleasant house in the high part of the town. Returned to Pittsfield on August 25, on an electric car, and may have been chilled. Stayed a few days after his return on Curtis Terrace, Morningside, before the house here was settled. Had headache for two or three days before the onset of fever, on September 9. Tomiting for two days and delirium. Constipated. On September 10, paralysis of both legs and both arms. Still unable to use legs; arms much improved (December 2). About the middle of November had serere choking attack, of half hour's duration.

Attended Orchard Street School, grade 5. 
Case 46.

C. W. N., thirty-five years, 85 Maplewood Avenue, Pittsfield. Dr. A. C. England, Pittsfield. Was in Albany on October S, marching with the militia at the Hudson-Fulton celebration. That evening he stumbled on the street, but did not fall. There was immediately a severe pain in the left leg and shin, so that he had difficulty in returning to Pittsfield. Fever and pain continued in the leg for one week. Redness appeared over the tibia, suggesting periostitis. A low leucocyte count prevented operative treatment. With the development of paralysis in the left leg on October 15, the acute symptoms abated.

The man is a plumbing contractor, with business largely in the shop and office. There is history of contact with an old case of two or more years' standing.

\section{Case 47.}

H. C., nineteen years, 350 Wahconah Street, Pittsfield. Dr. J. A. Langlois, Pittsfield. Suddenly, on arising on morning of October 27, found he could not use the left leg as usual. Fell two or three times attempting to get about the house. Unable to raise toes. Returned to work in draughting department at Stanley shops after two days. Walked by raising the left foot high enough so as not to strike the toes.

Two other ehildren in the family, 1 in business college, 1 in first year at high school. A case of two years' standing or more in a neighboring French family.

\section{Case 48.}

W. H. W., nineteen years, Richmond. Dr. W. W. Leavitt, Pittsfield. Had been working for two months on a farm in West Stockbridge at the time illness began. He had been ploughing for three days, when on October 28 he had backache, gradually increasing in severity during the day. $\mathrm{He}$ also had moderate fever, headache and some stiffness in the neck. On the following day there was paralysis of both legs, and inability to void urine. He was also unable to retain an enema. On this day he was removed to his own home in Richmond. He was stung once or twice by yellow jackets before he was taken ill.

An intimate chum of his had an attack of this same trouble two years ago. They were last together on October 18.

\section{Summary, Lee, Lenox and Stockbridge.}

There were 2 cases in Lee, 1 on October 3 (49), in South Lee, a fatal case, and the other in Lee a month later, on November 4 (50). The history of these cases does not disclose any possible contact with other cases.

There were 6 cases in Lenox. Isolated cases occurred April 12 (case 
51 ) and June 23 (case 52 ), at a time when hardly another case was known in the county.

On September 22 occurred another case (53). This child, at school during June, played with case 51, ill in April, and just recently, since the opening of the schools, walking to school, had been in contact more or less with a sister of case 52 (ill in June).

Case 55, October 1 , is apparently an isolated case, that of a two-yearold infant, living in the country, at New Lenox. During August the infant was with its mother in Pittsfield for one day. There was no known contact with other cases. This case is close to the electric railway, also near the railroad.

The 2 remaining cases, 56, October 1\%, and 5\%, November 15, are situated near the electric and steam car lines, near the Valley Paper Mill, at Lenox station and Lenoxdale, respectively.

The mother of the latter patient visited the preceding case, held the baby who was ill and kissed it, about a month before her own child developed the disease. The mother's sister, aunt of the latter case (57) acted as nurse for the preceding case (56), and during the time that she was so engaged she visited in the home of this patient at least once after the visit of the mother, abore mentioned. This would seem to account for the infection of the second case.

Case 58 and case 59, brother and sister, in Stockbridge, were taken ili on the same day, October 10.

Two days previously the sister went with her parents to Albany and return, by automobile. On October 9 there was some malaise, and on the 10th she was taken ill, almost at the same hour as her younger brother.

She speedily recovered after five days in bed, and may possibly be regarded as an abortive case.

Aside from possible contact with a case in Stockbridge of two or three years' standing, there was no known contact, direct or indirect, with other cases.

\section{Case 49.}

I. V., nine years, South Lee. Dr. Markham, Lee. Ill October 3, with fever and pain in the back. Later there was pain in the neck, arms and legs. On the third and fourth day there was vomiting. Bowels constipated. On October 8 the paralysis appeared in the right leg, then in the left leg; and on the following day in the left arm, then in the right arm. Later in the day the patient died, with paralysis of respiration, the throat muscles being involved also.

There are 3 other children in the family. After the first three or four days they were kept apart from the patient. The children attended school in South Lee. This was the only ease in South Lee. 
Case 50.

J. B., eight years, 34 Prospect Street, Lee. Dr. J. J. Hassett, Lee. On Norember 4 had fever, headache and vomiting, also some diarrhœa. On Norember 6 occurred paralysis of the right arm and forearm. Pain and tenderness in the arm became very severe on November 8 .

Patient attended the parochial school. Five other children in the family. This was the second of the 2 cases in Lee, and was in no way connected with the former. No known contact, direct or indirect, in either of the cases.

\section{Case 51.}

P. J., five years, Fairview, Lenox. Dr. Hale, Lenox. This is apparently an isolated case, occurring in the central portion of the town early in April. There may have been some exposure to cold a few nights before while watching a large fire. About April 12, fever began. About April 26, when paralysis of both legs occurred, the flesh was sore to the touch, the bones ached, the boy was listless and wanted to be held. Diarrhœa was present early.

A sister, eleven years, in the family. No known contact with other cases.

\section{Case 52.}

W. K., three years, Depot Street, Lenox. Dr. F. A. Roberts, Pittsfield. This, the second case in Lenox, also appears to be an isolated case. On May 29 mother thought the child was about to have a convulsion. On following day mouth and throat were sore. On June 2, the glands in the neck were swollen and so continued for two days. The first symptom of paralysis noted was on June 23, when the child began talking through the nose. Dr. Hale was called and thought of adenoids. On June 25 or 26, paralysis appeared in both arms and both legs. He was also unable to hold his head up.

Three other children in the family. No school at this season.

\section{Case 53.}

E. M., twelve years, Cliffwood Street, Lenox. Dr. A. C. England, Pittsi eld. On September 22, had fever and some pain and tenderness in the right leg, which became paralyzed on the evening of the same day.

Patient attended the Center School, and played with ease 51 (April) in June, and just recently walked to school with a sister of the preceding case (52, June 29). No other contact known.

\section{Case 54.}

E. H., Dr. J. J. Hassett, Lee. This case omitted from the summary, because it is now said to be a case of hip disease (Feb. 10, 1910). 
Case 55.

E. P., two years, New Lenox. Dr. I. S. F. Dodd, Pittsfield. An isolated case in the country, near an electric car line. In August the child was one day in Pittsfield with its mother. October 1, some pain in the head, face, and on October 2, paralysis of both legs, slight in the left. Constipated.

Two other children in the family; 1 in school.

\section{Case 56.}

J. T. C., eighteen months, Valley Mill, near Lenox station. Dr. J. J. Hassett, Lee. An isolated case near the electric and steam railways. Fever appeared on October 17 . On following day was paralyzed in both legs. There was constipation, and some pain in the left leg, which was the worse.

An only child. No other case near except the following (case 57). bis

\section{Case $5 \%$.}

G. L., two years, Lenoxdale. Dr. J. J. Hassett, Lee. Fever up to $102.5^{\circ}$ on November 16. On following day pain in the back and paralysis in both legs. Constipation. Mild case.

An only child. On line of electric and steam cars. The child's mother visited the preceding case (56) at Lenox station, held and kissed the baby, who was then ill, about a month before her own baby dereloped the disease. This baby's aunt, who assisted in caring for the C. baby (case 56), was also here at least once during her stay at the child's home. This is the only known contact with other cases.

\section{Case 58.}

L. B., two and a half years, Stockbridge. Dr. J. R. Hobbie, North Adams. Taken ill on October 10, with fever and considerable pain, apparently due to retention of urine, which continued for forty-eight hours. There was some retraction of the head. Constipation. On October 12 there was paralysis of the right leg.

A brother of case 59 .

\section{Case 59.}

A girl, B., eight years, Stockbridge. Dr. J. R. Hobbie, North Adams. On October 8 went with her parents in an automobile to Albany to see the Hudson-Fulton celebration. They returned the same day. On the following day she did not feel well. On the 10th of October, almost at the same hour as her brother, she had fever, and felt as if she could not move. Her head was retracted somewhat. She wias in bed for five days, for two days was unable to move her legs. She recorered speedily.

There is in the same town a case of two or three years' standing, with which there may have been some contact. 


\section{Summary, Great Barrington and Vicinity.}

In this group were 23 cases.

The first cases occurred in the country, near each other, on August 11 (case 80) and August 20 (case 81) in Sheffield and Egremont, respectively.

The 19 cases in Great Barrington occurred during September and the first week in October.

Two cases in Austerlitz, N. Y., included in this group, occurred on September 28.

In 18 cases there was paralysis.

Of the 5 cases which did not have paralysis, 3 were abortive $(62,69$, $79)$, and 2 had paresis of both legs $(70,71)$.

Nearly all of the cases in Great Barrington (16 out of 19) are located immediately upon or quite near the Housatonic River, 4 being on the west and 15 on the east side of the river.

The 4 cases on the west side of the river, $64,68,69$ and 71 , on September 19, 22, 24 and 25 , respectively, are well scattered.

These cases seem to have had no association with each other in any known manner, unless the possible indirect contact between case 68 (September 22), who was a first-year student in the high school, and case 69 (September 24), whose brother was in the eighth grade in the same building, be considered. Case 64 (September 19) was an only child, who had not been in school during the current school year.

This last case, and case 71 (September 25), had possible contact with cases on the opposite side of the river, as will appear later.

On the east side of the river were 15 cases, 10 of which were located on East Street and Avery Lane, practically a continuation of East Street. The 5 remaining cases were on cross streets near East Street.

From three households where were cases $(61,70,72)$; no members attended school.

Cases 61 (September 8) and 72 (September 25) lived in adjoining houses some 200 feet apart, at the south end of East Street. There was more or less indirect contact between these 2 cases, because the second case visited the neighbor's child after it was ill, but she did not go into the house, though her sister did go into the house and assisted at times in caring for the first patient.

The source of infection for case 61 is not evident, though for one or two unlikely possibilities reference is made to the special notes on the case.

Case 70 (September 14) was an only child of three and one-half years, daughter of the man for whom case 72 worked as bookkeeper. It was 
said that the latter had visited and held this child after it was ill, but this statement could not be verified. This child played much with a neighbor's children, one of whom attended the Bryant School, grade 2. There were no cases in this school.

Case 67 (September 22) was employed in a cotton mill, where were no other cases. A sister attended the eighth grade at the high school building, where the brother of case 69 also attended, with case 68 in the first year of the high school. There is no history, however, of any acquaintance or association other than the most casual between the one patient and the members of the other two households.

The group of cases ( 5 ) in Avery Lane, at the northerly part of the district, might readily be considered as contact cases, from association with each other, due to proximity, but further study of the matter makes it probable that they belong to a larger group, associated somewhat loosely with the Justin Dewey School.

To this group belong the 11 remaining cases on the east side of the river and cases 64 and 71 on the west side of the river. The details are as follows:-

The schools opened on September 7, and sessions continued through Friday, September 24, when a recess was taken for a week, on account of the Great Barrington fair. School work was resumed on Monday, October 4.

Whenever school is mentioned below, it refers to the Justin Dewey School.

Case 60 (September 3) did not attend school, but a brother regularly attended the fifth grade, while a brother and sister attended the fourth grade regularly.

Case 62, an abortive case, taken ill on September 16, attended school, grade 2, on September 7 and 8. She was then out till October 18. A sister attended the eighth grade regularly.

Case 63, a brother of the foregoing, became ill on September 23. These two children slept in the same bed with the mother, and the brother, who was four years of age, probably received his infection from the sister.

Case 63A (September 16) did not attend school, but two sisters did, one in the third grade and one in the second grade, and they were regularly present from the opening of the session on September \%. There was also contact with case 60 , because the families lired in closely adjoining houses, and the children played together considerably.

The teacher in grade 3 is an aunt of case 64, September 19, and is accustomed to seeing her niece (case 64) frequently.

Case 65 (September 20) attended grade 3 till September 22.

Case 66 (September 20), an infant, had a brother who attended grade 3 regularly. 



\section{DEWEY SCHOOL CASES, 1909.}

Red lines, patient attended school.

Black lines, others in family attended school.

Date. Case

Adjoining $\{$ Sept. $3 \quad 60$

houses, close con- $\{$ Sept. 16 63A
tact.

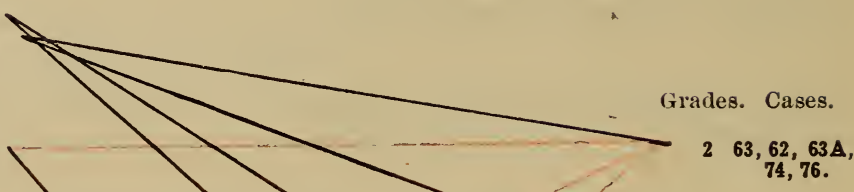

Same
family. $\begin{cases}\text { Sept. } 16 & 62 \\ \text { Sept. } 23 & 63\end{cases}$

Sept. 1964

Sept. 2065

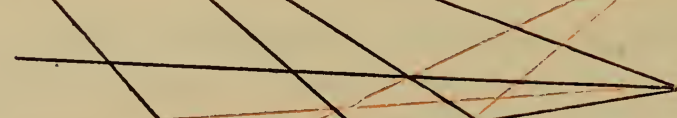

$363 A, 64,65$,

Sept. 2066

Sept. 2571

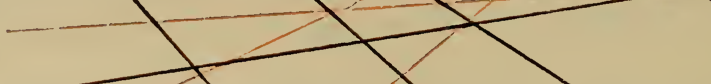

Same (Oct. 275 family. Oct. 676

Oct. 777

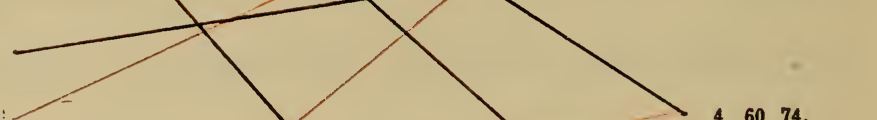

Sept. 2573

Sept. 25

74

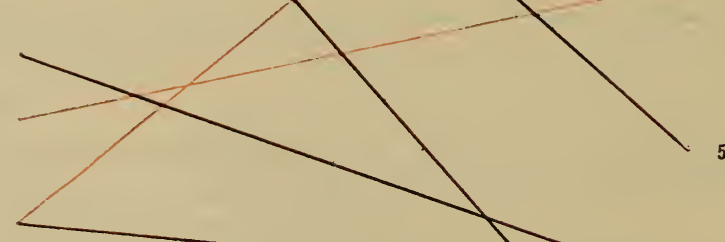

550.

862. 
Case 71 (September 25) attended grade 2 till September 24.

A boy in the family of case 73 (September 25) regularly attended grade 6 .

Case 74 (September 25) attended grade 4 regularly till September 24. He returned to school October 19. A brother of this patient attended grade 2 regularly.

Case 75 (October 2) had a brother, case 76 (October 6), who was in school October 4 and 5 after the recess for the fair. Another child, of whom there are 12 in this family, attended the sixth grade regularly.

A sister of case 77 (October 7 ) attended grade 6 regularly.

Thus between September 16 and October 7, 13 cases are associated directly or indirectly with the Justin Dewey School.

The diagram illustrates the distribution of the cases.

The 23 cases were cared for by four physicians. One physician had 10 cases, one 8 , one 3 and one 2 cases.

Three of the physicians have families and children. There were no cases in physicians' families.

The physician who had 10 cases, after being called to his first patient, visited two families where infantile paralysis occurred subsequently. These calls were on chronic cases of other illness, and he did not come in close contact, if, indeed, he even saw those who had anterior poliomyelitis later. Further, in each of these two instances there were other possibilities of direct contact with other cases of the disease.

Another physician, who between September 19 and 29 saw 8 cases, had not been in any of the homes in question for a considerable period until called for the present illness.

Only 3 of the cases are on the line of the electric railway or the route taken by automobiles in passing through the town, though 5 other cases are quite near.

Only 1 case is close to the line of the railroad.

\section{Case 60.}

E. C., six years, East Street, corner Cottage Street, Great Barrington. Dr. M. T. Cavanaugh, Main Street, Great Barrington. On September 2 was observed to limp slightly when walking. On the following day had fever $\left(100^{\circ}\right.$ to $\left.102^{\circ}\right)$, vomiting, and pain in leg and knee. On September 6 there was paralysis of the left leg.

There are 5 other children in the family. This child attends the Dewey School, grade 2, though he did not enter this year until October 18. Two or three of the other children attend the same school, up to the fifth or sixth grade. J. in the fifth. Father is a lineman for the Great Barrington Electric Light Company. 


\section{Case 61.}

M. F., two years, 215 East Street, Great Barrington. Dr. M. T. Caranaugh, Main Street, Great Barrington. Fever $\left(102^{\circ}\right)$ began on September 8, accompanied by some delirium; would not stay in bed; once fell to floor. A week later, on September 15, there was paralysis of both legs, left arm and left face. There was some retention of urine for nearly twenty-four hours. No evidence of paralysis now present (November 3). One other child, of four years of age, occupied the same bed with the patient throughout the whole illness, and still continues to do so.

The F. case (72, September 25) lives a short distance away in the adjoining house.

The Sheffield case (80, August 11) is a cousin of this boy's mother, but there had been no communication between the families for a long period prior to this child's illness.

A cousin's child on the father's side had an attack of this same disease in Sharon, Conn., early in the spring. Between these families there is a regular exchange of letters, with which this baby may hare played.

\section{Case 62.}

E. O., seven years, 72 State Road, Great Barrington. Dr. M. T. Caranaugh, Main Street, Great Barrington. Taken ill on September 16, with ferer, headache, pain in back of neck, lower part of back and leg ache. Slight sore throat. Pain in legs and ankles continued for two or three days. Tell since.

Attended Dewey School, grade 2. Entered on September 7. Beginning September 9 was out continuously to October 4, when she returned to school. Sister of case 63.

\section{Case 63.}

J. O., four years, 72 State Road, Great Barrington. Dr. M. T. Caranaugh. Main Street, Great Barrington. Taken ill with ferer $\left(104^{\circ}\right)$, romiting and pain between the shoulders on September 23. Constipated. On September 26 or 27 , paralysis of both legs.

This child and sister, above mentioned, slept in the same bed with the mother.

There are 2 older girls in the family who are not in school.

\section{Case $63 \mathrm{~A}$.}

D. G., four years, 6 Cottage Street Extension, Great Barrington. Dr. M. T. Cavanaugh, Main Street, Great Barrington. For two or three weeks before onset of illness, on September 16, complained of feeling tired, especially in the legs, on walking. On or about September 16 had high ferer, was dull and quiet, and wished to be let alone. There was pain under the left knee. About September 26 there was paralysis of the extensor muscles of the left 
leg; patient could not straighten out the left leg. Later she was unable to stand on that leg for several weeks. Now (April 5, 1910) quite well, except that she has less endurance than before.

Case 64.

H. M., six years, 34 Castle Hill, Great Barrington. Dr. Bebee, Main Street, Great Barrington. One week before illness was operated on for adenoids and tonsils at home, by Dr. Blanchard of Pittsfield. Two days before had a slight fall, no ill effects so far as known. Taken ill with fever and vomiting; was dull and sleepy on September 19, and on the following day there was paralysis of the left leg, of mild degree.

No other children in the family; not in school this year.

An aunt, teacher in Justin Dewey School, grade 3, is a frequent visitor.

Compare with case 78 , last paragraph.

\section{Case 65.}

G. J. F., seven years, 41 Russell Street, Great Barrington. Dr. M. T. Cavanaugh, Main Street, Great Barrington. No previous illness, except that two weeks before did considerable running and racing at school. On September 20, headache, also fever, which continued to September 26. From the 21 st to the 24th he was delirious. On September 22, vomiting and paralysis of both legs. Diarrhœa was present one day. Apparently recovered by October 11.

No other children. Attended Dewey School, grade 3. Was out of school from September 22 to October 17, inclusive.

\section{Case 66.}

M. E. WV., fourteen months, 63 East Street, Great Barrington. Dr. Bebee, Main Street, Great Barrington. Became ill with fever on September 20. Vomiting followed dose of castor oil. September 24 discovered that there was paralysis of both legs, the right more severely.

An only child. No known contact with other cases.

\section{Case 67.}

H. D., sixteen years, 49 Cottage Street, Great Barrington. Dr. Bebee, Main Street, Great Barrington. On September 22, medium headache, loss of appetite, malaise and slight fever. Considerable pain in lumbar region and in legs. On September 25, 26 and 27, vomiting. On September 26, paralysis of right leg, and paralysis of left leg on September 28.

Two other children in the family; none in school. This girl worked in the finishing room at the Edgemere Manufacturing Company (spreads).

\section{Case 68.}

D. B. R., fourteen years, 12 Barrington Place, Great Barrington. Dr. C. H. Chapin, Main Street, Great Barrington. On September 22, vomiting, 
which continued all of the following day, when fever appeared $\left(102^{\circ}\right.$ to $\left.103^{\circ}\right)$. On the evening of September 24 appeared paralysis of both sides of the face. On the 25th there was delirium, later dullness, gradually increasing till patient became comatose, death taking place on September 27. On September 25 there was paralysis of the labio-glosso-pharyngeal muscles, so that the jaw dropped and he could not put it forward. During the last twenty-four hours there was incontinence of urine and feces.

He was a first-year student in the high school, at Searles Building. Other children in family; none in school.

\section{Case 69.}

J. R., five years, 31 Dresser Avenue, Great Barrington. Dr. Bebee, Main Street, Great Barrington. On September 24, considerable fever. On 25th, headache, and on 26th gradually became completely unconscious, which condition lasted till the following day, nearly twenty-four hours in all. Rapid recovery followed.

A brother attends the eighth grade at high school, Searles Building. Two other boys in the family.

Compare eases 78 and 79 .

Case 70.

A. H., three and a half years, 135 East Street, Great Barrington. Dr. Bebee, Main Street, Great Barrington. This child, with its mother, was in Pittsfield on July 4. About September 14, without initial fever, there was noticeable lameness of the left leg, followed by a similar lameness in the right leg. On September 18 there was tenderness about the neck and arms, later in the legs. On September 20 vomiting began, which continued through the following day.

An only child. Played intimately with children on opposite side of the house, kissing the baby frequently. Case 72 (Sept. 25) was employed as bookkeeper by this child's father. No source of infection known.

\section{Case 71.}

G. B., seven years, 87 Railroad Avenue, Great Barrington. Dr. Bebee, Main Street, Great Barrington. Some fever and vomiting on September 25. Better the following day and went to church. On the 28th he went to the eattle show. On September 29, again had slight fever, headache and stomach ache. On September 30, paresis of right leg.

Only child in family. Attended Dewey School, grade 2, till September 24, then out till October 26. At Dewey School in possible contact with eases 60 and 76.

\section{Case 72.}

K. F., twenty-five years, 225 East Street, Great Barrington. Dr. M. T. Cavanaugh, Main Street, Great Barrington. On evening of September 25, vomiting. On 26 th and 27 th very nervous. On 28 th seen by physician. 
She had little or no fever. She was not seen on the 29th. On the 30th he found her sitting up, but in appearance sererely ill, with an acute infection; the mouth was dry, there was sordes on the teeth. No fever. She could move the right leg with great difficulty only. Later, the right arm and the right leg were paralyzed. On October 1, delirium appeared and continued for three days. On October 4 was unable to articulate distinctly, but the condition improved on the 5th and 6th. At that time (October 6) there was slight difficulty in swallowing, and on the night of the 6th of October patient died, with evidences of respiratory paralysis.

Was said to have seen her employer's child (case 70, September 14) a few days before her own illness. This however, is said not to be so by the latter's family. She went also to the house of case 61, living in the next house, some distance away, but did not go in. Her sisters, however, did go in, and one of them helped care for the child and kissed him. The patient, however, had a room to herself.

\section{Case 73.}

H. C., fourteen months, 32 Avery Lane, Great Barrington. Dr. M. T. Cavanaugh, Main Street, Great Barrington. A mild case, taken ill on September 25 or 26, with drowsiness and fever, pain in the legs. Previous to this time the baby crept and would take a few steps. With the onset as above described was unable to do either. On October 10, began again to creep slightly.

Other children in family. One boy is in Dewey School, grade 6. Cases 74 to 77 , inclusive, in the immediate neighborhood.

\section{Case 74.}

H. H., ten and one-half years, 16 Avery Lane, Great Barrington. Dr. C. S. Chapin, Main Street, Great Barrington. Early in September had a slight headache and some fever for two days. On September 28, fever, with some delirium for the first night, headache, nausea and some soreness in lower part of back and right leg. On October 5, paralysis of right leg. Slight disturbance of left leg for one day.

Attends the Dewey School, grade 4. Was out from September 24 to October 19, inclusive. A brother attends same school, grade 2, and had no absences. Cases 73 and 75 to 77 , inclusive, in the immediate neighborhood.

\section{Case 75.}

E. C. twenty months, 29 Avery Lane, Great Barrington. Dr. M. T. Cavanaugh, Main Street, Great Barrington. On October 2 walked poorly. On October 4, fever, pain in lower back and right leg and vomiting. On October 5, paralysis of right leg. Brother of the following case. 
Case 76.

J. C., seven years, 29 Avery Lane, Great Barrington. Dr. M. T. Cavanaugh, Main Street, Great Barrington. On October 6, severe headache, vomiting and delirium at night. Fever, $103^{\circ}$. Some pain about the face and in the legs. On October 8, paralysis of right side of face.

Brother of the foregoing case.

Attended school at Dewey School, grade 2. Another brother attended same school, grade 6. This brother was regularly in school. The patient attended from the beginning of the term till the vacation for the fair, on September 24, with the exception of September 22. He was in school October 4 and 5, leaving on October 6. There are 11 other children in the family, 12 in all. In close contact with other Avery Lane cases.

\section{Case 77.}

M. O., two and a half years, 26 Avery Lane, Great Barrington. Dr. C. S. Chapin, Main Street, Great Barrington. Fever, some headache, delirium, beginning on October 7. Moderate retraction of head, and pain in right leg. Vomiting. On October 11, paralysis of right leg.

Sister attends Dewrey School, grade 6. In contact,with cases 73 to 76 , inclusive, in same vicinity.

\section{Case 78.}

J. M., seven years, Austerlitz, N. Y. Dr. Bebee, Main Street, Great Barrington. This case and following are here included because they were seen by Dr. Bebee, and because of the resemblance of this case, in some particulars, to case 69. On September 28 returned from school, feeling miserable. On 29th was drowsy, and on the 30th still more so, becoming unconscious on the following day; and on this same day he became paralyzed in both arms and both legs. The unconsciousness continued almost without interruption till October 5 .

$\mathrm{He}$ is a nephew of the domestic employed at the home of case 64 (Sept. 19) in Great Barrington, but there was no visiting between the two places for a considerable time prior to the time case 64 became ill. Letters were received from the domestic telling of the case in her employer's family. Neither did the aunt visit Austerlitz till considerably later.

There was a second case, an abortive one, in the family, as follows:-

\section{Case 79.}

D. M., five years, Austerlitz, N. Y. Dr. Bebee, Main Street, Great Barrington. Brother of the foregoing. September 29, 30, and October 1, acted queerly, complained of being dizzy and unable to walk. Three days later was auite well again, and had no further trouble.

In the western part of the town, without any known connection between them, through schools or otherwise, there were said to be 3 other cases, 2 of them in one family. This is a country town, with hardly a village or hamlet, the houses being considerably seattered. 
Case 80.

G. D., twenty years, Sheffield, near Egremont line. Dr. A. T'. Wakefield, Sheffield. About August 11, taken ill with fever, $100.5^{\circ}$ to $102^{\circ}$, headache. Moderate retraction of head, pain and tenderness over lower dorsal and lumbar regions. On August 14, paralysis of both legs, and paresis of right arm.

No known contact with other cases. May have been in Great Barrington for a day previous to being ill, but at that time no cases in the town (Great Barrington). Lives on a farm, well isolated from any other case. Previous to his illness was an intimate associate with the following case.

\section{Case 81.}

F. L., twenty-one years, Egremont, near Sheffield line. Dr. A. T. Wakefield. Sheffield. Was an intimate friend of the preceding case $(80)$, though the date of the last contact between the two cannot now be established. On August 20, sudden headache, repeated vomiting, and fever, never over $101^{\circ}$. There was retraction of head, and considerable pain in back and legs. On August 21, paralysis of both legs, together with some disturbance of the arms and back. Retention of urine after first twenty-four hours. The paralysis increased, and on the morning of August 23 he died from paralysis of respiration.

\section{METHODS OF TREATMENT IN INFANTILE PARALYSIS. ${ }^{1}$}

E. H. Bradford, M.D.; R. W. Lovet, M.D.; E. G. Brackett, M.D.; Augustus Thorn. DIKE, M.D.; ROBERT SOUTTER, M.D.; ROBERT B. OSGOOD, M.D.

[Summarized by the Department of Orthopedic Surgery of the Harvard Medical School.]

The purpose of this paper is to furnish to the practitioner, as far as is possible, a summarized guide in the treatment of poliomyelitis in its various stages of development.

Especial attention has been recently called to the importance of this disease, but as the symptoms vary considerably in the course of the affection it is difficult to refer to a succinct statement, giving in brief the treatment needed in the different stages, which at present are under investigation by several special departments of medical study.

Infantile paralysis may be divided into well-marked and characteristic periods, requiring different methods of treatment, as follows :-

Stage of invasion; stage of recovery; stage of permanent paralysis and disability; stage of progressing deformity; stage of developed contraction and deformity.

The practitioner needs to be able to recognize the different stages of the affection, the prognosis with and without treatment, and the measures to be employed at each period. 


\section{Histori.}

The affection described in this instance as infantile paralysis was first recognized and attributed to its proper cause by Heine in 1840, although mentioned by Underwood in 1784. A notable contribution was later made by Medin, who, in the Swedish epidemic of 1899, was able to study the acute stage. On the ground that two of these are the great contributors to our knowledge of the disease, Wickman advocates calling the disease the Heine-Medin disease. The name "anterior poliomyelitis" is pathologically less correct than the term "polio-myelo-encephalitis." The term "infantile paralysis" will be used here, as being, on the whole, the most familiar and the most simple. 'The objection to its use is that it implies that the disease affects only children, whereas adults are frequently affected in some epidemics. The name "infantile spinal paralysis" is adrocated as being more exact than the term "infantile paralysis." The recognition of epidemics of infantile paralysis is of comparatively recent date. In 1841 Colmer, an American physician, described very briefly what was apparently an epidemic of 8 or 10 cases occurring in Louisiana, although he knew the facts only by hearsay and the authenticity of this epidemic is frequently denied. Bull, a Norwegian physician, in 1868 described, under the title of "meningitis spinalis acuta," an epidemic of 14 cases of what appears to have been anterior poliomyelitis. But Bergenholz, a Swede, writing in 1881, is generally credited with having been the first to recognize and describe such an epidemic with sufficient accuracy to make it acceptable. Since that time epidemics have been reported with increasing frequency. Our knowledge of the disease has been greatly increased in the last five years, the most important contributions being the monograph of Wickman, published in 1908, dealing with clinical phenomena on a new and much more extended basis than ever before. The pathological phenomena have been greatly cleared up by the work of Harbitz and Scheele, and the infectious nature of the disease proved by the work of Flexner and Lewis.

\section{Frequency.}

There is a general impression that anterior poliomyelitis is becoming more frequent and has increased in various parts of the world in the last few years. But such a conclusion must be accepted with caution, because of the fact that of late it has been called to the attention of the profession and is much more frequently recognized than it was formerly. An illustration of this possible source of error is furnished by the increased number of cases of congenital dislocation of the hip brought to American surgical clinics after the visit of Professor Lorenz and 
the attendant newspaper notoriety. For at least a year following this the number of cases of this deformity brought to the Boston Children's Hospital was such that had the affection been one open to such a suspicion, the conclusion might have been formed that an epidemic of such cases existed in New England.

Bearing this factor in mind, from a study of the literature the following conclusions with regard to the increasing frequency of infantile paralysis seem justified:-

1. That epidemics of infantile paralysis have very greatly increased in several parts of the world in the last five years in a measure not to be explained in any way by the increased interest in the disease.

2. That it is more prevalent in cold than in warm countries.

3. That the northern part of the United States has suffered more than any part of the world.

The study of the epidemics, reaching over a period of thirty years, has led, of course, to the knowledge of certain facts now embodied in our stock of knowledge with regard to the disease, but they have not given us the essential facts that we want to know; we do not know how the disease enters the body nor how to prevent or check its spread.

It has been thought that the disease occurred most in dry seasons, and that dust must be taken into account; playing in fresh earth has been noted in children affected in some localities; the food supply, fruit, milk and water, insects, vermin and wounds must all be regarded as possible sources of infection. Now that the infectious nature of the disease is established, our line of inquiry is narrowed and made more definite. We must find out how the organism enters the body.

\section{Communicability.}

Wickman's conclusion is that practically every case has had contact with another $(a)$ direct, $(b)$ by healthy person, $(c)$ by means of house. The following table shows the frequency of more than one case in a family:-

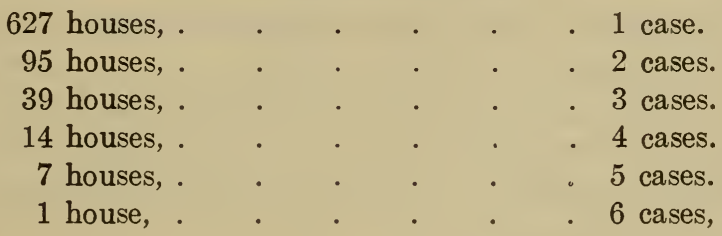

Bearing on the question of transmissibility, there are constant instances such as the following:-

From a German village where there had been no case for ten years, the wife of a railroad official took two children to visit in a village where 
the disease existed. Five days after their return both children developed infantile paralysis and one died.

In a small German city there had been no case for many years. Two healthy women came from an infected village to visit. Eight days later a child of the house where they were staying developed infantile paralysis. The healthy children of this house visited the school where the teacher's children lived. In a few days the teacher's child sickened with infantile paralysis.

On the other hand, the disease is evidently not very transmissible. In the epidemic in the Deerfield valley, so carefully studied by Emerson, there were 67 cases. There were 166 other children in the families of those affected, and 86 other children known to be in intimate contact with the 6\%. Of the 253, 4 later developed the disease.

\section{Disease in Animals.}

Although a disease has been produced in animals which closely resembles infantile paralysis by various experimental methods, these need only to be mentioned, since infantile paralysis has been proved to be infectious and transmissible by inoculation. Experimental paralysis has been produced $(a)$ by the injection into the lumbar arteries of dogs of finely divided powders; $(b)$ by poisoning with the heavy metals (lead, etc); (c) by inoculation with various bacteria (colon bacillus, streptococcus, staphylococcus, etc.); $(d)$ by the use of toxins; $(e)$ in young laboratory animals it may occur spontaneously.

In connection with epidemics of paralysis in human beings, disease and paralysis among the domestic animals of the vicinity have been frequently reported, but in the absence of definite data it is as yet impossible to state that the animal paralysis is of the same character as the human infantile paralysis.

\section{Infectious Character.}

Infantile paralysis is an infectious disease and can be transmitted to monkeys by inoculation with the emulsion of cord and brain tissue from human beings and from monkeys dying with the disease.

Landsteiner and Popper produced the disease in two monkeys by intraperitoneal inoculation in 1908, but could not transmit it by subinoculation to a second series.

Flexner and Lewis ${ }^{1}$ produced the disease in monkeys by intracerebral inoculation in October, 1909, and carried subinoculations through many series by the same and by other methods. Cultural and microscopic 
study was negative. This demonstrated that the disease was caused by a living organism, and established beyond question the infectious nature of the disease.

Römer, ${ }^{1}$ Knöpfelmacher, Strauss and Huntoon, ${ }^{2}$ Leiner and Wiesner, and Landsteiner and Levaditi ${ }^{3}$ subsequently succeeded in causing the disease in monkeys.

The virus is contained in the brain and spinal cord, the mucous membrane of the nasopharynx in infected lymph nodes, in the salivary glands, and, in the acute stage, in the cerebro-spinal fluid and the blood.

The disease may be produced by intracerebral, intraperitoneal, subdural, intraneural, perineural and subcutaneous injections, and by implantation in the anterior chamber of the eye. The disease has been caused by the introduction of the virus into the stomach by means of a catheter, and into the intestines, the peristalsis being prevented by opium.

The disease has also been caused by scarifying the nasal mucous membrane and rubbing the virus into the injured membrane (Flexner and Lewis) and through the sound membrane by Leiner and Wiesner.*

The latter also succeeded in producing it by inhalation of an emulsion containing the virus, and by implantation in the trachea.

It would seem, therefore, as if the disease might, in human beings, enter through either the respiratory or digestive tract.

All investigators who have discussed the matter agree that the intracranial route is the best for inoculation, parallel experiments having shown the marked superiority of the former (Leiner and Wiesner).

Inoculations into horses, calves, goats, pigs, doves, sheep, rats, cats, rabbits, mice, chickens, guinea pigs and dogs have proved negative except for the results of Krause and Meineke, ${ }^{5}$ who caused paralysis in rabbits by inoculation with similar material, but their results are not generally accepted by other observers as they are in contradiction to practically all other experimental work.

The virus is filterable, which places the disease in the category with foot and mouth disease, pleuropneumonia, yellow fever and other diseases less well known.

The virulence of an emulsion is not impaired by drying (seven days, Flexner) (nine days, L. and L.), by freezing, nor by suspension in glycerine, but it is injured by exposure to a temperature of $45^{\circ}$ to $50^{\circ} \mathrm{C}$. Emulsions of cord and brain from other diseases were inoculated into monkeys with no effect by Leiner and Wiesner (tuberculous meningitis, hydrocephalus, etc.).

1 Münch. MIed. Wochenschr., Dec. 7, 1909.

2 New York Medical Journal, Jan. 8, 1910.

3 Compt. Rend. Soc. de Biol., Dec. 3 and 24, 1909.
4 Wien. Med. Klin., 1909, xliv, 1671.

5 Deutsch. Jed. Wochenschr., Oct. 21, 1909. 
That one attack of the disease confers immunity seems generally admitted. The serum of healthy monkeys does not immunize against an attack, but that of monkeys who have had the disease does antagonize the virus of subsequent inoculations (Römer and Joseph).

As to bacterial findings of previous authors, the latest investigations have been almost wholly negative, and, having found an invisible organism which causes the disease, the previous inconstant data with regard to bacteria may be disregarded for the present. Leiner and Wiesner withdrew fluid from the brain and cord in such conditions as tuberculous meningitis, hydrocephalus, etc., in three parts, and found in many cases that the first portion was contaminated by various cocci, while the second and third portions remained sterile, which suggests the ease by which contamination may occur.

\section{Stage of Incubation.}

The disease in monkeys possesses the same general characteristics as in children, and the pathological changes are practically identical. The monkeys seem to have less fever than children, but the mortality is higher. The stage of incubation is from six to upwards of thirty days.

The period of incubation in human beings is not clearly known, but is generally stated as being from one to fourteen days.

\section{Symptoms.}

The occurrence and symptoms can only be mentioned here in the briefest possible way.

The disease ordinarily has an acute febrile onset, frequently with sore throat or digestive disturbance, and in this stage the diagnosis is rarely made. Again, occasionally the onset may be absent. Tenderness is a frequent and highly important symptom, and profuse sweating has lately been called to our attention as a prominent early symptom. Paralysis is generally noticed in from one to seven days after the acute attack, but may occur almost at once.

Suspicious early symptoms are profuse sweating, hyperesthesia of the body and pain in moving, especially in the neck and back.

Wickman has divided the disease into eight types, a matter which is of much value in formulating and recognizing the disease. These are:-

1. Spinal Poliomyetic Form. - This is the recognized type described in the text-books, where a sudden febrile onset is followed by a paralysis of one or more limbs.

2. The Ascending Form. - In this type the paralysis ascends perhaps 
to the thorax, often causing death by involvement of respiration. This covers many cases at least of so-called Landry's paralysis, the true nature of which may be recognized in adults, while in children the course of the affection cannot so well be followed. Most fatal cases belong to this type.

3. The Bulbar or Pontine Form. - Here there is involvement of the cranial nerves, most often the facial, hypoglossal and ocular, and there may be involvement of the throat and larynx. This type may exist alone or in connection with paralysis of the extremities.

4. The Cerebral or Encephalitic Form. - Although Wickman saw no case of this type personally in the large Swedish epidemic investigated by him, he heard of cases and collected others where a hemiplegia or spastic paralysis arose under circumistances suggesting that the cerebral lesion was really infantile paralysis. He concludes that the cerebral form may exist alone or in connection with spinal involvement, but this type cannot be regarded as satisfactorily established.

5. The Ataxic Form. - A disturbance of motion, not necessarily a pure ataxia, much like Friedrich's ataxia, may result from infantile paralysis. The seat of this ataxia may be in a lesion of the cerebellum, the middle brain or the bulbar portion, or it may be spinal.

6. The Polyneuritic Form. - This is characterized by points of pain and tenderness, and the diagnosis is frequently difficult from polyneuritis. The diagnosis of this form is not very clearly given, but the type is established by autopsy findings.

7. Meningitic Form. - Pain and stiffness in the neck, perhaps opisthotonos and meningeal symptoms, characterize this form. It is frequently confused with cerebro-spinal meningitis, which Wickman believes, after a long consideration of the evidence, to be a separate form of the disease.

8. Abortive Form. - In localities where infantile paralysis prevails occur many cases, often in the same families, where fever, headache, stiffness of the neck and general disturbance are present, but where the paralysis is slight and transitory or does not occur at all.

This form is of great importance as forming a probable link in the transmission of the affection. From the study of $15 \%$ abortive cases Wickman divides them as follows: -

(1) General infection.

(2) Symptoms of meningeal irritation.

(3) Cases with much pain, like influenza.

(4) Cases with marked digestive disturbance. 


\section{Diagnosis.}

The diagnosis of the affection is rarely made before the paralysis occurs, nor is the possibility of the presence of the disease so often remembered as would seem advisable.

The diagnosis in the earliest stage must now be made by exclusion, for we have no positive signs at present, although recent laboratory data offer the hope that by means of examination of the blood and cerebrospinal fluid a diagnosis may be possible in the stage preceding the paralysis.

The spinal fluid contains no organisms as yet recognized by the best observers, and those who find organisms do not find the same one.

The withdrawal of spinal fluid may be of diagnostic service, however. It may show the presence of tuberculous or cerebro-spinal meningitis, the diagnosis of which from infantile paralysis is not always easy. Certain important points may be mentioned as bearing on the diagnosis. The disease occurs oftenest in the late summer; it is epidemic in many localities; it affects most often children in the first dentition; the onset is a febrile attack, with most often excess of pain, sweating and often drowsiness. The throat or intestinal tract are frequently involred. Meningeal symptoms in any degree are very suspicious. Tenderness of the spine, body or limbs should awaken suspicions at once.

If these facts are borne in mind, many more early diagnoses can be made. There is no criterion for the diagnosis of abortive cases, nor can the diagnosis in any case as yet surely be made in the absence of paralysis.

In many instances the prodromal stage of general indisposition is slight and the affection is treated by cathartics or a febrifuge or disregarded. In some instances severe pain referred to certain regions is observed, and the affection is regarded as rheumatism, peritonitis, pleurisy, etc., and if cerebral symptoms are present, cerebro-spinal meningitis is suspected.

Where motor paralysis is present, the sudden onset, the absence of reflexes, the progress of muscular flaccidity, surface coldness, the absence of sensory paralyses, with or without a short period of pain, followed by muscular atrophy, combine to form a characteristic group of symptoms, making the diagnosis an easy one.

In the later stages of infantile paralysis, when contractions and deformity are present, there is, as a rule, no difficulty in recognizing the disease, as the history of the case, the flaccidity and atrophy of certain muscles, with the presence of normal sensations, are sufficient to establish the diagnosis. 
Cases of hysterical paralysis may simulate poliomyelitis, but the symptoms in purely functional cases do not group themselves usually in a manner typical of infantile paralysis.

\section{Prognosis in Untreated Cases.}

It is extremely difficult for a physician in examining a case in the early stages of its development to estimate the outcome of the attack. As a rule, the painful stage is brief, lasting but a few days, and at most not longer than a few weeks. Spontaneous recovery of great improvement can be expected in all but the fatal cases. The recovery is gradual, and may be expected to continue during six months or a year after the attack of the paralysis. Even later the improvement in the functional activity of the affected limb may occur following the use of the affected limb.

An exact determination of the extent of the paralysis by examining the electrical reaction is difficult in young children, and, for this reason, often impracticable. The surface temperature, that is, coldness of the limb or region, to the touch, offers a ready means of estimating the extent of the region involved.

\section{Treatment.}

The consideration of the treatment of anterior poliomyelitis may be divided into that of the affection during three stages; i.e., (1) the early stage of acute onset and fever; (2) the subacute stage; and (3) the stage of established paralysis and convalescence.

\section{Treatment of the First Stage.}

The early stage of acute onset and fever extends from the first appearance of the symptoms indicating the infection until the entire subsidence of the fever and acute pain. The duration of this stage necessarily varies. The symptoms demanding attention in this period are the preliminary chill, fever (with or without delirium), pain and marked sensitiveness.

These suggest at the onset the general treatment used in all febrile attacks, - mild cathartics if digestive disturbances are present, and rest.

1. Rest. - The question of rest is one which largely settles itself, since the acuteness of the symptoms demands the utmost quiet. In the early stage there is fever, possibly delirium, and marked depression, all of which are found in varying degrees of intensity. Attending these is marked sensitiveness to all motion, which demands that the patient be kept in the utmost quiet. When sensitiveness is not prominent, and does not of itself demand quiet, it is wise to enforce this during the early stage. 
2. Drugs. - The drugs to be considered in this early stage are: $(a)$ antipyretics; $(b)$ sedatives and analgesics; $(c)$ internal antiseptics; (d) nerve stimulants; $(e)$ external applications.

(a) The use of antipyretics, except as perhaps temporary expedients with very high and early temperature, is not advisable, owing to their depressing action.

(b) Sedatives and analgesics, and drugs of this class, may be distinctly indicated in the early stages in more severe cases, especially those presenting delirium or excessive spinal and occipital pain. Owing to the rather depressing effect of sedatives, it is wiser to use analgesics, either codeia or morphia, if they are distinctly necessary, but it is well to enforce the necessity of the avoidance of all drugs of this kind whenever possible.

(c) Internal antiseptics. The use of the internal antiseptics in this class of cases must be at present considered to be in the trial stage. It is well proven that drugs such as urotropin, cystogen, aminoform, formin, etc., are internal antiseptics, and that their action is demonstrable in the excreta, in the blood and in some of the tissues. Their usefulness has been proven in some cases of infection. Their trial, therefore, is to be advocated as early as it may be possible to feel confident of the probable diagnosis.

(d) Nerve stimulants. Nerve stimulants, chief among these being strychnia, should be avoided during this acute stage.

(e) External applications, such as physical therapeutics and hydrotherapeutics, are of doubtful usefulness in this early stage, and are liable to disturb the rest which is so strongly indicated at this time. The use of electricity in this stage is to be carefully avoided.

3. Lumbar Puncture is not advisable either for diagnostic or therapeutic purposes with our present knowledge, although it is not improbable that in the future the method may have its use.

\section{The Treatment of the Second Stage.}

The second stage may be considered as extending from the end of the first period of onset to the time of the disappearance of all sensitiveness, fever and nerve tenderness. This stage will vary much in duration, and usually does not extend over a period of more than three to four weeks, or less, but is occasionally prolonged to five or six weeks. In this stage the fever and early pain have entirely subsided, but there is frequently left sensitiveness along the nerve trunks, pain, motion of the limbs and sometimes of the back. There may also be found contraction of the limbs, mainly of the hips and knees, due to the persistence of sensitiveness, which does not allow the limbs to be brought into the 
straight and normal positions. The patient should be kept from unnecessary morement and should be moved on pillows or bed frames when practicable. There is often more or less exhaustion following the early fever and infection, and in such cases stimulation of the general condition is indicated.

It is important in this stage to prevent the overstretching of paralyzed muscles, either from pressure of bed clothes, position of decubitus or force of gravity, or the unantagonized pull of the sound muscles. Deformities of position may be developed even in this stage, and, although not necessarily permanent, add much to the discomfort in the later correction. These are to be guarded against and prevented unless the appropriate measure gires actual pain. Splints or a weight pull are rarely necessary for retention in this early period, but the position can be arranged by pillows, sandbags, cradles for the bedclothes, etc., to prevent the dévelopment of such. In many cases, however, the deformities due to pain on moving limbs disappear on the subsidence of the pain. The application of heat, either a warm, moist or dry pack, or the electric pad, will often be found to relieve pain. Gentle massage is often difficult on account of the presence of pain, but may give relief if carefully applied.

Drugs are to be used with much discretion in this stage.

\section{The Treatment of the Third or Convalescent Stage.}

This stage can be considered to extend from the period of the entire disappearance of the sensitiveness and the contractions of the early irritant stages until the time that all potential power has been regained, or until the deformities require no further attention. The time in which it is possible for further increase of muscle power to be regained varies very decidely with different cases, but the time during which deformity requires attention cannot be considered to end until the full growth of the individual has been attained. Two special demands are important throughout this stage, and although intimately related are more practically considered independently, both in their description and clinical manifestations. These two are:-

1. The prevention of deformity.

2. The regaining of nerve and muscle power.

1. Prevention of Deformity. - Deformities which occur in the course of recovery from infantile paralysis are those of the limbs and those of the spine, a form of scoliosis. Deformities of the limbs from adaptive tissue changes are due either to the constant contraction of the unantagonized sound muscles, or else from faulty position, the paralyzed limb hanging unnaturally or bearing weight wrongly. From the maintenance of these 
positions contractions occur which make permanent the deformities, and if these are allowed to continue during the child's growth, distortions in the shape of the bones occur as well as in the soft parts, which render the deformities still more permanent. It is especially needful that apparatus be employed in this stage for a twofold object, i.e., first, to prevent the overstretching of the paralyzed muscles during the early stages; and, second, to prevent the permanency of the deformities. mentioned.

The need of the early detection of a faulty position of the spine and of early care in the prevention of scoliosis cannot be too strongly stated. On account of the general muscular weakness and of the unequal pull of the trunk muscles, the asymmetrical methods of walking and standing and the faulty superimposed weight, or the one-sided use of the arms in cases of paralysis of the upper extremity, all motions on the part of the patient tend to exaggerate the development of deformity when once under way. For this reason this form of scoliosis presents a most obstinate type for treatment, and as soon as there is any evidence of a beginning deformity of the spine every effort should be directed to check its derelopment.

2. The Regaining of Nerve and IIuscle Pouer. - It is unfortunately a prevalent idea that recovered power is gained within the first few months of the convalescence, and that after this the child should not be burdened with special efforts directed toward developing individual muscles and nerves, the natural use of the regained muscles being sufficient to establish all the cure which is possible. This idea is particularly unfortunate, for the clinical facts prove the contrary. It is possible to gain a return of muscle power after a long period following the onset of disease, even when during the interval there has been no evidence of actual local return of power. It is very essential, therefore, that treatment directed to this end be carried out, not only in a most thorough manner, but also over an extended period. The indications during the early convalescent stage are two, viz., for:-

(1) The stimulation of the nerves to prevent all possible degeneration until all possible repair has taken place; and

(2) Stimulation and protection of muscles to prevent atrophy and to keep the muscle in condition, that it may respond quickly when nerve impulses are restored. Incidental to this the all-important reason that it is essential that muscles be not allowed to be overstretched, but the parts be so held as to prevent deformity. This is easy and demands the application of the lightest form of braces or apparatus for this purpose, and not only prevents the overstretching of muscles, which is so essential, but also prevents the correction of unnecessary deformity in the later stages. 
For stimulation of nerves and muscles the means to be employed are:-

1. Electricity.

2. Baking and different forms of high heat.

3. Physical therapy (including mechanotherapy, hydrotherapy and massage).

4. Muscle training.

The first three of these must be considered as means of artificially stimulating the parts by maintaining nutrition, with the exception, possibly, of the electricity. It is wise to have the different methods well in hand, because we have reason to believe that the effect of the different methods of artificial stimulation are not exactly the same, and it gives the opportunity of change from one form to another at different periods, both with the idea of rest to the patients and to obtain the different forms of stimulation as well. The lack of use, with its attendant sluggish circulation, if not counteracted, is a distinct obstacle to the proper nourishment of the part, and it is, therefore, necessary to use all methods which are possible to maintain this to the highest standard that is possible.

1. Electricity. - The different forms which may be used for this are the galvanic, faradic, static and high-frequency currents. In the early stages galvanism should be used on the nerve trunks and faradism on the muscles, so long as their irritability for contraction is maintained. When the irritability of contraction to the faradic is lost, galvanism should then be used, as having more influence on nutrition. With the returning muscle irritability, faradism should be used, and best by the use of the electrodes over the muscle points so as to obtain actual contraction of muscles rather than by the application of the electrical current to broad surfaces. This serves as a distinct exercise to the muscle during its early stage of weak contraction. High-frequency and static electricity can both be used for their influence on nutrition rather than for their direct action on muscle contraction. It may be stated in this connection that the main dependence for actual results must be placed upon the galvanic and faradic currents.

2. Baking and the Other Means of applying High Degrees of Heat. Paralyzed limbs in these cases are almost always cold and the circulation distinctly defective. It is found after the use of baking and different methods of applying high degrees of heat that the extremities remain warm for a longer time; that the circulation is more active; the blush and the temperature remain higher for some time; and the patient is able to use the very weak muscles much better, and with better control, during the time that the limbs remain warm. It is frequently found that after continued use of high degrees of heat this improvement of circu- 
lation and the local heat of the limb become more and more permanent, frequently lasting for the larger part of the day or longer. It is essential that the baking should not be used in too high degrees (probably not more than $250^{\circ}$ ) and not continued for too long a time (fifteen to twenty minutes), the shorter application being quite sufficient to bring out the changes of circulation desired.

3. Physical Therapy (including Mechanotherapy, Massage, etc.).These constitute another means of artificial stimulation, both of nerve and muscle, particularly in their effect upon the circulatory changes. The physicotherapeutic methods are less generally applicable, demanding apparatus for their use, but massage, however, should be given the highest place in all stages of this affection. In conjunction with massage, however, it is wise to reiterate the caution that it is necessary not to rely upon massage alone, but that this means should be regarded as an adjunct only to the other forms of muscle and nerve stimulation. Ton frequently has it been remarked that massage alone is used to the neglect of many of the other means fully as important.

4. Muscle Training. - Probably no other means at our disposal has a more important place or more extended usefulness, both in the variety of its application and in the length of time that it may be used, than the different methods which may be grouped under this head. It is applicable as soon as any sign of returning power is found, and is best applied through the "assistive form" of exercise, which has the advantage of allowing actual work to the muscle long before power is sufficient to give any practical result in movement. The difficulty with the usual forms of gymnastic exercise in these cases is that the stronger muscles receive the greater part of the exercise, while the weaker and most needy muscles receive but little. Most cases present so many individual needs that it is necessary to concentrate the work, and for this reason it is essential that the weaker muscles obtain all possible results from the means employed. Such is not possible when the patient is given the ordinary gymnastic exercise, relying upon the stronger muscles to bring about the movement and giving the weaker muscles the opportunity to participate in the movement. This method is applied in detail as follows: -

The part to which the muscle belongs is put through passive movement, with slow rhythm, in the direction that is desired. The patient is then directed to make effort to move the part in the same direction to whatever extent is possible, the assistant supplying the power needed to complete the actual motion. In this way the paralyzed muscle is allowed to contract in the same manner as if it were doing the whole of the work, and has the benefit of the contraction and of the movement during the whole arc of motion. As the muscle becomes stronger, the assistive force 


\section{3}

supplied becomes less, so that the muscle is allowed to take up more of the work during the whole of the exercise, and receives the maximum amount of exercise possible to a muscle in its condition. In all the other forms of exercise one must be contented with the mere effort of the muscle to make contraction, without allowing contraction through a distinct are of motion.

In the treatment of cases of infantile paralysis at this stage it is difficult to apply the needed remedies for a sufficiently long period to accomplish the good which can be obtained. Patients remote from physicians' offices or hospitals equipped for special treatment cannot receive it satisfactorily. In most instances home nursing must be relied upon, and electricity crudely or infrequently applied is of no benefit. Under such circumstances the physician should direct his attention to enforcing, for a long period, such measures as can be used effectively, viz., hot-air, hot-water or hot-sand baths of the paralyzed limbs at frequent intervals, and passive and active movements of the limbs, improvement of the circulation by muscle kneading, and especially muscle training, continued daily for a long period. The aid of an expert is undoubtedly advisable, but the constant daily faithful work of home attendants is more beneficial than occasional treatment at infrequent intervals.

\section{Nerve Grafting.}

The success which has been obtained in a few instances of nerve grafting has been such as to encourage the belief that great relief could be furnished in confirmed paralysis from anterior poliomyelitis by this surgical procedure, but clinical evidence so far collected does not substantiate such an opinion. The method may be regarded as still in the experimental stage, and at present it does offer much hope of relief, and the number of cases to which it is applicable is small.

\section{Mechanical Treatment.}

The objects of mechanical treatment for infantile paralysis are:-

1. To correct the deformities of the limb.

2. To prevent the development of new deformities.

3. To aid locomotion by furnishing, through the mechanical stops and checks, a substitute for the action of muscles weakened or paralyzed by the disease.

The number of types of appliances which can be derived is great. Those which are simple, light, easily designed and easily applied are to be preferred. Expensive, heary and complicated forms of apparatus are undesirable. 
Those which have been for many years used at the Boston Children's Hospital will be referred to in this report because, in design and construction, they are suited to the practice of any general practitiones who is ready to give personal attention to making, fitting and adjusting an appliance to prevent the development of deformity in his patient.

\section{Early Stage of Paralysis.}

Appliances for this stage should interfere with the circulation as little as possible, since it is desirable to develop the impaired nutrition and circulation, not to impede it. For this reason plaster bandages and splints tightly secured by a muslin bandage are less used than formerly.

Toe-drop can easily be prevented while the child is in bed by fixing the limb on a simple posterior wire splint such as one uses for fractures (Fig. 1).
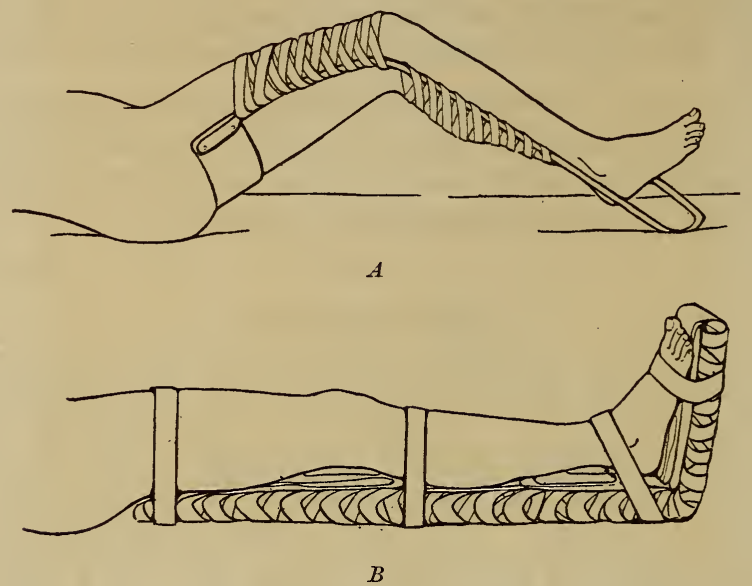

FIG. 1. $-A$. Wire splint for straightening contracted knee. $B$. For preventing drawing up of the knees and dropping the front of the foot.

Iron wire three-sixteenths of an inch in diameter is stiff enough; this is bent to the proper shape, thickly wound with cotton wadding, firmly covered with a roller bandage, and a cover of stout cotton cloth is sewed over it all. Sufficient padding is provided under the calf and under the sole of the foot to entirely remove pressure on the back of the heel; the leg and foot are fastened to the splint by adhesive plaster straps, applied so as to keep the axis of the foot at a right angle with the leg.

If this splint be prolonged to reach the upper part of the thigh, and is made stiff enough, contraction of the knee can also be prevented. A roller bandage should only be used to make the adhesive plaster stick. 
While this is sufficient during the stage when the patient is unable to stand, a stronger appliance is needed when he begins to walk.

\section{Splints for Walking.}

These splints are designed for two classes of cases, - those in which a flaccid paralysis is present in some of the muscles, and those where, in addition to the paralysis, a contraction and shortening has taken place in muscles which are not paralyzed but have lost their antagonists.

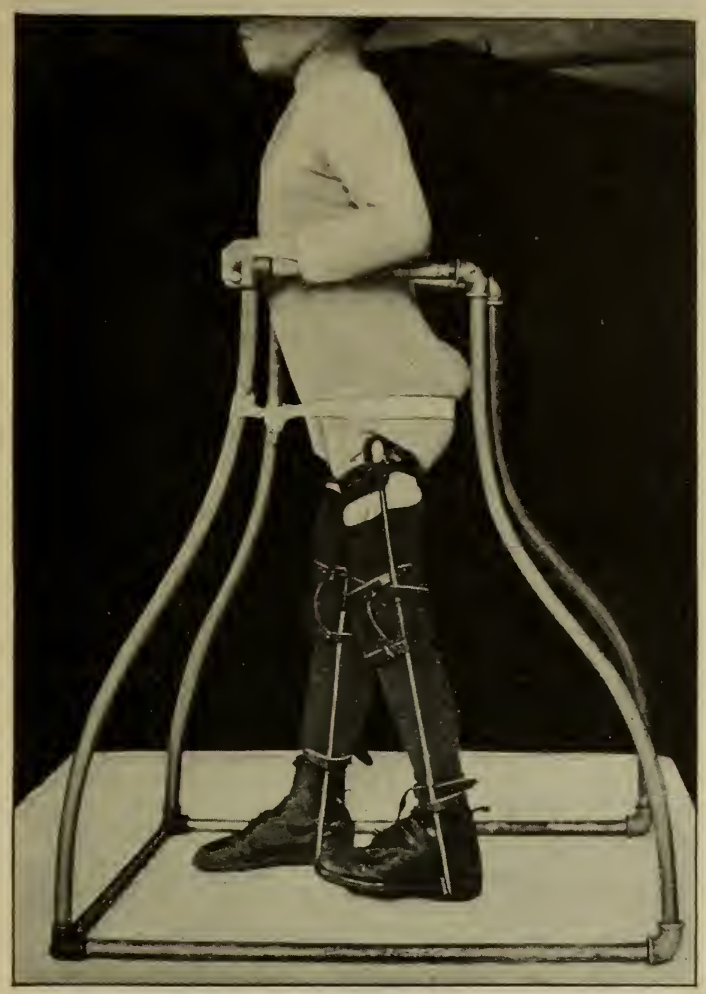

FIG. 2. - Paralyzed child strapped in a walking frame wearing splints to prevent forward dropping of the knee.

In the first class no stiffness or contraction is present, and splints may be needed to prevent (1) toe-drop; (2) dropping of the tarsus to the inner side; (3) dropping of the tarsus to the outer side; (4) walking on the heel, i.e., the equinus, valgus, varus or calcaneus positions of the foot; and (5) to hold the knee straight in paralysis of the muscles of the front of the thigh. 
For Flaccid Paralysis.

Where no stiffness from contraction is present, this simple apparatus can be furnished to prevent toe-drop (Fig. 5). It is called a short caliper splint. It consists of two parts, the splint and the socket attached to the boot.

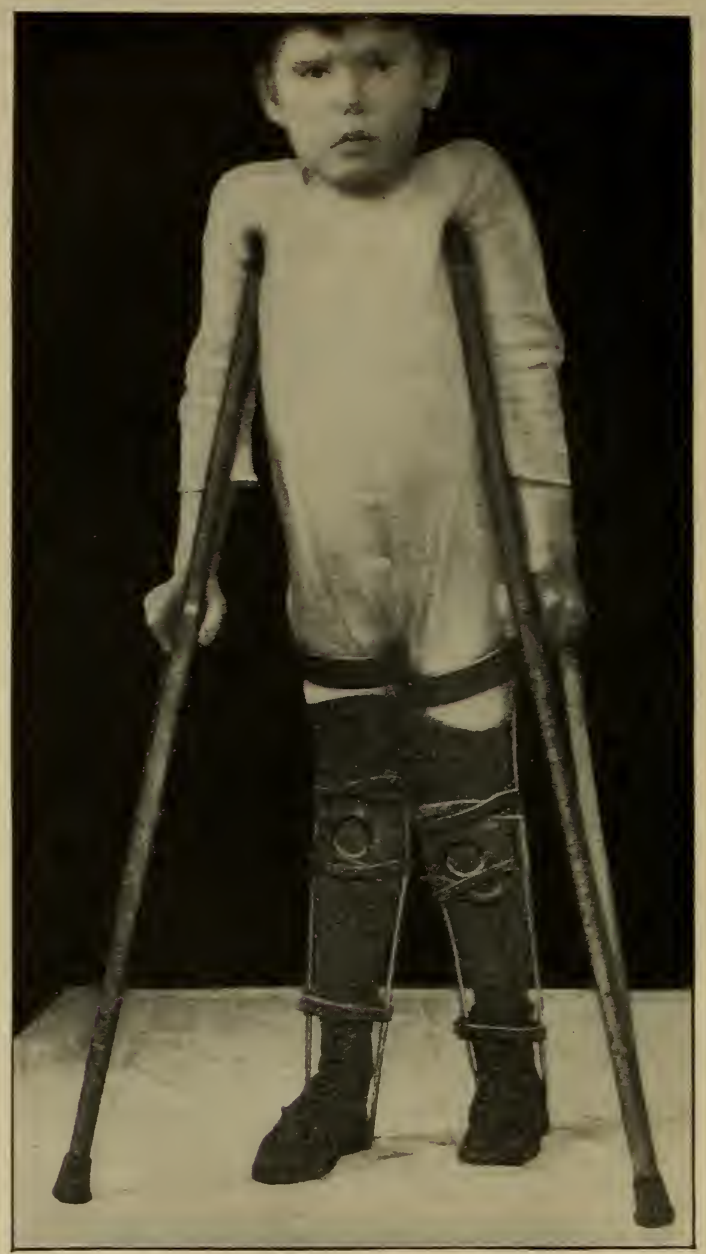

FIG. 3.- Child walking with crutches and splints.

The socket is made of a thin iron plate, made to fit under the heel and the shank of the child's boot, as far forward as the metatarsophalangeal joint. The heel of the boot is first removed, and a deep 
groove or socket is fashioned in the plate by forging, so that when it is applied to the boot it will receive at the heel the end of the upright, as if in a tube. A small spur piece, which is left projecting outside the boot, is bent up after it is applied, so as to act as a stop, as shown in the illustration (Fig. 8), and the boot heel is reapplied.

For the uprights the same sort of wire is used as for the posterior wire splint already described. At the top the wires are slightly flattened and attached to a thin metal calf-band fitted to the calf of the leg; at the bottom they are sharply bent inward at a right angle so as to fit in the socket. The uprights may follow the shape of the leg, or be left straight, provided they allow width enough so that the ankles do not touch them.

This simple splint can be easily improvised with the help of a cobbler and a blacksmith or carriagesmith at very slight expense. It is held in place by a strap at the top and one around the ankle.

Should the patient, instead of having toe-drop, have paralysis of the calf muscles, while the muscles of the front of the leg are strong, he will walk on his heel, with the front of the foot raised. In order to apply the sole of the boot to the ground, the same splint may be used to advantage if the socket be made so that the stop comes in front of the upright instead of behind it. This is shown in Fig. 4, on the left leg.

Should the child stand with the foot in the varus or club-foot position, a stout leather $\mathrm{T}$ strap should be added, which is sewed to the upper of the boot, just in front of the external malleolus; the horizontal arms buckle into each other and include the inner upright of the splint.

Should, on the other hand, a pronated or valgus position appear in weight bearing, the $\mathrm{T}$ strap should be on the opposite side of the boot below the inner malleolus, and the arms strapped around the outer upright so as to maintain the arch of the foot by preventing the ankle from sagging inward (Fig. 7). These appliances are for flaccid joints only.

Again, if, owing to paralysis of the muscles of the front of the thigh, the quadriceps extensor cruris, the child cannot hold the knee stiff in standing, then the caliper splint should be made to reach the upper third of the thigh and the knee be kept straight by a leather knee cap, as shown in Figs. 2, 3 and 4, which also show the method of teaching the child to walk stiff-kneed.

\section{For Paralysis with Slight Contractions.}

Any paralytic deformity in time develops contraction of the strong unaffected muscles. This is especially true if the calf muscles are not affected. 


\section{Equinus Deformity.}

In slight degrees, contraction of the short tendo Achilles can be overcome by stretching the muscles with a special splint in walking, if the heel can be held down firmly against a foot plate which extends well forward, while toe-drop is prevented by a stop in the ankle-joint of the upright (Fig. 5). At times it is hard to accomplish this because the heel refuses to stay down on the sole-plate, but it may be held there either by a strong ankle strap or by a strip of adhesive plaster attached to the skin of the calf of the leg above and to the lower surface of the sole-plate below. Such an apparatus can be worn inside of the boot. The correcting force is the body weight. This may be increased if the appliance be made long enough to reach to the upper thigh and prevent bending the knee. It can be worn day and night, and additional corrective force may be added by an elastic strap extending from the front of the sole-plate to a buckle on the upright near the knee.

\section{Varus with Slight Contraction.}

In paralytic varus deformity a thick leather wedge is pegged to the lower surface of the sole of the boot under the cuboid, so that the foot in walking strikes first on the heel, then on the wedge which projects more than the heel, and forces the foot to turn outward to prevent loss of balance, so that the foot at the end of a step, before leaving the ground, receives the body weight wholly on the abducted front portion.

\section{Valgus with Slight Contraction.}

In paralytic valgus deformity, when the contraction of the peronei muscles is slight, the position of the walking foot as it bears on the ground can be improved by supporting the sagging arch, both by an upright and $\mathrm{T}$ strap (Fig. 7 ), and by pegging a thick wedge of leather on the lower surface of the sole of the boot, extending forward along the inner side from the heel to the scaphoid, or under the first metatarsal, as the case may require.

\section{Calcaneus.}

In cases with slight contraction the position of the walking foot, as it strikes the ground, can be improved by prolonging the heel backwards (Fig. 8).

Appliances to overcome Stronger Contractions.

The above-mentioned appliances are only for slight contractions; when firm contractures have developed, they are to be stretched or divided by an operation, under full anesthesia, either by manual force, tenotomy or 
incision, as may be needed; but for a few mild cases the gradual corrections are sufficient which one obtains by plaster bandages or mechanical appliances.

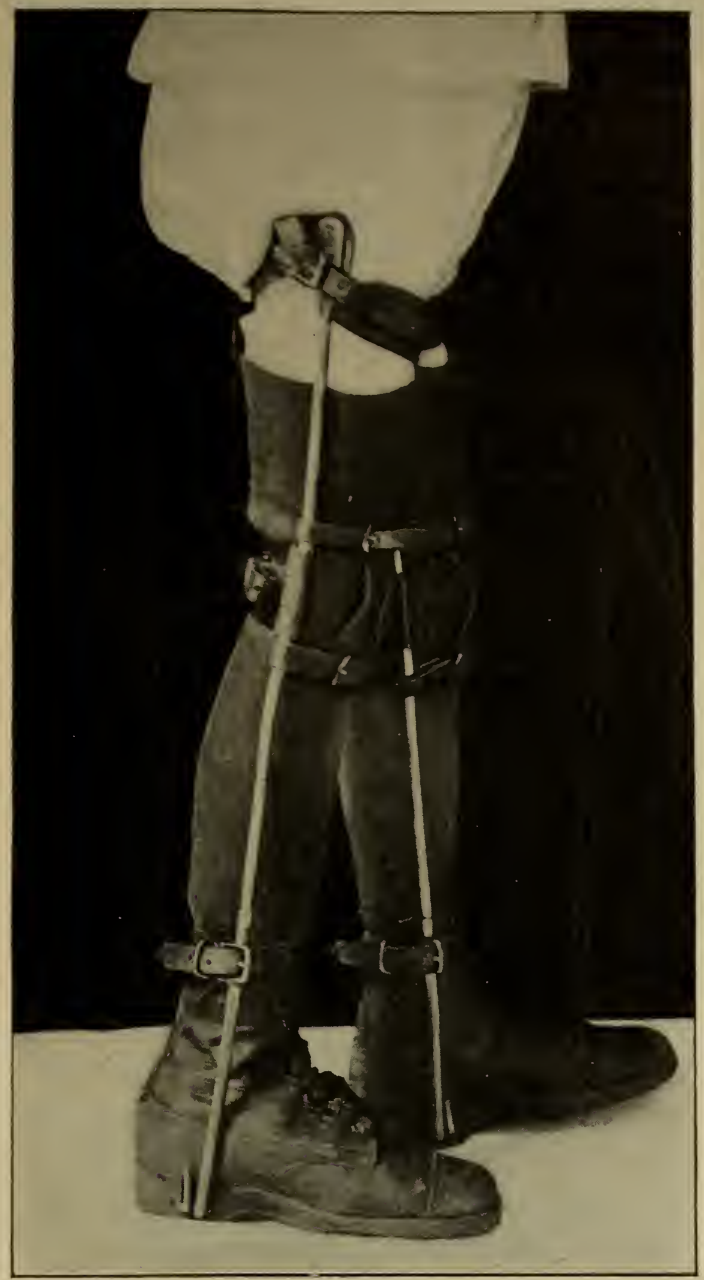

FIG. 4. - Side view of "caliper" splint, with knee strap and checks in the heel to prevent the dropping of the heel or front of the foot as may be needed.

\section{Plaster Bandages.}

Gradual correction by the frequently repeated application of plaster bandages is obtained by holding the limb in as corrected a position as possible while the plaster sets, without the aid of an anesthetic. It is effective in recent contractures in young children. The method has to 
its disadvantage that both muscular atrophy and weakening of undestroyed muscles are favored by the prolonged use of stiff bandages; therefore this method should not be continued during a long period.

The contractures which the surgeon has most frequently to overcome are those of the tendo Achilles, the ham-strings, the tensor vaginæ femoris and fascia adjacent, the psoas and iliacus muscles; also contractions of the tendons and fascia in the various paralytic deformities of the foot. These are caused partly by the shortening of unopposed muscles and partly by adaptive shortening or stretching of ligaments and fascia from habitually assumed positions of deformity, either on account of gravity or disturbed muscular balance.

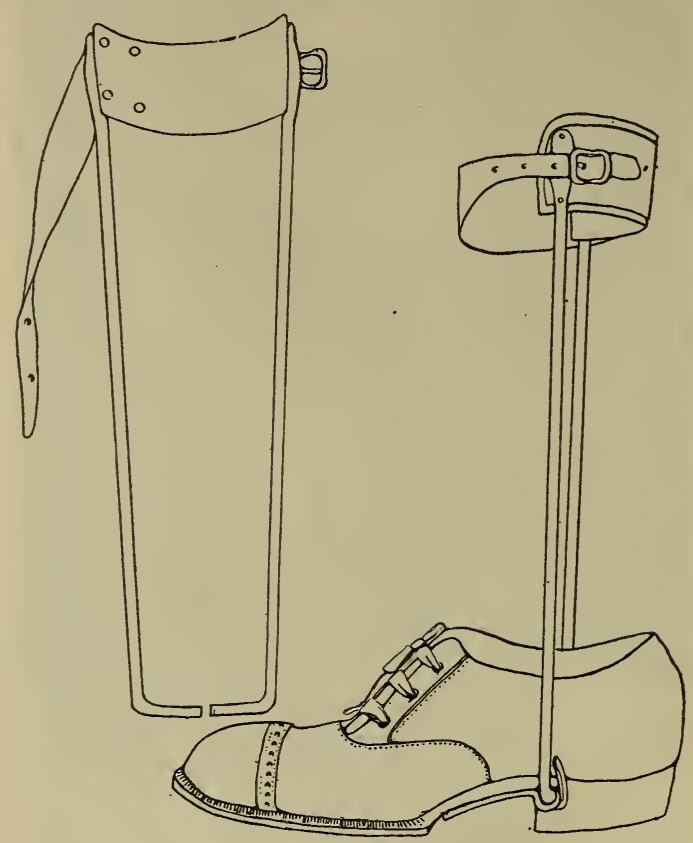

FIG. 5. - Detail of wire splint, showing adjustment to the shoe, with check to prevent toe-drop.

For the correction of contracted ankle, unless the equinus position yield's readily to mechanical means, tenotomy of the tendo Achilles is decidedly preferable.

For a contracted or flexed knee, mechanical measures are better adapted. If the type be mild it can be overcome by the application of a splint resembling both Thomas' knee splint and his caliper splint, already described, to which the limb can be bandaged in the manner shown in Fig. 6. The corrective pressure is obtained largely from the bandage 
over the thigh and knee, which should be applied at least twice a day. This apparatus can also be used to walk with. If any form of acquired club-foot is combined with the contracted knee, it may be corrected simultaneously in the manner already described.

For contractions of the hip-joint not severe enough to demand operation, two common methods of correction are in use.

1. By encasing in a plaster bandage the limb, with the knee straight, its weight may be utilized to stretch very gradually the contracted muscles and fascix of the hip; this may be done either while the child is walking about, or, preferably, while he is in bed, on a bed-frame. Sometimes a separate plaster jacket is required for these recumbent cases, to prevent lordosis of the lumbar spine.

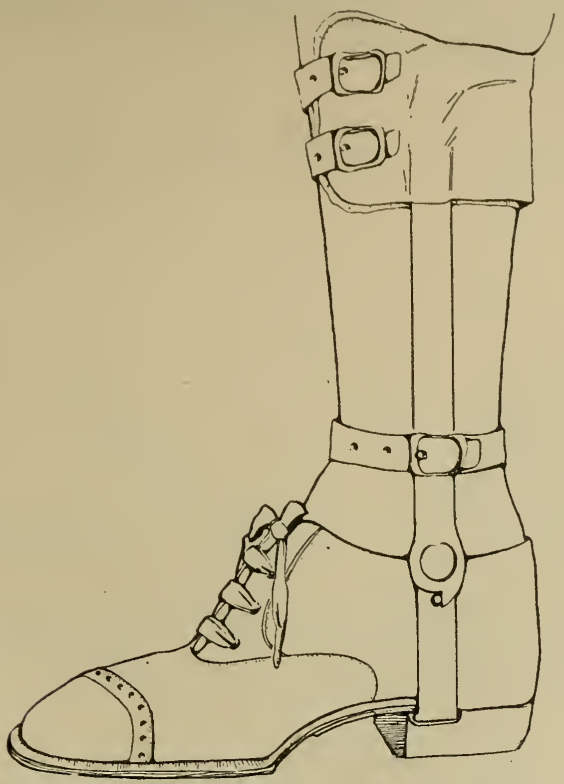

FIG. 6. - Apparatus to prevent toe-drop slip. ping in a socket at the heel. An ankle strap secures the leg.

2. A direct pull or traction may be used, such as one would use to correct flexion in hip disease. The patient is then kept on a bed-frame with the pelvis fixed by extreme flexion of the unaffected thigh, and the paralyzed leg is elevated, and traction is applied in such a position that the line of pull coincides with the new direction of the femur; traction is first made in this direction, and from this position the limb is straightened very gradually day by day.

All contractions at the hip may without doubt be overcome more 
quickly by the use of the knife, with subsequent fixation, than by mechanical means, but an objection is often encountered in children with extensive paralysis because there remains in the limb so little muscle power that any loss, whether from tenotomy, myotomy or prolonged use of plaster bandages, is risky, as every particle of muscle power must be treasured and developed to enable the child to stand upon his feet when the deformity is sufficiently reduced.

\section{Supports for the Trunk.}

Plaster jackets may be applied in several different ways, and when properly applied are efficient supports to the paralyzed trunk. They may also be used to straighten the abnormal twists and curves of the spine which develop as the result of poliomyelitic paralysis, and are then termed "corrective jackets."
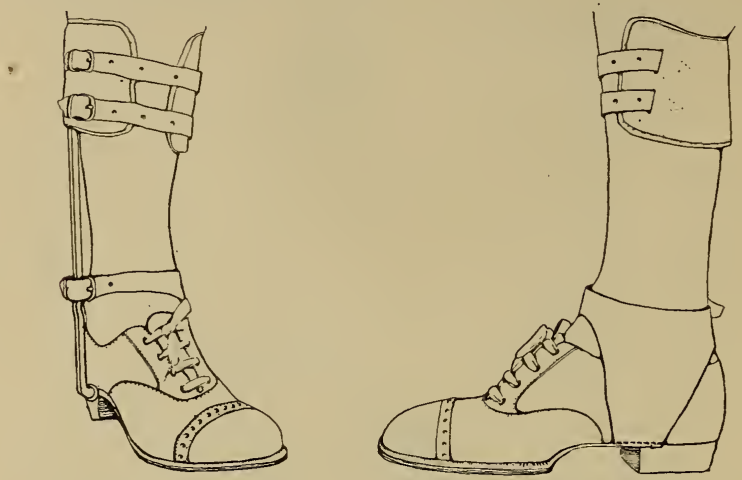

Frg. 7.-Apparatus similar to Fig. 6, with ankle strap to check paralytic valgus. If the upright is applied to the inside with the ankle strap applied to the outside a varus deformity is checked.

Plaster jackets may be made removable by splitting down the front and sewing to each side of the border a strip of leather, with eyelets or hooks for a lacing. They are more convenient for reasons of cleanliness, but soon lose their efficiency because they crack and weaken if frequently removed. More durable jackets are made of leather, celluloid or muslin-paper-and-glue molded on a cast made from a plaster jacket. For the details of manufacture the reader is referred to the text-books of orthopedic surgery.

Lateral curvatures from poliomyelitis sometimes require treatment by recumbency to obliterate or diminish the curves, but in most instances plaster corrective jackets are required for the severe types of curvature, and the subsequent use of stiff leather or celluloid corsets is often necessary for a long time to keep the curvature from increasing. 
Apparatus to strengthen Weak Muscles.

Poliomyelitis may weaken certain muscles without paralyzing them; it is desirable to lessen the disability by developing their strength again, and, as far as possible, to secure a return of normal motions of the limb. This can usually be accomplished by systematic exercises carried out regularly once or twice a day.

Again, certain muscles may be weakened, not by the disease itself, but by disuse entailed by it, although not in themselves involved in the paralytic attack. For these also it is desirable to use a simple means of exercise.

Exercises can be made to vary almost indefinitely; but simple exercises, with manual resistance, or with the weight and pulley, have proved of great value. They can be arranged to suit the action and development of any group of muscles.

The stationary bicycle has also been an excellent means of exercising the feet and legs of weak-limbed children.

\section{How to place a Long-paralyzed Child on its Feet.}

If a child who has been long paralyzed begins to move the legs and ankles, but cannot yet stiffen the knee, a pair of simple caliper splints, like Figs. 3 and 4, should be fitted and applied. Then he is dressed, placed on a bed-frame which is raised at the head, so that he gets used gradually to a more and more inclined position, until one day he can lean in his frame almost straight against the wall, with the feet resting on the floor. When the child becomes afraid of falling sideways, crutches are giren him; then he is taught for some days to kick the feet out, alternately resting on one or the other foot. When he has acquired sufficient confidence and control of these motions, the frame is tipped forward, he leans upon his crutches and tries his first steps, still with the bed-frame strapped to his back and steadying him. This must be accomplished very slowly if the child has long been bedridden.

Another device which has proved of great use is the modified babyjumper, shown in the illustration (Fig. 2). Fig. 3 shows the same child, who has discarded this apparatus for crutches; and Fig. 4 shows him walking without crutches.

\section{Operative Measures.}

In the later stages of infantile paralysis surgical measures may be necessary; first, to overcome contractions which have developed; second, to improve the functional usefulness of the paralyzed limb after mechanical apparatus and prosthetic appliances have failed to accomplish all 
that can be desired. In many instances contractions can be better overcome by means of operative intervention than by apparatus, and the appliances needed for locomotion will not be needed after successful arthrodesis, or muscle transference.

It is not within the scope of this paper to give the details of the surgical procedures which may be of use; but it is desirable that every practitioner should be informed of such measures as are frequently employed in alleviating the disability resulting from anterior poliomyelitis.

\section{Operative Measures to correct Deformity.}

1. To overcome Contractions. - In orercoming contractions, the contracted soft parts need to be divided, either by an open incision, in the more resistant cases, or by tenotomy. Open incision is usually the better procedure in contractions of the hip and in the more resistant, old deformities at the knee, but in distortions of the foot, knee and hip in young children, tenotomy followed by forcible correction will be suffcient. The contracted limb, after operative correction, can be placed for a short time in a plaster bandage, to be followed by a suitable apparatus.

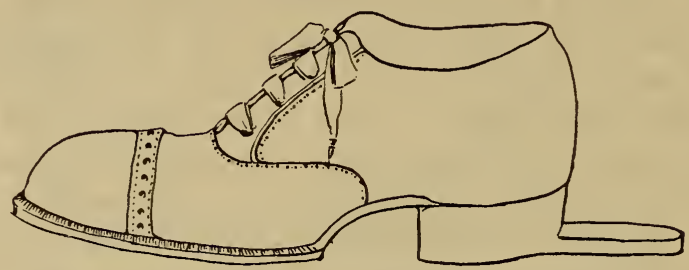

Fig. 8. - Heel extension to be used to check calcaneus deformity.

Osteotomy. - Division of the bone is rarely necessary in the deformities following infantile paralysis. In the extreme cases, however, a linear osteotomy of the lower end of the femur is sometimes needed; in older patients, a wedge-shaped excision of the bone may, in addition to tenotomies and open incisions, be necessary to correct the more extreme deformities of the knee and foot.

2. Operative Measures to aid Functional Activity. - Poliomyelitis injures the usefulness of the limb either by impairing the strength of some of the muscles, completely paralyzing others, or by a total destruction of the functional power of all the muscles of the limb. The needed operative measures are of two kinds:-

(1) Those designed to stiffen flail or loose joints so that the joint may be made capable of bearing weight; or 
(2) Measures which will give voluntary motion in the directions where power has been lost by paralysis.

(1) Joint Stiffening. - If weight is thrown upon a paralyzed lower extremity the knee bends forward and the patient falls. It is evident that if the knee-joint is stiffened in such a way that it cannot bend, the bones will be capable of sustaining the superimposed weight. This can be made possible at the hip, ankle and mid-tarsal joints. The operation of joint stiffening or arthrodesis is, therefore, one which has received much attention from surgeons. The cartilaginous surfaces of the two adjacent bones are removed in the expectation that the bared bone surfaces will unite, forming an ankylosis, and a stiff joint result. Practical experience has shown that this method is not applicable to young children, and should not be undertaken in children under ten, particularly arthrodesis of the knee and foot.

In young children the ends of the bones are largely cartilaginous, and the amount which it is necessary to remove to obtain an ankylosis is considerable, and mutilation necessarily results, sometimes to an undesirable degree.

In addition to this, in children, when a growth of the limb takes place, the limb may grow in a direction of distortion, and the ultimate condition may be worse than if no operation had been attempted, the patient wearing a suitable correcting apparatus.

The operation of arthrodesis is one which can be applied to the shoulder-joint and to the hip-joint. In the shoulder-joint the arm should be after operation, during the period of healing, placed in a position somewhat abducted from the body. Arthrodesis of the hip-joint is less frequently needed, but has been found beneficial in some instances. Arthrodesis at the knee-joint leaves the patient with an awkward limb, which for practical purposes is not as serviceable as one supplied with a suitable prosthetic appliance. In certain instances, however, where it is difficult to furnish a proper apparatus, patients often prefer the inconvenience of a stiff knee to the constant use of an appliance.

In deformities of the foot, where no muscular strength remains and the patients are not young, an arthrodesis between the astragalus and tibia, the os calcis and astragalus, and the midtarsal articulations (the astragalo-scaphoid and calcaneocuboid) is often of benefit.

Successful attempts have been made to substitute for the complete stiffening of the joints by erasion of the cartilaginous surfaces a stiffening of the joints by periosteal flaps. This has been performed chiefly at the ankle-joint, where a periosteal flap from the lower end of the tibia has been freed and attached to the astragalus and scaphoid. This involves less mutilation than cartilage erasion, and is more suitable for young children. 


\section{Silk Ligaments.}

Partial stiffening of the joint by means of the insertion of silk strands, properly sterilized, quilted in the periosteum of the bones adjacent to the affected joint, has been successfully performed preventing toe-drop and checking the slighter forms of valgus and varus in children and adolescents. The method is one which requires technical skill and experience.

It has been found that these silk ligaments, properly inserted, remain in the tissues and become in time surrounded by fibrous tissue, which serve the purpose of checks, capable of permanently preventing the development of severe deformity.

\section{Whitman's Operation.}

In cases of calcaneus deformity, that is, the paralytic deformity where the weight is borne on the end of the os calcis, the front of the foot not being able to strike the ground, owing to the weakness of the gastrocnemius muscles, a serviceable operation has been devised by Whitman, consisting of the ablation of the astragalus and the slipping of the foot backward, so that the weight is borne upon the middle of the foot instead of its posterior third. A useful foot results, the ultimate functional result being excellent.

\section{Fixation by Skin Scar Contraction.}

This method has been employed by Jones of Liverpool in flail elbow, and is one of ready accomplishment. A flap of the skin is dissected at the bend of the elbow and sutured into the lower portion of the upper arm. On healing, the arm will be held bent, and will become more useful than a loose elbow.

\section{Muscle and Tendon Transference.}

Where certain groups of muscles are paralyzed and the opponents remain strong, a transference of one or more of the strong muscles to perform the function of the weak muscles has been proved to be of benefit. Tendon grafting, that is, the insertion of the tendon of a strong muscle into the tendon of a weak muscle, although temporarily a help, has not, as a rule, been found to be as permanently beneficial as the transference of muscle or tendon with the periosteal insertion of the transferred tendon on a point of bone where a strong attachment can be secured to the periosteum. This gives a proper point for the contraction of the transferred muscle to perform the function lost by the 
paralytic attack. Where the transferred muscle or tendon is not sufficiently long to furnish a periosteal insertion, the tendon can be elongated by means of silk strands properly prepared. This measure is especially suitable in paralytic affections of the foot, of the knee and of the shoulder-joint; it has also been used for paralyzed muscles about the hip. It is manifest that, in the successful performance of this operation, strictly aseptic precautions are necessary. 'The silk strands should be not only thoroughly sterilized, but it has been found advisable, as pointed out by Lange, who introduced the method, that the silk strands should be boiled in a solution of 1-1000 of corrosive sublimate, subsequently boiled in a solution of paraffin, in order to prevent the irritating effect of the silk. These silk strands are quilted into the tendon of the muscle to be transferred. The tendon is then divided, and, with the silk strands attached, is passed by means of long forceps through the subcutaneous tissue and brought out through an incision at the point needed for periosteal insertion. The silk strands are then inserted by means of proper needles into the periosteum or bone tissue, the foot being placed in an over-corrected position. In some instances it may be well to supplement tendon transference with silk ligaments inserted, as already mentioned, after the operation. The limb should be held in a corrected or over-corrected position by means of plaster bandages, which are to be worn for several weeks, and followed by a suitable retention appliance, which is to be worn for several months.

In quadriceps paralysis of the knee-joint, the ham-strings can be transferred forward and inserted into the patella and into the ligamentum patellæ. In deltoid paralysis, strands of the trapezius have been transferred in such a way. In paralysis of the glutei muscles, the vastus or the rectus femoris have been utilized for transference, and also strands of the erector spinæ. In paralysis of the tibial muscles, the peronei hare been transferred, and vice versa. In paralysis of the extensor communis of the foot, the flexors have been used, or portions of the tendo Achilles.

It is manifest that before this operation is performed all deformities should be corrected. The operation is one which should not be undertaken until it is certain that no spontaneous recorery, or partial recorery by use, is to be expected from any of the ordinary therapeutic measures devoted to the development of weakened muscles in this affection, but it is one devoid of danger and with a good promise of benefit in suitable cases.

The procedure of muscle and tendon transference requires strict attention to important details, for which the reader must be referred to a more complete description than is possible in this short article (Lange). 
Prognosis in Cases under Treatment.

In an affection where recovery, sometimes rapid recovery, not infrequently takes place without treatment, and where spontaneous improvement is the rule in the months following the onset of the disease, it is difficult to determine the exact value of remedial measures. The arguments for measures stimulating the tissues affected are theoretical rather than demonstrable, yet they are based upon such sound reasoning that they should not be neglected but thoroughly applied.

The benefit to be obtained in the latest stages from the correction of deformity, in the use of proper appliances aiding in locomotion, in muscle transferrence and suitable operations, making the joints and limbs more serviceable for activity, is without question, and by no means inconsiderable in a large number of cases.

To give to the bed or chair ridden child, even by the employment of surgical skill, an active and useful life is a high achievement. It is one which is possible, in almost all instances, where the physician is able to enforce the thorough employment of the appropriate measures.

In infantile paralysis, marked improvement is the rule after the initial attack, and there is nerer a second attack.

The disease is a formidable one, but much can be done by the art of medicine to check or relieve its rarages.

Tоте. - The reader is referred for fuller particulars to the following important papers:-

Report of the Collective Investigation Committee on the New York Epidemic of 1907. Nervous and Mental Disease Monograph No. 6.

Annual Report of the Massachusetts State Board of Health for 1908.

Flexner and Lewis: Journal American Medical Association, Nov. 15, 1909;

Dec. 4 and Dec. 18, 1909; Jan. 1 and Feb. 12, 1910.

Congrès Français de Chirurgie, 1907, p. 380.

Hoffa Archiv. für klin. Chir., Ixxxi., 1 .

Lange: Joachimsthal's Handbuch der Orth. Chir., Berlin, 1904.

Robert Jones: British Medical Journal, March 28, 1908.

Journal American Medical Association, Nov. 14, 1908.

American Journal Orthopedic Surgery, 1908, vi., pp. 184, 202, 319.

Boston Medical and Surgical Journal, Nov. 7, 1907; Nov. 14, 1907; June 4, 1908 . 


\section{THE DIAGNOSIS OF INFANTILE PARALYSIS IN THE PROD- ROMAL AND EARLY ACUTE STAGE, AS FOUND IN THE EXPERIMENTAL STUDY OF ACUTE POLIOMYELITIS IN MONKEYS. WITH REPORT OF FINDINGS IN FOUR HU- MAN CASES.'}

By William Palmer LuCas, M.D., of Boston.

'The past year has brought out so many interesting facts about the infectious nature of acute anterior poliomyelitis, its transmissibility, its epidemiology, and, recently, some valuable facts in experimental immunity, that now great efforts are being made to discover some means of protection. In view of such a discovery, and having failed thus far to. find the specific etiological cause, it seems of some import to find somemeans of making a fairly accurate diagnosis early in the disease, as there is little or no hope of being able to check the process after paralysis. has appeared. The invasion of the white matter of the cord is undoubtedly an end result of the acute process, so that when the paralysis is first. observed the virus has already about spent itself. This being so, there must be some indication in almost every case that the virus is at work some time before the paralysis appears.

The New York investigation of the prodromal symptoms agrees completely with the early symptoms found in animal experimentation. The most noterrorthy signs are those of change of disposition. At times slight, but fairly constant and characteristic, is the restlessness and irritability that often appears several days before any other symptoms. Or the other extreme of apathy may be moderately marked for a number of days before one is aware that the paralysis is present. In these cases the occurrence of paralysis is much harder to determine, or, at least, we are not so apt to notice it as early as in the irritative cases. The paralysis may even be ushered in with delirium and convulsions, or epileptiform attacks, which may last for several days before the paralysis is noted. In the exceedingly irritative cases the diagnosis of epidemic meningitis is most often made. And, indeed, it is really a distinct type of acute meningitic anterior poliomyelitis. Experimentally it is hard to be sure of pain, but pain in the prodromal stage is by no means an uncommon finding, most often in the back along the spine, or in the joints of the extremities, which may show swelling and tenderness. Headache, general or frontal, is not infrequently met with in children old enough to locate the pain, and this is often accompanied with rigidity of the neck. If with any of these nerrous manifestations there should be any trouble

1 Work done under a grant from the Proctor fund in the departments of Surgical Research and Serum Diagnosis, Harvard Medical School. Read before the Massachusetts Medical Society, June 8, 1910. 
in the upper air passages, as coryza, bronchitis or sore throat, suspicion should at once be aroused. In all of our animals and in each of our four human cases there was some affection of the upper air passages along with one or more of the above nervous manifestations. Temperature, though present in nearly every case, is not typical, and is of little use as a guide. It is usually of short duration, two or three days, though a low temperature of about $100^{\circ}$ may continue for a week or more, as may be seen in our four cases, in three of which it persisted for over three weeks. The bowels show no particular change in the majority of cases, though either constipation or a moderate diarrhœa may exist.

These clinical manifestations, in conjunction with certain definite laboratory findings which I have been able to show in an experimental study and in a few human cases that I had the good fortune to see about the same time, make the diagnosis somewhat more certain, though of course not as exact as some specific reaction, by which we had hoped to be able to make a positive diagnosis but in which so far we have failed. Yet this combined information should be of great assistance toward making a more accurate and early diagnosis in this condition.

\section{Points of Diagnosis from Spinal Fluid and Blood in the Prod- romal and Acute State of Anterior Poliomyelitis, from Ex- PERIMENTAL AND HuMaN Study.}

The original material for experimental work was obtained through the kindness of Dr. Flexner, who furnished us with two different strains of virus. We were able to produce paralysis in three monkeys from this original virus, and were able to transfer paralysis through two subsequent series of inoculations. The work of diagnosis may be divided into two parts as we carried them out. First, the ordinary laboratory methods of blood and spinal fluid examination, and second, the more complicated biological tests of these same fluids. All these tests were made before the inoculation in a large enough number to give us a fair idea of what normal findings were. These same tests were carried on during the period of incubation, through the prodromal stage and through the acute stage, until the fluids examined returned apparently to their normal findings. The temperature findings were not constant, except that in the first irritative stage there was a fairly uniform rise, with a drop to normal, often subnormal, during the acute stage, with at times a further rise toward the end of the acute stage or beginning of convalescence.

The study of the blood brought out at least two very interesting facts, and when taken in conjunction with certain findings in the spinal fluid will certainly make a strong diagnostic point early in the disease. The normal differential count ran about, polynuclears, 60 per cent; large and 
small mononuclears, 25 per cent; lymphocytes, 12 per cent; eosinophiles, 3 per cent. In the acute stage there was a moderate to a constant lymphocytosis, the count being polynuclears, 40 per cent.; large mononuclears, 15 per cent; lymphocytes, 40 per cent; eosinophiles, 5 per cent. Parallel with this lymphocytosis there was a marked and constant leukopenia. This drop in the white count lasted fairly consistently with the acute stage, disappearing about the time that the hyperæsthesia or other manifestations of the acute stage disappeared. The average normal count of our monkeys was in the neighborhood of 20,000 per cubic millimeter. This count did not change during the incubation period, but did change occasionally during the irritative or prodromal stage, when there was a marked or moderate drop in the white count. During the acute stage there was always a marked drop, the lowest count being 8,000 , on the second day after paralysis was first noted.

\section{SPINAL Fluid.}

The spinal fluid shows even more marked and very characteristic constant findings during the incubation period, prodromal and acute stage, disappearing about the time that the acute symptoms begin to subside, being at its height either in the prodromal stage or on the first or second day of the acute stage. Before inoculation it is often impossible to get even one drop of spinal fluid from a lumbar puncture; most of our attempts gave nothing more than dry taps. However, when successful, there were only one or two cells to be seen in an ordinary Thoma-Zeiss counting chamber, and on staining, these were apparently large mononuclears or plasma cells. During the incubation period there is a marked increase in the amount of fluid that may be obtained from lumbar puncture, and the cells in the fluid are very markedly and characteristically increased, anywhere from 100 to 300 cells per cubic millimeter. These cells are mainly of the large mononuclear type, with some polynuclear cells and lymphocytes. In the prodromal stage there is even a more marked increase in the cells, often reaching 1,000 per cubic millimeter. In this stage, also, polynuclears are still present, in some cases as high as 60 per cent, though the large mononuclears and lymphocytes were very evident. In the early acute stage the increase in cells is very marked. The cells are now, however, mostly of the lymphocytic or very early form of cells, and sometimes very hard to place, as they are apparently undifferentiated cells. As the cells decrease in number the polynuclears begin to return, and at the end of a week or ten days there are very few cells present, mostly large mononuclears with a few polynuclears. In the prodromal and acute stage there was at times a fibrin clot. This clot would disappear fairly early during the acute stage. Fluid in our monkeys was never under any great pressure, though the 
amount was sometimes increased so that 5 cubic centimeters was easily withdrawn. This occurred fairly regularly in the meningeal type of the infection.

A comparison of these experimental findings with the findings in four cases of acute poliomyelitis in children is of considerable value. These four cases were seen first between the second and fifth day of the acute onset. When seen all of them were running a slight temperature and were still in the hyper-sensitive state, with paralysis just commencing, so that the first findings in these cases are comparable with our findings in the early acute stage of our experimental studies. It will be seen from the chart that the blood findings show from a moderate to a quite marked drop in the white blood count, with a lymphocytosis moderately marked in all but one of the cases, which was the one examined at the latest day. The spinal fluid findings are very interesting in all these cases from the fact that in two of them definite fibrin formation was present early, which disappeared rapidly in one and very slowly in the other. The increase in cells was marked in all at the first puncture, and in three of the cases increased slightly later on in the course of the acute stage. The increase of cells was still present in two cases as late as the twentieth day of the acute onset. The type of cells found was practically parallel with the findings of the experimental spinal fluids, the lymphocytes and small mononuclears predominating on the first examinations, later being replaced by large mononuclears, and in the last findings polynuclears were beginning to reappear.

\section{TABLE 1. - Noteworthy Prodromal Symptoms.}

1. Irritability.

2. Restlessness.

3. Pain in spine or extremities.

4. Apathy.

\section{TABLE 2. - Important Symptoms during Acute Stage.}

1. Fever, $100^{\circ}$ to $106^{\circ}$. Duration of fever two to seven days.

2. Vomiting (25 per cent. in New York series).

3. Restlessness.

4. Apathy.

5. Rigidity of neck.

6. Headache (frontal).

7. Delirium.

8. Stupor.

9. Convulsions.

10. Photophobia.

11. Dysphagia.

12. Sluggish pupils. 


\section{3}

13. General pain (early in 58 per cent.).

14. Absence of deep reflexes.

15. Cold extremities (vasomotor changes).

TABle 3. - Types of Acute Poliomyelitis (Wickman).

1. Spinal poliomyelitic form.

Sudden onset, followed by paralysis.

2. The ascending form (Landry's paralysis).

Involvement of respiratory centers.

Most fatal cases belong to this type.

3. The bulbar or pontine form.

Nerves most often involved: facial, ocular, hypoglossal.

May exist alone or with paralysis of extremities.

4. Encephalitic or cercbral form.

May exist alone or with spinal involvement.

5. The ataxic form.

Much like Friedreich's ataxia.

6. Polyneuritic form.

7. Meningitic form.

9. Abortive form.

1. General infection.

2. Symptoms of meningeal irritation.

3. Cases of much pain like influenza.

4. Cases with marked digestive disturbances.

ТАвцE 4. - Intracranial Injections, producing Acule Poliomyelitis in Monkeys.

\begin{tabular}{|c|c|c|c|c|c|c|}
\hline $\begin{array}{l}\text { Monkey } \\
\text { So. }\end{array}$ & Material uned. & $\begin{array}{l}\text { Incuba } \\
\text { tlon,1 }\end{array}$ & $\begin{array}{l}\text { P'rodromal } \\
\text { Bymiptoms } \\
\text { during - }\end{array}$ & $\begin{array}{c}\text { Acute } \\
\text { onnet on - }\end{array}$ & Died on - & Type of Dimeane. \\
\hline 1 , & $\begin{array}{l}\text { VIrns (K. Flexner } \\
\text { l,ewla), } 4 \text { cuble } \\
\text { centlmeters. }\end{array}$ & 7 1вуя, & $\begin{array}{l}\text { 6. da y s : }{ }^{2} \\
\text { days well. }\end{array}$ & 12th diny, & $\begin{array}{l}\text { 17th day; } \\
\text { ehloro: } \\
\text { formed. }\end{array}$ & $\begin{array}{l}\text { Marked prof romata; } \\
\text { mylnal pollomyelfele } \\
\text { form. }\end{array}$ \\
\hline 3 & $\begin{array}{l}\text { Eim ul alon cord } \\
\text { (roonkey), 12 ctu. } \\
\text { blis centimetsers. }\end{array}$ & 2 lnys, & 1 ding, . & 4th day, & Gth day, . & $\begin{array}{l}\text { Bulbar, pont In'e } \\
\text { ty pe; resplratory } \\
\text { puralyals. }\end{array}$ \\
\hline$i$, & 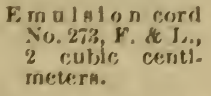 & 6 days, & 1 day, . & ith dny, & 12th day, & $\begin{array}{l}\text { Splnal poliomyelitic } \\
\text { form. }\end{array}$ \\
\hline 3 , & $\begin{array}{l}\text { Virus M. A. (F' } \\
\text { J., }) \text { f cuble } \\
\text { centlmeters. }\end{array}$ & 12 daун, & 2 days, & lsth disy, & 4oth diny, & $\begin{array}{l}\text { Splnal pollomyelitio, } \\
\text { form. }\end{array}$ \\
\hline 12 , & $\begin{array}{l}\text { Eimulalon No. } 2 \% \text {, } \\
\text { ( } \boldsymbol{F} \text {. L.), } 2 \text { cubles } \\
\text { centimsters. }\end{array}$ & 4 drys, & 1 day,. & fith diny, & seth dssy,. & $\begin{array}{l}\text { Splolnal pollomyelltic } \\
\text { form. }\end{array}$ \\
\hline 15, & $\begin{array}{l}\text { E. mulalon corrl } \\
\text { (monkey) No. } \\
2 \text { (ouble cents. } \\
\text { meteris. }\end{array}$ & 7 daym, & 2 drays, & Joth day, & 10th duy, & Menlngltile form. \\
\hline
\end{tabular}


TABle 5. - Spinal Fluid in Acute Poliomyelitis (Monkeys).

\begin{tabular}{|c|c|c|c|c|}
\hline $\begin{array}{c}\text { Monkey } \\
\text { No. }\end{array}$ & Normal. & During Incubation. & Prodromal. & Acute Stage. \\
\hline 1 & $\begin{array}{l}\text { Tro cells seen, } \\
\text { 1 large mono- } \\
\text { n u cle a r, 1 } \\
\text { small plasma } \\
\text { cell. }\end{array}$ & $\begin{array}{l}\text { 6th day, } 100 \text { cells per } \\
\text { cubic millimeter; } \\
\text { large mon o n } \mathrm{x} \text { : } \\
\text { clears, } 40 \text { per cent.; } \\
\text { small (lymphocy. } \\
\text { tes), } 60 \text { per cent. }\end{array}$ & $\begin{array}{c}\text { 10th day, } 240 \text { cells per } \\
\text { cubic millimeter; } \\
\text { large and small } \\
\text { mononuclears, } 60 \\
\text { per cent.; lympho- } \\
\text { cytes, } 40 \text { per cent. }\end{array}$ & $\begin{array}{l}\text { 14th day, } 400 \text { cells per } \\
\text { cubic milli m e t e r; } \\
\text { mostly lymphocytes; } \\
\text { 16th day, } 60 \text { cells per } \\
\text { cubic millimeter; lym- } \\
\text { phocytes; \& few poly- } \\
\text { nuclears. }\end{array}$ \\
\hline 5 , & Drs tap, . & - & $\begin{array}{l}3 \text { day, } 1,000 \text { cells per } \\
\text { cubic millimeter; } \\
\text { poly nu lear } 8,60 \\
\text { per cent.; mononu. } \\
\text { clears, } 40 \text { per cent. }\end{array}$ & $\begin{array}{l}\text { 4th day, } 800 \text { cells per cubic } \\
\text { millimeter; 5th day, } \\
1,000 \text { cells per cubic mill- } \\
\text { limeter; lymphocytes } \\
\text { and pol y n cle ar } 8 \text {; } \\
\text { roung cells unditferen- } \\
\text { tiated. }\end{array}$ \\
\hline$i$ & No cells seen, & - & $\begin{array}{l}\text { 6th day, } 160 \text { cells per } \\
\text { cubic millimeter; } \\
\text { excess of large } \\
\text { mononuclears. }\end{array}$ & $\begin{array}{l}\text { 7th day, } 12 \text { cells per cubic } \\
\text { millimeter; lymphocy- } \\
\text { tes; 8th day, } 90 \text { cells per } \\
\text { cubic millimeter; lym- } \\
\text { phocytes; 12th day, 20 } \\
\text { cells per cubic milli- } \\
\text { meter; large mononu- } \\
\text { clears: a few polynu- } \\
\text { clears. }\end{array}$ \\
\hline 9 & $\begin{array}{l}\text { One (?) plasma } \\
\text { cell. }\end{array}$ & - & $\begin{array}{l}\text { 14th day, } 120 \text { cells per } \\
\text { cubic millimeter; } \\
\text { lymphocytes, } 40 \\
\text { per cent.; large } \\
\text { mononuclears, } 60 \\
\text { per cent. }\end{array}$ & $\begin{array}{l}\text { 16th day, } 200 \text { cells per } \\
\text { cubic millimeter; all } \\
\text { lymphocytes or small } \\
\text { mononuclears (5oung } \\
\text { cells). }\end{array}$ \\
\hline 12, & Dry tap, . & - & - & $\begin{array}{l}\text { 7th day, } 80 \text { cells per cubic } \\
\text { millimeter; lymphocy- } \\
\text { tes. }\end{array}$ \\
\hline 15, & $\begin{array}{l}\text { A few large } \\
\text { cells and } 1(?) \\
\text { plasma cell. }\end{array}$ & $\begin{array}{l}6 \text { th day, } 300 \text { cells per } \\
\text { cubic millimeter; } \\
\text { large mo n o nu: } \\
\text { clears, } 60 \text { per cent. }\end{array}$ & $\begin{array}{l}\text { 9th das, } 150 \text { cells per } \\
\text { cubic millimeter; } \\
\text { larg e m o n o n u: } \\
\text { clears, } 30 \text { per cent.; } \\
\text { lymphocytes, } 60 \text { per } \\
\text { cent.; polynuclears } \\
10 \text { per cent. }\end{array}$ & $\begin{array}{l}\text { 10th day, } 180 \text { cells per } \\
\text { cubic millimeter; lym- } \\
\text { phocrtes; } 30 \text { th day, few } \\
\text { polynuclears found. }\end{array}$ \\
\hline
\end{tabular}

Table 6. - Blood (W. B. C.) in Acute Poliomyelitis (Monkeys).

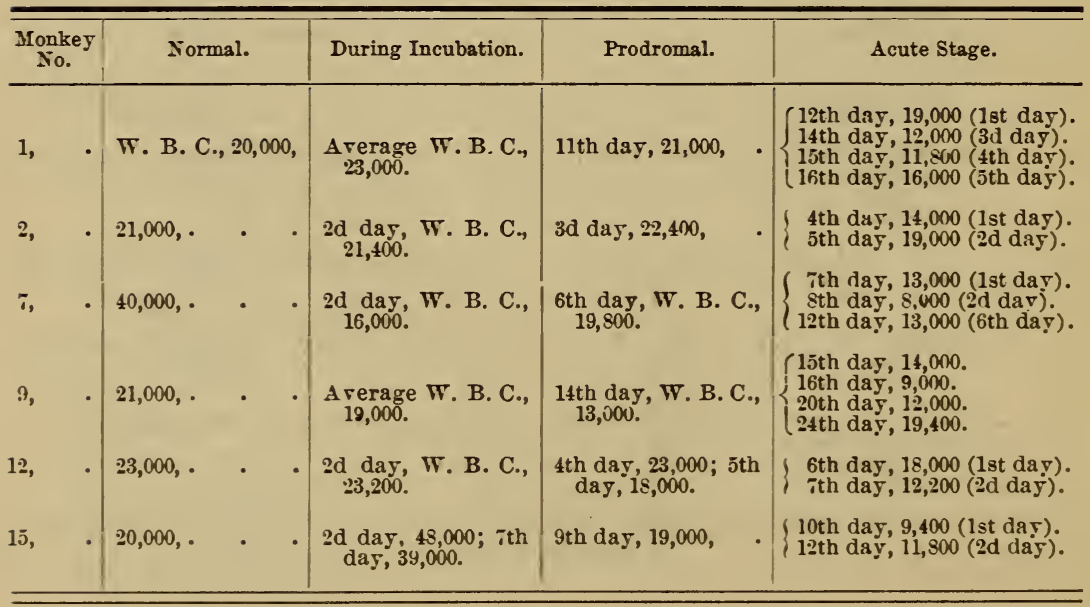


TABLe 7.

Case 1.-R. R.

\begin{tabular}{|c|c|c|c|c|c|}
\hline \multicolumn{3}{|c|}{ Day. } & $\begin{array}{l}\text { Tempersture } \\
\text { (Degrees). }\end{array}$ & Blood. & SpinaI Fluid. \\
\hline 5 th, & - & - & 100.0 & $\begin{array}{l}\text { W. B. C., 17,400; differ- } \\
\text { entiated lymphocy- } \\
\text { tosis. }\end{array}$ & $\begin{array}{l}10 \text { cubic centimeters; } 180 \text { cubic millimeters, } \\
\text { no clot; lymphocy tosis, } 98 \text { per cent. }\end{array}$ \\
\hline 8th, & - & - & 100.0 & $\begin{array}{l}\text { W. B. C., 12,000; ly mph. } \\
\text { ocytosis. }\end{array}$ & $\begin{array}{l}20 \text { cubic centimeters: } 50 \text { cubic millimeters, } \\
\text { no clot; mononuclears, degenerated } \\
\text { forms. }\end{array}$ \\
\hline 13th, & - & - & 99.0 & W. B. C., 11,600. & $\begin{array}{l}10 \text { cublc centimeters; } 80 \text { cuble millimeters; } \\
\text { no clot; large mononuclears and degen- } \\
\text { erated forms. }\end{array}$ \\
\hline
\end{tabular}

Case 2.

\begin{tabular}{|c|c|c|c|c|}
\hline 2d, & - & 100.0 & $\begin{array}{l}\text { W. B. C., } 10,000 ; 1 \mathrm{ymph} \text { - } \\
\text { ocytosis, } 62 \text { per cent. }\end{array}$ & $\begin{array}{l}5 \text { cubic centimeters clear; clot in } 24 ; 350 \\
\text { cells per cubic millimeter; degenerated } \\
\text { mononuclears. }\end{array}$ \\
\hline 5 th, & - & 98.5 & - & $\begin{array}{l}\text { Blood fluid with clot. } 20 \text { cubic centime- } \\
\text { ters; very few leucocytes. }\end{array}$ \\
\hline ith, & . $\quad$. & 100.0 & $\begin{array}{l}\text { W. B. C., } 7,800 \text { : ly mph. } \\
\text { ocytosis. }\end{array}$ & $\begin{array}{l}35 \text { cubic centimeters bloody fluid; clot; } \\
\text { few degenerated mononuclears. }\end{array}$ \\
\hline 9 th, & - & 99.5 & W. B. C., 12,200. & - \\
\hline 12th, & - & 100.0 & W. B. C., 11,800 . & $\begin{array}{l}30 \text { cubic centimeters; 1st lot clear; slight } \\
\text { clot; } 80 \text { cells to cubic milliimeter; mono- } \\
\text { nuclears; } 3 \mathrm{~d} \text { lot opaque; clot; } 580 \text { cells } \\
\text { to cubic millimeter; mononuclears and } \\
\text { lymphocytes. }\end{array}$ \\
\hline
\end{tabular}

Case 3.

\begin{tabular}{c|c|c|c}
\hline 4th, & 101.0 & 12,$000 ;$ normal dif. & $\begin{array}{c}50 \text { cubic centimeters clear; no clot: high } \\
\text { pressure; 60 cells per cubic millimeter. } \\
\text { cubic centimeters clear; 510 cells per } \\
\text { mononuclears and } \\
\text { cubic millimeter; mon } \\
\text { lymphocytes. } \\
10 \text { cubic centimeters clear; } 240 \text { cells per } \\
\text { cubic millimeter. }\end{array}$ \\
\hline
\end{tabular}

Case 4.

\begin{tabular}{l|c|c|c}
\hline 4th, & 99.0 & $\begin{array}{c}13,400 ; \text { differentiated } \\
\text { polynuclears, 75.5; } \\
\text { mononuclears, 24.5. }\end{array}$ & $\begin{array}{c}20 \text { cubic centimeters clear; fibrin clot; 50 } \\
\text { cells per cubic millimeter; degenerated } \\
\text { small and large mononuclears. }\end{array}$ \\
$\begin{array}{l}5 \text { th, } \\
\text { sth, }\end{array}$ & - & - & $\begin{array}{c}30 \text { cubic centimeters clear; fluid; 130 cells } \\
\text { per cubic millimeter; mononuclears and } \\
\text { fymphocytes. }\end{array}$ \\
\hline
\end{tabular}




LEN'II 


\section{INFANTILE PARALYSIS}

\section{IN MASSACHUSETTS IN 1909.}

I. The Occurrence of Infantile Paralysis in Massachusetts in 1909.

Reported for the Massachusetts State Board of Health by Robert W. Lovett, M.D.

II. Infantile Paralysis as Observed in Health District No. 15 during 1909. By Lyman A. Jones, M.D.

III. Methods of Treatment in Infantile Paralysis.

By E. H. Bradford, M.D., Robert W. Lovett, M.D., E. G. Brackett, M.D., Augustus Thorndike, M.D., Robert Soutter, M.D., Robert B. Osgood, M.D.

IV. The Diagnosis of Infantile Paralysis in the Prodromal and Early Acute Stage, as Found in the Experimental Study of Acute Poliomyelitis in Monkeys. With Report of Findings in Four Human Cases.

By William P. Lucas, M.D.

Reprinted from the

Monthly Bulletin of the Massachusetts State Board of Health for June, 1910.

BOSTON:

WRIGHT \& POTTER PRINTING CO., STATE PRINTERS, 18 POST OFFICE SQUARE. 




LIBRARY OF CONGRESS

|||||||||||||||||||||||||| |||||||||

00221694120 